\title{
'Celebrating Cancer': Young Women Negotiating the Cultural Politics of Survivorship
}

by

Vanessa Elizabeth Peck

B.A with Honours in Sociology, Carleton University 2011

A thesis submitted to the Faculty of Graduate and Postdoctoral Affairs in partial fulfillment of the requirements for the degree of

\author{
Master of Arts \\ in \\ Sociology
}

Carleton University

Ottawa, Ontario

2013

(C) 2013, Vanessa Elizabeth Peck 


\section{Abstract}

This thesis begins with a critical observation that over the past decade, Canadians have witnessed an explosion of discussions in the public sphere about cancer and survivorship, including the celebration of cancer survivors. The proliferation of cancer/survivor discourses circulates expectations about how cancer should be taken on and embodied. There is an urgent need to investigate the effects of such discourses on young women's (a) access to state and community resources, (b) constructions of health, risk and wellbeing, and (c) personal accounts of their bodies and illness experiences.

Drawing on 17 in-depth interviews with young female cancer survivors, this thesis investigates the effects of dominant cancer/survivor discourses on the social and material contexts of young women's cancer experiences. I argue that young women's cancer narratives are embedded in discourses of exclusion and responsibilization that actively shape and define what it means to be a 'good' survivor/citizen. 


\section{Acknowledgements}

There have been many people who have been a part of this journey and who have supported the various turns and twists I have made throughout this process. I would like to thank the 17 women who graciously shared their time and stories with me. Without all of you this project would not have been possible. I would like to thank both of my supervisors, Dr. Janet Siltanen and Dr. Xiaobei Chen, for their constant support, words of encouragement and invaluable guidance over the past two years. Thank you for continually inspiring me to re-think and re-imagine. It has been a privilege to learn from such excellent scholars. My peers, especially, Jenelle Williams and Cristine Rotenberg, thank you for all the good laughs and endless support along the way. Finally, I would like to thank my Mom, sisters - Christina and Victoria - Nonna, and Bubbie for their love, support and patience, without which I would not have been able to write this thesis. 


\section{Table of Contents}

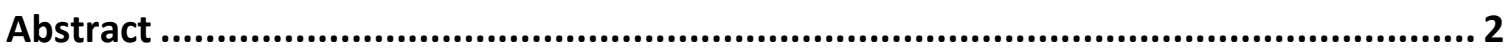

Acknowledgements .................................................................................................... 3

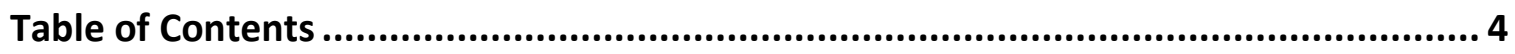

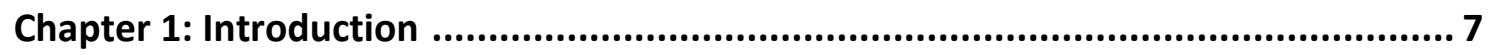

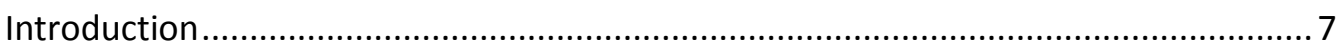

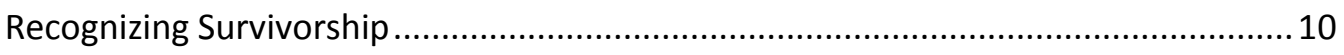

Research Questions, Arguments and Literature Review..........................................16

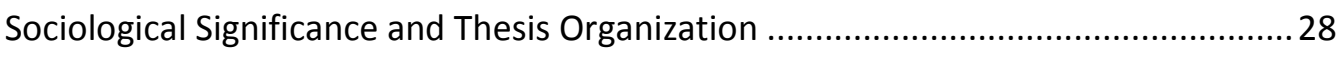

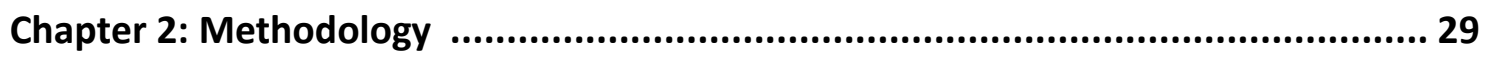

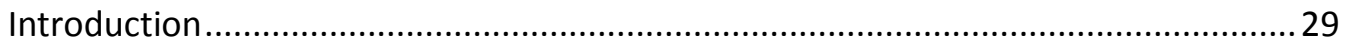

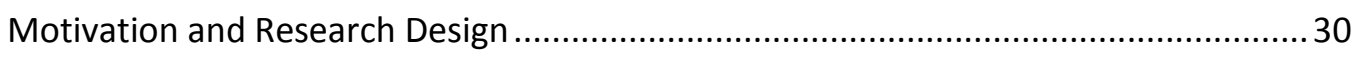

Practicing Reflexivity: My Role as the Researcher .....................................................33

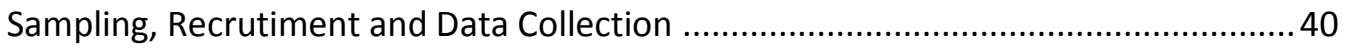

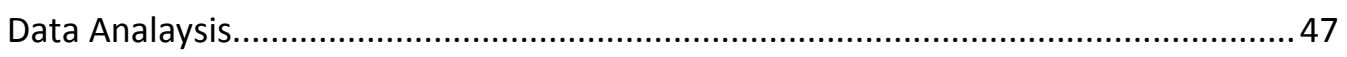

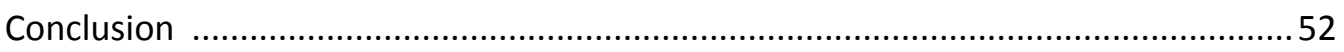

Chapter 3: Lost in a Sea of Pink .......................................................................... 54

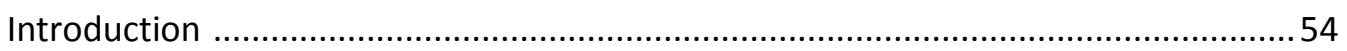

Evolution of Breast Cancer Culture in Ontario ........................................................56

At the Margins: Cancer Care Disparities Among Breast Cancer Patients .....................74

At the Margins: Cancer Care Disparities Between and Among Young Female Cancer

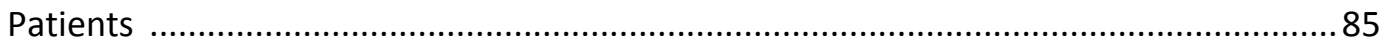

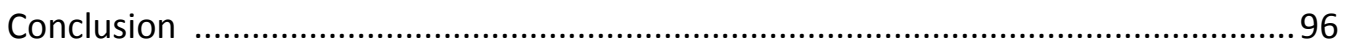


Health Initiatives as Teachable Moments: Taking Charge of Your Own

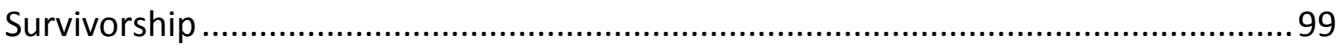

'Remaking the Self Post-Cancer': Ideal Survivors and Model Citizens ....................... 106

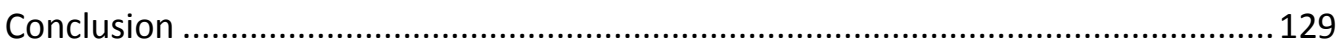

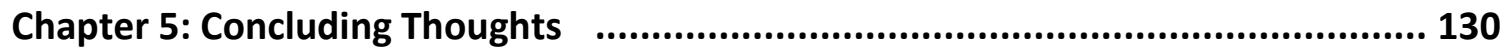

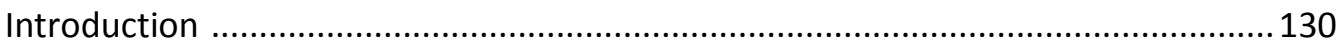

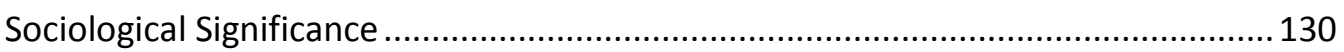

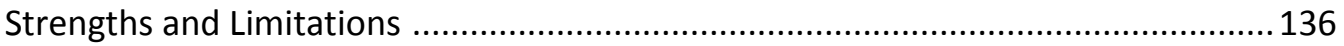

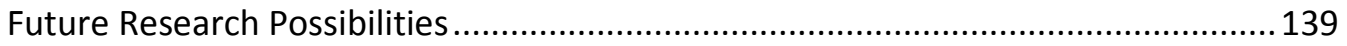

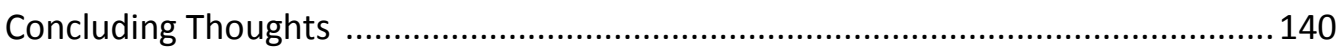

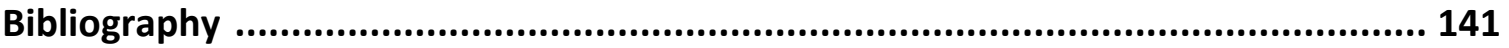

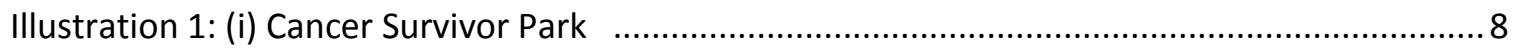

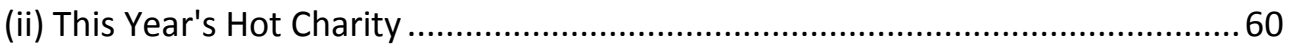

(iii) You Can't Look Away Anymore ...................................................................62

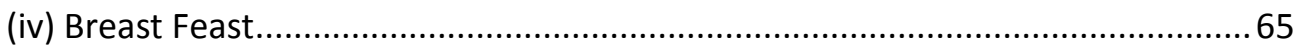

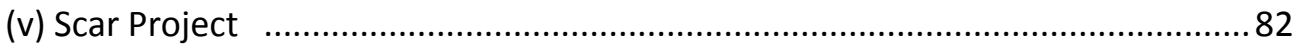

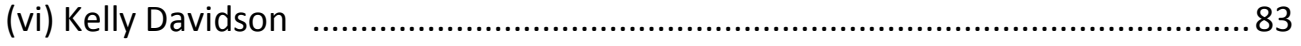

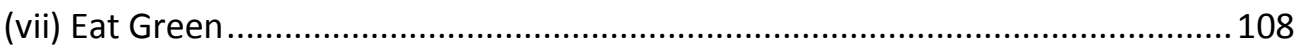

(viii) Foods that Fight Cancer...................................................................... 108

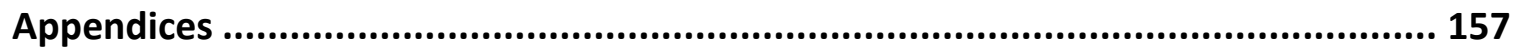

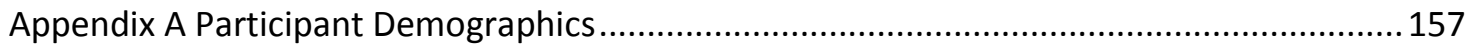




\section{Chapter 1: Introduction}

\section{Introduction}

Over the past decade, Canadians have witnessed an explosion of discussions in the public sphere about cancer and survivorship, within which the celebration of cancer survivors has emerged as a central theme. Indeed, it is now widely accepted that 'cancer can be beaten' (Sinding and Gray 2005). These developments speak to the emergence of a new cancer discourse, one premised on survival (Bell 2012; Kaiser 2008; King 2006; Zebrack 2000). Like other dominant health discourses, cancer/survivor discourses have saturated all areas of social life and have exposed Canadians to vast amounts of information about this condition and life thereafter. ${ }^{1}$ Also, like other discourses, as scholars like Bell (2012), King (2006) and others (Ehrenreich 2001; Kaiser 2008; Kendrick 2008; Seale 2002; Segal 2010, 2012; Sinding and Gray 2005) suggest, cancer/survivor discourses are not value free. Rather they are intertwined with popular notions of femininity, health, risk, self-transformation and citizenship, which work in ways that construct particular kinds of knowledges and subjects, and which set parameters around how this condition is defined, understood, and experienced. In other words, cancer/survivor discourses circulate expectations about how cancer should be taken on and embodied. Thus, the language used to talk about cancer and survivorship is a powerful vehicle of communication that works on people in particular ways. With all of this in mind, this project examines the links between cancer/survivor discourses and the 'effects' they have on young women's experiences of illness. In order to embark on such

\footnotetext{
${ }^{1}$ In this thesis, I use the term survivor and survivorship discourses inter-changeably.
} 
an exploration, one must first ask: what are dominant cancer/ survivor discourses and what ideas do they perpetuate?

One might begin to answer this question by noting that over the past few decades there has been a cultural shift in the ways people think and talk about cancer and those living therewith. For example, individuals living with cancer are now often identified as survivors rather than as victims or as patients. Presently, the term survivor is most broadly used to describe individuals who have had a life threatening illness but who are now disease free (Rowland et al. 2006).

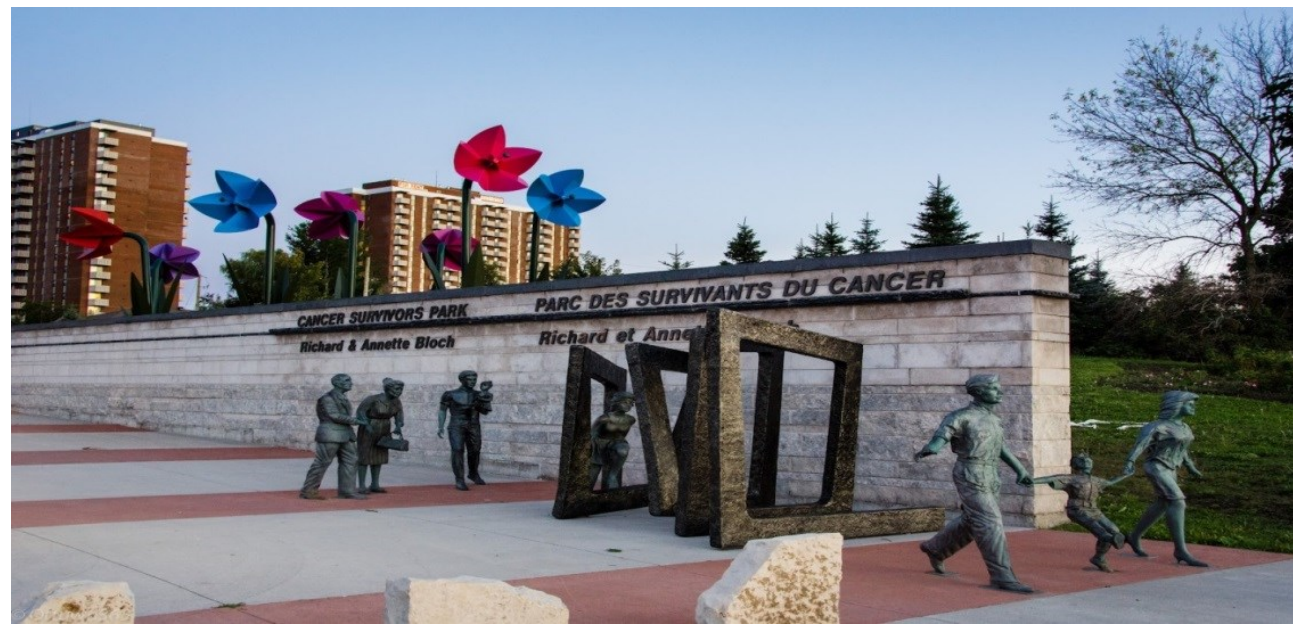

Cancer Survivor Park, Ottawa Ontario

Interestingly, such a definition emphasizes the transition into stages of remission and thus valorizes those people who successfully overcome the disease over those who do not. While this shift in language is predominantly viewed by physicians, some feminist scholars and society as a positive development, it is important to note that the term survivor has cultural connotations that stem from the historical use of warfare metaphors to describe experiences of cancer (Orgad 2009; Sontag 1979). 
For instance, in Teratologies: A Cultural Study of Cancer, Stacey (1997) highlights how a dominant narrative of cancer heroism - patients as fighters, battling the odds and triumphing -influences both the construction of the ideal survivor and its up-take as a desirable role which patients are encouraged to assume (see also, Orgad 2009). In this sense, survivor discourses emphasize certain values and virtues "that translate into implicit expectations of what people who have experienced cancer should be like" (Bell and Ristovski-Slijepcevic 2013: 410). Stated directly, the ideal cancer survivor is an individual who is resilient, positive, dedicated towards finding a cure and assumes personal responsibility for their own health and wellbeing.

Although numerous scholars have noted that the term survivor is contested amongst those living beyond cancer, this discourse continues to be embraced by a number of interdisciplinary scholars. Indeed, the term survivor is embraced by many people working within the fields of biomedics, social psychology, feminist studies and women's health (for example, Bell 2012; Bell and Ristovski-Slijepcevic 2013; Ehrenreich 2001; Kasier 2008; King 2006; Khan et al. 2012; Mullan 1985; Orgad 2009; Seale 2002; Sinding and Gray 2005; Twombly 2004; Zebrack 2000). In addition, popular media play a central role in the production and proliferation of survivor discourses which, as Judy Segal $(2010,2012)$ argues, seek to limit the ways cancer can be talked about and experienced (see also, Orgad 2009; Seale 2002). Following this reasoning, dominant survivor discourses silence and dismiss narratives of anger, uncertainty, despair and death. Stories about restitution, as Frank (1995) argues, are valued as far more compelling, culturally preferred and institutionally prescribed. As this discussion is 
meant to make clear, cancer/survivor discourses shape the context of cancer and survivorship care in Canada, as elsewhere.

In light of these issues, the aim of this research is two-fold. First, it attempts to demonstrate how cancer/survivor discourses work in ways that construct boundaries between and amongst different cancers and those who are thereby affected, thus resulting in material differences in types of care available to young women diagnosed with less publicized cancers. Second, this research explores the ways such discourses promote a neoliberal ethic of personal care that seeks to responsibilize individuals for their own health and wellbeing. In what follows, I provide a brief overview of the ascendency of survivorship discourse in Canada and more specifically in Ontario. Next, I present my main research questions and argument and situate these in relation to the relevant sociological literatures and concepts used throughout the thesis. The present chapter concludes with a statement about the sociological significance of this study and an overview of the following chapters.

\section{Recognizing Survivorship}

The politics of cancer and survivorship is an emerging field, one that is capturing the attention and interest of both American and Canadian scholars. While my focus is on cancer/survivor discourses in the Canadian context, this discussion partly draws on some major American scholarship in addition to the work of Canadian scholars in an attempt to fully understand the complexities surrounding these phenomena (Gould 2004; Gould et al. 2006; Segal 2007, 2010, 2012; Sinding 2010; Sinding and Gray 2005). 
Like most post-industrial societies, Canada has undergone a shift in patterns of disease and illness. In particular, epidemiological trends suggest that the main causes of death and disability are a result of non-communicable illnesses - cancer, heart disease, mental health, autoimmune disorders - and that rates of infectious diseases are declining (Bezruchka 2010). As such, over the past four decades, cancer has captured the attention of various stakeholders - politicians, scientists and medical professionals, academics, bio-medical /pharmaceutical agents, non-profit, advocacy and corporate philanthropists - and has become one of the most discussed, recognized and dreaded diseases of the contemporary era (Ehrenreich 2001; King 2006). Indeed, few other diseases have received as much attention and support from public, private and state institutions. Although many research efforts are aimed at finding a cure, great strides also have been made in public health initiatives in the areas of cancer prevention, detection, treatment and prognosis. As a result of these achievements, there has been an increase in the numbers of individuals transitioning into stages of remission and survivorship (Aziz 2008; Hewitt et al. 2006; Howell et al. 2011).

Survivorship refers to a distinct stage in the cancer trajectory "which is posttreatment [and] separate from diagnosis and treatment and from end-of-life care" (Twombly 2004: 1415).While presently it is estimated that there are close to 1 million cancer survivors in Canada, it has only been within the past decade that issues surrounding survivorship have come to the forefront of Canadian health politics (Bell 2012; Doll et al. 2012; Rutledge and Robinson 2009; Ristovski-Slijepcevic 2008). These issues include but are not limited to increased follow-up post-treatment care, more 
extensive pyscho-social supports, and increased recognition of the financial burden associated with cancer.

Despite the growing number of cancer survivors, it is well noted that prior to 2008, Canadians were particularly lax in recognizing survivorship as an area requiring further investigation and resources (Ali and Warner 2013; Gould et al. 2006; Rutledge and Robinson 2009; Ristovski-Slijepcevic 2008). Rather, in past years, survivorship was often unrecognized as a distinct phase in the continuum of care. As a result, survivorship care was patchy, unreliable, and not of good quality (Ristovski-Slijepcevic 2008). However, an increasing number of cancer survivors and a better understanding of the social burden of illness have meant that issues surrounding survivorship are now at the forefront of many joint ventures between private industry, non-profit organizations and government agencies. More to the point, in an effort to acknowledge and legitimize survivorship needs, the stories and lives of survivors have played significant roles in securing financial resources that support prevention, surveillance, intervention and coordination efforts and, more recently, survivorship care.

\section{Survivorship in Ontario}

In Ontario, research in the area of survivorship, in conjunction with increasing demands from those living in stages of remission, are resulting in a multitude of new resources and services specifically designed to address life after cancer diagnosis and treatment (Ali and Warner 2013; Bell and Ristovski-Slijepcevic 2013; Gould et al. 2006; Hewitt et al. 2006; Rutledge and Robinson 2009). In this province, Toronto is often 
considered the vanguard for survivorship resources. For instance, breast cancer organizations have been successful at addressing and prioritizing survivorship issues and have established state-of-the-art support networks that are available to young breast cancer patients living in the greater Toronto area (Ali and Warner 2013). Although, across the province breast cancer organizations continue to implement survivorship resources specifically for breast cancer patients, they do so at a slower pace and their offerings are much more limited in comparison to what is made available to those in Toronto (Ali and Warner 2013).

That said, over the last couple of years, non-profit, community-based survivorship centers have sprung up across Ontario and are becoming permanent spaces in most metropolitan cities. In an effort to fill voids in survivorship care, such centers provide a variety of free programs, resources and support for all cancer patients, survivors and families regardless of their cancer diagnosis. Within the cancer community, survivorship centers are increasingly viewed as extensions of primary care services (Green et al. 2005). As such, one might note that survivorship centers now are recognized and legitimized as being of value to people across the continuum of cancer care.

Despite these vast improvements in recognizing survivorship services as essential, there continues to be a general lack of understanding about how cancer affects young adults. Some studies have suggested that young adults aged 18 to 39 years have unique needs regarding treatment and care post cancer (Daugherty 2013; Zebrack 2009). A report by the Canadian Cancer Society (2009), for example, identifies 
specific challenges that can hinder the overall health of young adults transitioning from cancer treatment to survivorship. These challenges include delays in formal diagnosis, lack of age appropriate care, low participation in clinical trials, insufficient support during treatment, risk of developing secondary cancers, and lack of long-term psychosocial support (see also Zebrack 2009). Moreover, this research suggests that cancer diagnoses amongst young adults are on the rise and that slightly more young females than males are being diagnosed with this illness.

It is significant to note that in addition to the above-noted challenges, young women diagnosed with cancer encounter a different set of challenges related to reproduction and sexuality, body image, childcare and domestic duties than their male counterparts (Ali and Warner 2013; Gould et al. 2006; Health Canada 1999). As such, the Women's Health Strategy (Health Canada 1999) encourages researchers and institutions - both public and private - to consider the ways sex (i.e. biological attributes) and gender (i.e. social and cultural conditions) affect people's experiences of health and illness. However, such considerations have only recently been taken up and explored within the context of treatment and survivorship needs among young adult women (Ali and Warner 2013; Gould et al. 2006).

In other words, despite the realization that young adults require specialized treatment and survivorship supports, there continues to be a lack of formal, unified and accredited programs and services available to young adults in Ontario, and specifically for young females living with and beyond cancer (Green et al. 2005; Gould et al. 2006). This is not to say that such spaces do not exist; there are some non-profit, community- 
based organizations in Ontario that play a significant role in developing and providing survivorship care to young adults (i.e. Young Adult Cancer Canada (located across Canada), Maplesoft Center (Ottawa), Stepping Stones (Ottawa) and Wellspring (located across Ontario) to name a few). While these organizations deliver valuable survivorship services, I am concerned about the ways such programming relies on and reproduces dominant cancer/survivor discourses, and do little to account for the different ways cancer is experienced because of personal beliefs and/or social locations. While there has been some recent examination of dominant cancer/survivor discourses (Bell 2012; Ehrenreich 2001; 2009; King 2006; Segal 2007,2010,2012) many of these investigations have failed to account for the ways in which such external forces intersect with young women's personal experiences of cancer. This thesis seeks to address this lacuna by examining young women's cancer narratives and identifying the 'effects' of dominant cancer/survivor discourses on shaping illness experience.

In light of the cultural transformation and public celebration of cancer and survivorship, I present an argument that is critical of the phenomena surrounding cancer/survivor discourses due to their links to neoliberal understandings of health, citizenship, and illness. In line with this concern, in this thesis I question the effects of such discourses on young women's experiences of living with and through cancer. Although the effects of dominant cancer/survivor discourses are largely unexamined, it seems to me that they have significant implications for establishing inclusions and exclusions based on the type of cancer, ideal representations for how cancer-based illness should be taken on and embodied, and normative expectations and guidelines for 
living responsibly and healthily post-cancer. As I elaborate below, it is urgent to investigate the potential effects of such discourses on young women's (a) access to state and community resources, (b) constructions of health, risk and wellbeing, and (c) personal accounts of their body and illness experience.

\section{Research Questions, Argument and Literature Review}

Broadly speaking, this thesis is an attempt to build upon existing sociological work to further understand how dominant cancer/survivor discourses might inform and shape the material realities and subjectivities of young female cancer patients and survivors. The two central research questions which guide this project are:

a) how does the governance of cancer care shape young women's experiences of cancer? (addressed in chapter 3); and

b) how does the dominant framing of cancer narratives reflect broader notions of 'good' citizenship in our neoliberal times? (addressed in chapter 4)

These questions stem from my engagement with scholarship which suggests that the landscape of cancer care and survivorship in Ontario is diverse, complex and multifaceted, and that there is an increasing need to better understand how cancer/ survivor discourses affect the social and material contexts of young women's cancer experiences (Fitch 2003; Gould 2004; Gould et al. 2009; Sinding 2010; Sinding et al. 2012). ${ }^{2}$ While both research questions are concerned with young women's experiences

\footnotetext{
${ }^{2}$ The specific details of my cancer experience and its relation to this project are discussed in detail in Chapter Two of this thesis. As a prelude to this discussion, please note that I was diagnosed with Hodgkin's Lymphoma in November 2008 and I have been in remission since June 2009. Without question, my own experiences and interpretations thereof have greatly informed how I approach this project.
} 
of cancer-based illness, they seek to address different areas and issues within the continuum of what might be thought of as one's illness trajectory.

In an effort to further grasp the complexities surrounding cancer care and survivorship and the ways they influence young women's cancer experiences, the research draws upon different configurations of sociological literature. The aim is to attain a better understanding of the ways external forces such as dominant cancer/survivor discourses intersect with and become embedded in participants' experiences and narratives of illness. In chapter three, I situate my analysis primarily within sociological discussions of women's health, community-based cancer activism and literature focusing on inclusion and exclusion. In chapter four, I explore assumptions and practices which inform survivorship centers. Using a governmentality lens, I analyze the various ways young women interpret and explain their lifestyles and behaviours post-cancer. Drawing on various sociological works, this thesis attempts to gain a greater perspective on the ways dominant cancer/survivor discourses intersect with women's social locations and how they come to shape their current understandings of their social worlds, experiences of illness and selves. In doing so, the present research project demonstrates how various sociological literatures can be marshalled to explore certain aspects and complexities of cancer survivorship.

The research uses participants' narratives to illuminate the ways in which cancer/survivor discourses act as a type of narrative communication with symbolic effects and implications. Such implications influence the governance of care and impact participants' lived experiences of cancer and their individual subjectivities - that is: the 
very ways people know themselves. Young women's cancer narratives tell us something significant about cancer/survivor discourses and the politics of health, citizenship and everyday life. Specifically, based on an analysis of these narratives I argue that participants' cancer narratives are embedded in discourses of exclusion and responsibilization that actively shape and define what it means to be a 'good' survivor/citizen.

Below I outline the main theoretical works and concepts that inform my analysis of young women's experiences of illness. First, I offer a brief review of post-structuralist theory. This discussion leads to a review of Foucault's theory of discourse, power and knowledge. Then I discuss some literature that critically examines the genres of illness stories and their connections with dominant discourses. To conclude this section, I will briefly explore the relationship between citizenship, neoliberalism and health and the ways that citizenship is embodied.

\section{Post-Structuralist Theory}

Post-structuralist scholars recognize the multiple nature of reality and are concerned with how certain knowledges come to be identified as 'truths'. Works under this umbrella are particularly focused on interrogating language, meaning and subjectivity and authors do so by "challeng[ing] the notion that language is [a] neutral, objective, value-free conveyer of aspects of reality. Rather, they expose and interrogate language itself as being both constituted by, and constitutive of, the social reality that it seeks to represent" (Cheek 2000: 40). A main claim within this literature is that the 
analysis of language is imperative to understanding the ways individuals construct their senses of self, their subjectivities and their experiences in and of this world. More to the point, the social, cultural and institutional contexts in which language is constructed and used is taken by post-structuralists to be central to "understand[ing] existing power relations" and the ways discourses exert certain forms of social power over individuals while also distinguishing what is socially acceptable from what is not (Abou-Rizk 2012; Cheek 2000; Weedon 1997: 40).

A key concept that is central to post-structuralism and thus to examinations of language is discourse. Lupton (1994: 17) defines discourse

As a pattern of words, figures of speech, concepts, values and symbols. A discourse is a coherent way of describing and categorizing the social and physical worlds. Discourses gather around an object, person, social groups or event of interest, providing a means of 'making sense' of that object, person and so on.

Following this understanding, language is embedded within social and political contexts and is used for specific purposes. In other words, this particular understanding of discourse highlights the relationship between language, images and symbols and the ways they shape individual social realities. At the same time, this definition stresses that the production of knowledge through discourse is never value-free but rather is replete with authority by "virtue of the power given to the discourse by society" (Bassett-Smith 2001: 45). Following this logic, the aim of post-structural analyses is to explore the ways discourses exercise power over individuals. 


\section{Foucauldian Theory: Power, Knowledge and Truth}

Foucault's theory of power and knowledge is particularly useful for understanding how individual subjectivities and experiences come to be shaped by discourses. One of Foucault's key contributions to the study of power is the idea that power exists in and mediates everyday social relations (Foucault 1990). In his work, Foucault does consider authoritarian forms of power, i.e. sovereign power. However, for Foucault (1979), power is not only imposed from above in a hierarchal mode; rather, especially in liberal societies power is often fluid and circulates from innumerable points which provide numerous sites of resistance. Power is not just suppressive, it is also productive, in the sense that power produces, encourages, fosters certain norms, practices, subjectivities, and relations that circulate and exist within and through the discourses. In this sense, the power of discourses lies in their abilities to shape societal norms and govern individuals' thinking, practices and subjectivities. This is one key aspect of Foucault's theorization of the interconnections between power and knowledge.

Foucault's (1972) definition of discourse is the production of knowledge through language. Indeed, Foucault conceptualizes discourses as systems of thoughts or collections of connected statements that are composed of ideas, beliefs, attitudes, actions and practices which provide a language or a means of talking about a particular topic. Power, for Foucault, is situated within discourse, in that it provides certain ways of talking about and representing the world while also setting parameters around how topics get defined (see also, Hall 1997). 
Drawing on this perspective, Cheek (2000: 45) suggests that subjects can only exist in a meaningful way when they are contextualized within discourses that construct them. For example, consider that the cancer survivor only becomes celebrated when framed within discourses of survivorship, biomedicine, women's health and/or citizenship. This means that, theoretically speaking, survivors only become knowable and valued when represented as taking charge of their survival thus resisting passivity.

Foucault's view that knowledge and power are inextricably bound together suggests that "it is not possible for power to be expressed without knowledge, [and] it is impossible for knowledge not to engender power" (Foucault 1975: 52). Stated otherwise, knowledge triggers power and power produces knowledge. Discourse, then, is where power and knowledge come together to construct particular meanings that perpetuates certain 'truths'. Indeed, for Foucault (1980: 132), "truth" is to be understood as a system of ordered procedures for the production, regulation, distribution, circulation and operation of statements. 'Truth' is linked in a circular relation with systems of power which produce and sustain it, and to effects of power which it induces and which extend it. As such, what is significant about discourses is the ways knowledge and power co-constitutes one another, thus producing new bodies of information and regimes of truth.

Rose (1993) builds on this conceptualization by arguing that regimes of truth are central to the governance of individuals in advanced capitalist societies. It is through the production of truth, Rose says, that people organize, operate and govern themselves. Given that discourses are foundational to our understanding of ourselves and others, 
this literature will provide an analytical means of accounting for the ways cancer/survivor discourses are influencing young women's experiences of illness and the stories they tell.

\section{IIIness Stories}

The telling of stories is a fundamental part of human social communication and is one of the most significant mediums through which we define, shape and interpret ourselves and the social world (Frank 2002, 2005, 2010; Kleinman 1988). As such, it is argued that stories are a means of making sense of one's life and are regarded as a valuable source of knowledge (Bury 2001; Charmaz 1999; Frank 1994, 1995, 2010; Josselson 1995). In recent years, scholars across disciplines have become increasingly interested in 'listening' to the stories of others. One area of study in which autobiographical stories have proliferated is the field of health and illness. This is likely because, as a number of scholars note, illness stories provide deep, vivid and reflective accounts of subjective experiences, thereby contributing invaluable insights to the study and understanding of illness, wellbeing and healing (Frank 1991; Sakalys 2003). In addition to their therapeutic value, illness stories are useful mechanisms for examining how personal experiences of illness are influenced by dominant discourses and the ways public values are taken up in individual bodies (Frank 1995; Segal 2007).

In an effort to understand the interconnectedness of individual illness experiences and our social world, Frank identifies 'narrative types' that most commonly emerge from telling illness stories: restitution, chaos and quest narratives. He explains 
(1995: 75) that individual stories are fabricated through a weave of narrative types which he refers to as "the most general storyline that can be recognized underlying the plot and tension of particular stories". The significance of Frank's narrative types lies in their ability to account for the ways people draw on common social relations and cultural ideas about health, illness and wellness as a way of articulating and makingsense of their experiences (Kleinman 1988). As such, narrative types provide a framework for analyzing genres of illness stories and the ways dominant discourses shape and inform such stories.

According to Frank (1995: 77) the restitution narrative is the most culturally accepted illness narrative and is the story of falling ill, suffering and returning back to a state of wellbeing. This type of story is true in most cases of illness and is often culturally honoured and validated. The second narrative that Frank (1995: 97) describes is the chaos narrative which "imagines life [as] never getting better". In these stories, illness is on-going and is often filled with sentiments of vulnerability, anger and helplessness (Frank 1995: 97). Chaos narratives tend to depict people as being "sucked into the undertow of illness" (Frank 1995: 97). This narrative type is the least commonly told story and I suggest that this may be in part due to contemporary society's belief that illness should be positively taken on and beaten. Lastly, the quest narrative is also a culturally preferred narrative and is where illness becomes a quest from which something can be learned and thus shared with others. In these stories, illness is often viewed as a challenge that becomes a positive motivator for personal change. In these stories, the point is to make meaning out of suffering (Frank 1995). While these 
narrative types are useful for analyzing individual illness stories, my interest lies in how they are able to provide researchers "with a means of exploring the links between culture, individuals and their experiences of illness" (Thomas-MacLean 2004: 1649).

Given the importance of the social and cultural in developing and expressing stories, it is not surprising that public values and dominant discourses are increasingly becoming embedded in personal illness stories. Interestingly, all three of Frank's (1995: 76) narrative types - restitution, chaos and quest -are also being appropriated by numerous stakeholders who are increasingly using them as means of marketing. In recent years, cancer patient and survivor stories are being incorporated and strategically deployed by numerous stakeholders in efforts to humanize illness, dispel myths, promote healthy behaviors and to raise money and support. ${ }^{3}$ This is likely because, as Frank (2010: 3; 2002) and Kleinman (1988) note, stories are powerful insofar as they "animate human life" and, in the case of cancer, are an expression of people's experiences of living with and through this illness. Cancer and survivor stories work on people in particular ways, "affecting what people are able to see as real, as possible, and as worth doing or best avoided" (Frank 2010: 3). In this sense, narratives are powerful tools that every individual possesses; storytelling not only invites others to listen, to share, to contemplate, and to evaluate other's experiences, it also is way to claim what counts. ${ }^{4}$ As such, cancer and survivor stories often reinforce and perpetuate restitution and quest narratives while disregarding and silencing experiences of chaos and limit the

\footnotetext{
${ }^{3}$ Such stakeholders include but are not limited to: government agents, non-profit workers, biomedical/pharmaceutical employees, advocacy groups and corporate philanthropists

${ }^{4}$ Chapter two provides a much more detailed account of narrative analysis as a qualitative method. The purpose of discussing stories here is to illustrate the ways stories are embedded in and reflective of sociocultural discourses.
} 
ways individuals come to experience and understand their illness. Thus, the stories that are most publicly available are reflective of the ways cultural discourses shape individual narratives.

\section{Citizenship, Neoliberalism and Health}

In Canada, shifts in state governance and health discourses reveal a changing political, economic and social landscape - one which points to a transition from a society based on equality, social democracy and citizenship entitlements to one that prioritizes the reduction in overall size and intervention capacities of governmental agents. These political shifts are altering the relationship between individual citizens and the state and the market. Many social scientists concur that these political shifts are intimately linked to neoliberal ideologies and rationalities which privilege individual freedom and responsibility over state control and responsibility (Brodie 1997; Gazso and McDaniel 2010; Ilcan 2009; Larner 2000; Lemke 2001). In recent years, Canadian scholars across disciplines are demonstrating the ways neoliberal logics are transforming notions of citizenship. In particular, there is a vast scholarship pointing to how neoliberal policies now refer to citizens as 'clients' thus transferring responsibility from the state to the individual (Armstrong and Armstrong 2010; Bacchi and Beasley 2002; Brodie 1997; Coulter 2009; Fafard et al. 2009; Fischer et al. 2004; Gazso 2009; Gazso and McDaniel 2010). This depiction of citizenship strips away entitlements as a social right and emphasizes the primacy of the market. In this sense, neoliberalism can be understood as a form of governance which calls forth the construction of new subjects (Dean 1997; O’Malley 2000; Peterson and Lupton 1996; Rose 1999). 
Neoliberalism is largely understood as a pervasive rationality and political project that shifts power away from the state by cultivating the conditions that facilitate and enable autonomous self-regulation (Larner 2000). Thus, within what are described as neoliberal contexts, individuals are conceptualized as rational, responsible, self-reliant and self-sufficient actors who should reject "public or social intervention in their lives" (Howard 2007: 3). Stated otherwise, individuals are increasingly encouraged to assume a degree of responsibility for managing their own risks and choices - health related or otherwise (Rose 1996). ${ }^{5}$ Importantly, such neoliberal objectives are achieved not through the repression of power, but rather by prompting individuals to exercise their autonomy and to make regulated choices via expert knowledge towards their own selfgovernance (Miller and Rose 1994). Under these conditions, individuals are expected to be active in the process of their own self-governance - that is, in "processes of endless self-examination, self-care and self-improvement" (Petersen 1997: 194).

Presently, notions of personal responsibility and health are inextricably linked to neoliberal ideas of citizenship. The growing individualistic imperative of 'responsible healthy living' actively shapes and defines what it means to be a 'good' citizen (Lupton 1995; Petersen and Lupton 1996). As such, good citizenship entails becoming responsible for managing one's own risks while also maintain and improving one's own health. In this sense, neoliberalism privileges particular subjects: the construction of 'healthy citizens' (Petersen and Lupton 1996). 'Healthy citizens' are individuals who not

\footnotetext{
${ }^{5}$ Robert Crawford (1980) coined the term healthism to refer to the shift toward transferring the responsibility of health from the state to the individual. As such, neoliberal ideas of health encourage individualized and privatized approaches to maintaining and improving one's own health.
} 
only assume responsibility for managing their own health but are also individuals who engage in work and are "able to take part, to the best of his or her physical ability, in contributing to the nation's prosperity" (Gazso and McDaniel 2010; Ilcan 2009; Miller and Rose 2008; Petersen and Lupton 1996: 68). Health - the valorized norm - is an essential component in defining good citizens while illness - the deviation - is thus evidence that one has not behaved responsibly and is morally culpable in light of known risks (Galvin 2002). More importantly, the neoliberal imperative of health discourages any meaningful conversation about the structural causations of illness.

\section{Sociological Significance and Thesis Organization}

The present study contributes to a growing body of research on the politics of health and citizenship by exploring young women's cancer narratives through lenses offered by different sociological literatures. The aim is to understand the complexities of young women's survivorship experiences as, at least partly, the effects of dominant and widely circulating cancer/survivor discourses. This research is distinctive in that it is concerned with understanding and giving voice to young female cancer survivors who have often been excluded from much academic investigation. More to the point, it highlights some of their unique medical, psychological, financial, and social needs. In addition, this study adds a sociological perspective to academic and public discourses surrounding cancer and survivorship. Rather than focusing solely on the psychological and clinical benefits of organized survivorship communities, this study explores how contemporary forms of government and governance infuse these spheres in ways that have implications for people's social identities and individual subjectivities. 
The thesis is divided into four chapters. Chapter two discusses my methodological approach and specific data collection and analysis methods. I both identify qualitative methods as the most appropriate for the current study and critically reflect upon my personal positioning in relation to this research. Chapter three examines the political and cultural climate of cancer support in Canada and the establishment of a cancer hierarchy (Gray 2010). The main claim put forth in this chapter is that tendencies to favour breast cancer over other types of cancers result in complex and uneven distributions of resources, power, knowledge and access to health services amongst cancer survivors. In Chapter four I examine participants' understanding of their roles in managing their health risks and discuss the measures that they accept as necessary for sustaining a disease-free state of being. Finally, in Chapter five, I return to the research questions and goals outlined in this first chapter in light of my specific research findings and discuss the implications of this study for the burgeoning survivorship community. 


\section{Chapter 2: Methodology}

\section{Introduction}

Not everything that can be counted counts, and not everything that counts can be counted.

\section{- $\quad$ Albert Einstein}

Much of the inspiration behind this research project stems from the above insight and in some ways speaks to my desire to 'give voice' to the lived realities of the women who participated in this research. Qualitative methods allow researchers to go beyond statistics and so called scientific 'facts' and ask critical questions that seek to understand why things are the way they are, why do they occur in particular ways, whose perspective counts, in what context and so on (Nelson et al. 2009). By employing qualitative methods, and more specifically narrative analysis, I am able to highlight the increasingly complex relationships between human experience and social relations that is the interconnectedness of young women's individual experiences of cancer and our social world (Kleinman 1988). The purpose of this chapter is to discuss the research process while practising critical reflection. I briefly describe my motivation for the project and research design; my role in the research; sampling, recruitment and data collection; and how the data was analyzed within a narrative analysis framework. Throughout this project, I reflect on my position as an 'insider' and document the ways in which my experiences may have shaped the research design, data collection and analysis, my decision-making and the final report. 


\section{Motivation and Research Design}

My interest in young women's experiences of cancer, the lack of social supports and issues of citizenship primarily stems from my own cancer diagnosis. In November 2008 , I was diagnosed with stage 4 B Hodgkin's lymphoma at the age of 21 and underwent a year of treatment that included both chemotherapy and radiation. During the entire year of treatment I felt isolated as a result of my illness. Despite being physically ill and having little energy to participate in social activities, I never met or crossed paths with any other young adult cancer patients and/or survivors - even in the hospital or medical day care when receiving chemotherapy - even though I knew that my particular cancer affected mostly young adults.

A year after completing treatment I made the decision to begin actively seeking out other young female cancer survivors and began participating in several local cancer organizations in hopes of supporting and helping others navigate their cancer journey. It was through these various organizations and support groups that I began to meet other young women who had similar cancer experiences and became an active member in the Ottawa cancer community. From my experiences of interacting in this community, I began to witness the difficulties that other young women living with cancer encounter, observed the inequalities between and amongst different types of cancer and noticed the subtle ways cancer organizations pressured young women to participate in the cancer community. I also noticed that these women often described this overwhelming desire to be more involved in the cancer community whether it be supporting other cancer patients directly, participating in fundraising initiatives, blogging about their past 
and present experiences and making both themselves and their stories available to others. In some instances many of these women's - including my own - illness experience became an obligation to pay it forward. Through these experiences I began to recognize that one's health status - as a cancer survivor- evokes a moral responsibility towards giving back. Reflecting upon encounters and discussions with other female cancer survivors I began to see how individual cancer narratives often discursively operate to distinguish and make up particular kinds of citizens - ones who are morally good and responsible, and ones who are not.

With these insights in mind, my thesis question crystalized through a process that included reflecting upon cancer related advertisements and their use of cancer survivors as ambassadors for recruiting others to help support the cause. The months of September through November are particularly important for several cancer communities (including the so-called blood cancers leukemia/lymphoma, breast and prostate cancer) as these three months are dedicated towards raising significant monetary funds while generating awareness about each particular disease. ${ }^{6}$ In spite of my strong position towards health awareness and education, these particular advertisements - which often present survivors as actively defining the life one will lead post treatment -prompted my exploration of critical questions. The questions that inform this research are directed towards understanding how does the governance of cancer care shape young women's experiences of cancer?; and how does the dominant

\footnotetext{
${ }^{6}$ A common strategy amongst large non-profit cancer organizations used to generate corporate, community and individual support is to designate particular months to certain issues for the purpose of raising money and awareness (King 2006). September is Lymphoma awareness, October is breast cancer and blood cancer awareness and November is prostate cancer awareness.
} 
framing of cancer narratives reflect broader notions of 'good' citizenship in our neoliberal times?

Evidently, my cancer journey made me aware of the ways in which women's cancerous bodies and subjectivities are vulnerable to forms of power: surveillance, guidance, discipline, or outright control. This has shaped my thesis project. My own experience of illness informed and became an integral part of this research, with its benefits and dilemmas. To begin with, my objective is not to strive for value-neutrality. In contrast to positivist forms of social science research, qualitative methods do not "pretend to emulate the natural science by producing cumulative and predictive theory" (Flyvbjerg 2005: 38). Rather, qualitative approaches are a conscious effort to move away from practices which dehumanize data and undervalue human experience. Qualitative methods, and more specifically narrative analysis, regard values as an important component of the research process and more importantly acknowledges that the voice of an individual is never only their own, "each voice always contains the voices of others" (Frank 2005: 966). As such, stories and storytelling are a dialogical relationship where individuals (tellers and listeners) and stories develop gradually alongside and shape one another allowing my own experiences to be situated within the research (Frank 2002). ${ }^{7}$

\footnotetext{
${ }^{7}$ Although, stories and narratives are often used interchangeably, Frank (2010: 14) distinguishes stories from narratives in that stories are "living, local and specific referring to immediate concrete events, people, scientific findings and more". Narratives on the other hand are the resources, templates and plots that are often culturally specific that people use to construct their stories.
} 
This study has also taken up the challenge of incorporating feminist principles of reflexivity into the collection, analysis and writing of my findings. Wasserfall (1993) describes reflexivity as both a practical and conceptual tool that allows the researcher to acknowledge their own subjectivities and influence on the research process.

Furthermore, feminist scholars suggest that reflexivity can also be used to equalize power relations between the researcher and the participants while also dispersing differences in class, race, gender, ethnicity, sexual orientation and ability (Doucet and Mauthner 2008; Wasserfall 1993). These issues will be addressed in greater detail throughout this chapter.

\section{Practicing Reflexivity: My Role as the Researcher}

Postmodern critiques of positivist methodologies have resulted in the emergence of reflexive sociology - a new paradigm in which qualitative researchers engage in self-reflection that continually accounts for and evaluates "subjective responses, inter-subjective dynamics and the research process itself" (Finlay 2002:

532). Historically, subjectivity was thought to be the nemesis of scientific validity and researchers who were unable to maintain detachment from their values, positions and participants were highly criticized (Bloom 1996). However, in an effort to transcend conventional scientific standards of objectivity, reliability, and validity, Denzin and Lincoln (2005) suggest that the "reflexive turn" in qualitative sociology acknowledges that researchers are not outside their field of study and that they too participate in the co-construction of knowledge. Reflexivity creates a space that allows the researcher to 
articulate and locate their own subjectivities and be 'written in' to the world that they study.

Denzin and Lincoln (2005) stress that qualitative methods seek to develop a better understanding of the meanings, processes and lived experiences of everyday life and emphasize that research is value-laden. In keeping with this line of thought, each researcher's personal characteristics and social location play an important role in shaping one's preconceptions and assumptions toward the world in which they inhabit. As such, in order for a researcher to capture and attempt to make sense of the social world they too must be immersed in it (Hammersley and Atkinson 1983). Following this rational, I did not attempt to detach myself from the research process or the research participants. On the contrary, I began this research with the view that my own life history, and more specifically story of illness, would be an important asset in creating engagement, bonds and trust, but may also generate certain dilemmas with research participants. Although Ellis (2004: 195) makes the compelling argument that personal narratives can "open up the possibility of dialogue, collaboration and relationship" whereby interviews may materialize as pleasant conversations rather than formal interrogations, my status as a cancer survivor could not always outweigh my other social characteristics that in some instances positioned me as an outsider.

Throughout this entire process, I suspected that my personal biography gender, age, race, insider status (cancer survivor) and class - would be an asset and help facilitate recruitment, data collection, and data analysis. I assumed that my position as a 
cancer survivor would be enough to establish rapport with participants and while at times it was, there were instances in which it was often not enough to prevent both the challenges that my social characteristics presented and also the struggles that are associated with being an 'insider' (Twine and Warren 2000). For example, several of the women interviewed were either pregnant or had just given birth when they received a cancer diagnosis and I mistakenly took for granted that we could share a similar understanding of the degree to which young women would require additional social support. Although I could empathize with what it was like to receive a life altering illness diagnosis, I could not fully relate to how each women negotiated and often sacrificed their own care and wellbeing in order to care for and bond with their newborns. As such, many of these young women had different ideas in regards to what kinds and degrees of social support were needed. In what follows, I reflect upon both the benefits and dilemmas that arose in revealing my insider status.

In some respects, my 'insider status' was beneficial in establishing rapport and working relationships with several local cancer support groups and even helpful in forming intimate familiarity and trusting spaces for participants. ${ }^{8}$ I took great efforts in considering how to best use my 'insider status' and not misrepresent myself in any manner. For example, my ethics clearance allowed me to present myself as an academic researcher while also revealing my own health status. Within this context, I was able to present myself in a way that allowed me to be honest, professional and ensured that my

\footnotetext{
${ }^{8}$ Frank (2010) argues that stories play an influential role in whether people fit into groups or not. One's knowledge of certain stories and/or one's ability to know how to react to certain stories is often recognition of belonging to a particular group.
} 
position both as a researcher and cancer survivor was clearly stated and known. ${ }^{9}$ । believe that revealing my own health status had a positive influence on recruiting participants precisely because I also belonged to this circle, thus legitimizing my intentions for researching this particular sub-set of women. In addition, I also felt that my being a young female cancer survivor would make it more comfortable for the women to openly speak about their private and intimate experiences.

Many of the women I interviewed were often interested in how I came to use my own cancer experience as the basis or catalyst for further research. Many scholars argue that establishing openness is an important component in the research process so that participants feel comfortable and at ease with the researcher (Grills 1998; Kvale 2006). A dilemma that I constantly grappled with was how much of my own experience do I reveal? In some instances, it was difficult to decide how much information to share and/or how to answer particular questions because (1) all women interviewed were at different stages of healing both physically, psychologically and emotionally, (2) I did not want to interject my values and beliefs onto them and (3) I wanted to create a space where all women were able to share and express their thoughts, feelings, and experiences without the fear that they had to defend their positions. In the end, in addition to informing them I was a Hodgkin's lymphoma survivor, I evaluated each situation independently and considered what impact the level of my disclosure might have on the interview.

\footnotetext{
${ }^{9}$ The Chair of the Carleton University Ethics Board commended me on the amount of detail and consideration I had given to ethical issues in my application.
} 
In balancing my own hesitations with ethical dilemmas of revealing my health status, much of the literature suggests that self-disclosure is a strategy that contributes towards building trust and also balances power inequalities between the interviewer/interviewee (Abel et al. 2006). In an effort to create a common ground between myself and the participants I began each interview with a brief synopsis of my own cancer story and informed all participants that I would happily share further details at the end of the interview. I clearly let each of the participants know that I wanted to use the interview time to focus on their stories. In some instances, I did rely on my personal experiences when participants required clarification in regards to certain questions. I also empathized with participants when we shared similar experiences with sayings like "I get it" or "I completely understand". I believe that this approach promoted a natural flow of conversation - one that would be encountered between friends- which I believe allowed the participants to feel at ease and forthcoming with their stories. I tended to share less information with the women who were still navigating the early stages of the healing process unless I was able to provide them with some particular advice or resources that would be of interest or value to them. Interestingly, however, I was happily surprised at how much I learned from each participant and how they have shaped and contributed specifically to my own cancer journey and more generally to my everyday life.

Despite countless hours of researching and writing about breast cancer, I initially thought that I had a thorough understanding of the ways in which bodily transformation inevitably affect individual self-identity. Prior to the commencement of this project I had 
given a lot of thought to the amount of sensitivity that would need to be provided in this area. In doing so, I often allowed the women to direct the conversation on bodily changes and only probed if I thought the participant was comfortable in discussing this area. All of the breast cancer survivors were indeed at ease discussing changes in both their physical appearances and sexuality and they tended to elaborate with great detail when talking about this topic. Given that much academic focus has been given to bodily transformations and the self (Kendrick 2008; Klawiter 2005; Langellier and Sullivan 1998; Ucok 2005, 2007; Waskul and van der Riet 2002) I was somewhat unprepared for how these women described and compared their scars to other types of cancer treatments.

Interestingly, breast cancer survivors often discussed how uncomfortable they thought it would be to participate in support groups that included women with various types of cancers precisely because their type of cancer left them with visible bodily changes - several of the women I interviewed had to wait to have breast reconstruction after having a mastectomy. In particular, while the women acknowledged that all types of cancer diagnoses are life altering and leave both visible and invisible scars, they stressed that losing a breast(s) forever changes you as a woman. In these instances, I felt like a complete outsider and that my status as a young female Hodgkin's lymphoma survivor and the hardships that I experienced were being challenged and in some ways delegitimized by the very fact that I had not lost a breast - a visual and social signifier of womanhood. However, despite not losing a breast or being diagnosed with a woman's cancer, I too, like many other young female cancer survivors face the reality that our womanhood - one's ability to reproduce and experience sexual pleasure - is also 
threatened. Regardless of popular claims, it is not necessarily the type of cancer diagnosis that threatens a woman's sexuality and reproductive capacity. Rather, the course of treatment, drugs, dose, intensity, method of administration, size/location of the radiation field in addition to one's age are often much more important factors in determining the extent of sexual and reproductive complications (Lee et al. 2006; Meirow and Nugent 2001).

In these moments, I did not allow these particular comments or beliefs to upset me or interfere with the flow of the interview. Rather they became specific occasions for later self-reflection. I used these comments to truly consider what it would be like to be a young woman diagnosed with breast cancer and thought about the ways that I would not only have to negotiate the very idea that I was diagnosed with a life threatening illness but in addition, having a daily reminder - losing a breast(s) - of the loss associated with breast cancer. More than this, I thought about how young women's experiences of breast cancer are almost non-existent in popular representations of the breast cancer movement, and the potential fear and isolation that can be associated with such a diagnosis and the lack of resources, knowledge and social supports available. Thinking through this lens, it became clear as to why young breast cancer patients craved a space specifically designated for them and how their experiences may require additional privacy, sensitivity and empathy. Critically reflecting on my own illness in relation to these women's experiences, I recognize that there are dangers in assuming that one's insider status provides access to 'knowing' or 'understanding' 
others experiences in spite of the similarities that individuals and/or communities may share.

I acknowledge that my own cancer experiences have informed and are incorporated in all aspects of this project. It is evident that this research begins from the assumption that the stories individuals tell are never truly their own but rather they are produced dialogically with others and always multi-voiced (Doucet and Mauthner 2008; Frank 2002, 2005, 2010). I have tried to be aware of my position as an 'insider' and recognize that it is a highly fluid position that can often "change even in the course of a single interview" (Hesse-Biber 2007: 143). I have also tried to be reflexive of my decision making in order to provide honest representational accounts of the individual experiences of the participants to the best of my ability.

\section{Sampling, Recruitment and Data Collection}

Qualitative research does not set forth any defined rules for determining sample size, instead emphasis is placed on pursuing a richness of data that is often associated with small sample sizes with the aim of collecting depth and detail (Patton 1990). Quantitative methods rely on large samples often selected randomly with the end goal of statistical generalization. However, qualitative researchers sample purposefully and select information-rich cases in "which one can learn a great deal about issues of importance" (Patton 1990: 169). A dilemma often encountered by qualitative researchers is that the amount of data required cannot be fully determined ahead of time. This is to say, the number of research participants needed for complete results 
emerges during the process of conducting research (Sandelowski 1995). During the design stage, I estimated that a sample size of 20 young female cancer survivors to be ample and feasible. Over the course of this project, these numbers were modified due to time constraints and difficulty scheduling the last few interviews. Nevertheless, common themes and patterns emerged and it became apparent that data had reached a point of saturation.

After receiving ethics clearance from the Carleton University Ethics Board I began my field work in September 2012. Between September 2012 and April 2013, 17 semi-structured interviews were conducted with women over the age of 18 , who were not in active treatment, and who received a cancer diagnosis between the ages of 1835. My research sample is relatively homogenous in terms of age, race, class, sexuality, ability and level of education. Additionally, I was able to recruit women with various types of cancer diagnoses, however, the majority of the women had either been diagnosed with Hodgkin's lymphoma or breast cancer. I choose to include only young female cancer survivors because the literature suggests that young women are increasingly influenced by dominant health and beauty discourses generally and more specifically there are significant gender differences in the manifestation and experiences of cancer and illness (Abou-Rizk 2012; George and Rail 2005; Lightman et al. 2009; MacDonald et al. 2010; Tritter and Calnan 2002; Wendell 2001). In particular, I decided to explore the experiences of young women living with cancer for several reasons: (1) young women - between the ages of 20-44 - account for almost two thirds of all young adult cancer diagnoses; (2) young female cancer patients/survivors require specific 
health and social supports, however there are complex and uneven distributions of resources, power, knowledge and access to health services; (3) contemporary understandings of health, well-being and lifestyle are inherently linked to one's citizen status; and (4) cancer programs, health material and cancer activism (more generally) shape and individualize one's biological status (as healthy or ill) in individualized ways. My interest lies in understanding how the cancer experience ultimately shapes a particular form of self-governance that supports the 'making-up' of good citizens.

My sample of 17 young female cancer survivors was recruited through purposeful snowball sampling methods. Due to the time constraints of this project, I felt that it was necessary to employ an 'information-orientated' selection approach that would allow me to focus on cases that had the potential to provide sufficient information about the phenomena being studied. According to Flyvbjerg (2005: 79) "cases are selected on the basis of expectations about their information content". Following this rationale, I choose to approach local cancer support groups, personal acquaintances who are situated within this community, as well as Young Adult Cancer Canada - the largest cancer support network specifically aimed at supporting young adults. By focusing on a variety of cancer communities, my aim was to recruit a diverse sample of young women with regard to various cancer diagnoses, social location, and biographies. In addition, after the completion of each interview I provided each woman with a recruitment flyer and invitation letter and asked if she could distribute it to other young female cancer survivors she may have known and who may have wanted to participate. Through snowball sampling, I was able to generate an additional eight 
interviews while also ensuring that confidentiality was maintained, as each woman did not know whether her acquaintances had contacted me to be a participant.

Initially, my intentions were to have at least half of my sample meet a criterion of having applied for and/or received state supports such as Employment Insurance (EI) Sick Benefits, Canadian Pension Plan (CPP), Ontario Disability Support Program (ODSP) or Ontario Works. However, after a month and a half into the recruitment process it became evident that many of the young women who were contacting me did not have any experiences applying for these types of social citizenship benefits. In fact, most of the women who were in contact with me either had access to long term disability through work, support from a spouse or were living at home with their family of origin. At the outset, I had assumed that most young women diagnosed with a long term illness would seek out state financial aid. But, as I found out, the participants in this study were well educated and most of them had stable employment offering additional benefits such as short and long term disability and extended medical and pharmaceutical benefits. After six interviews and finding two participants who used state supports, I decided that half of the sample did not have to have prior experiences of trying to access these programs simply because these themes were not coming out in the data. Perhaps having a set number of participants meeting this criterion would have been possible had my recruitment strategies been more diverse and included other cities in the province of Ontario other than Ottawa which is known for its relatively stable economy and more advantaged white collar employment. 
Interestingly, however, several themes began to arise out of the data and I decided to focus my attention on these emerging key findings. First, participants who were diagnosed with non-women's cancers often referenced the lack of supports and awareness about their cancer in comparison to women's cancers, most notably breast cancer. And second, the idea of living a 'healthy' life and the ways in which health is practiced and consumed emerged from the participants' stories. In an effort to further examine these developments, I determined that it would be necessary to have a minimum of five women diagnosed with women's cancers in order to adequately compare differences in access to support services. Furthermore, I adjusted some of my interview questions to further probe when participants brought up ideas of health and healthy living in order to understand where and how these ideas shape their cancer experiences.

All of the seventeen young female cancer survivors who participated in this study completed one in-depth interview. The women's ages ranged from 22 to 39 with most of the women being in their early thirties. All the women had received a cancer diagnosis and were all in various stages of remission. At the time of the interview seven of the women were not in martial relationships. Six of the women were married and all had children with the exception of one woman who was pregnant with her first child. The study sample was racially and ethnically homogenous. All the women but one identified as being white and Canadian, the exception identified as a Portuguese 
Canadian. ${ }^{10}$ While information about race and ethnicity was not actively sought, it was revealed during the interview. The lack of diversity in the sample could be a reflection of my recruitment strategy that focuses solely on cancer support groups rather than also including non-institutional informal networks or culture-specific community centers. Scholars note that vulnerable populations - women of colour, poor women, disabled women, trans- women and people who live at the intersections of these identities tend to have greater difficulty accessing knowledge about available resources and services and more importantly services are not geared towards inclusion and sensitivity towards their specific needs (Gould et al. 2009). As such, there is a lack of diversity among those who utilize available community driven cancer support programs.

The majority of the interviews took place in the privacy of the participant's home. Two interviews occurred over the telephone due to poor weather conditions. I asked each of the women to choose a location in which they would feel most comfortable and most of them chose to invite me into their homes. Rapley (2001) suggests that the researcher needs to account for the environment in which the interview takes place. Taking this view into consideration, and due to the sensitive and confidential nature of the conversations, I thought that it might be inappropriate to conduct the interview in a public space. As such, I considered conducting the interviews in the participant's home to be a way of dispersing traditional power relations between the researcher and interviewee while also ensuring that the participants were at ease as much as possible. I found that conducting the interviews in the participant's homes to

\footnotetext{
${ }^{10}$ For a complete view of participant demographics please see Appendix A.
} 
be a relaxed and warm space that encouraged friendly dialogue that could be found between friends. At no point did I feel uncomfortable or unsafe. Rather, each time I was invited into a participant's home I was cautiously reminded that I sat on the "precarious edge" of being an insider (Kelly 2012). Prior to the commencement of the interview, each woman was provided a consent form that further explained the purpose of my research, issues of confidentiality and informed consent. I ensured that all women knew that all of their answers were voluntary and that they did not have to answer a question if they so chose. Furthermore, I also informed them that they could withdrawal from the study at any time. Each participant read and signed the consent form that was approved by the Carleton University Research Ethics Board.

During the interviews, I encouraged each participant to freely respond to each question as they best saw fit and provided additional time at the end of the interview for them to address or speak about anything that they might have felt was important, that I had missed and/or thought I should know. More importantly, I also left each woman with my e-mail address to provide them with an opportunity to add, change, or clarify their stories. Interviews ranged between 1 and 3 hours and during each interview women were asked general questions about their cancer experiences. More specifically, participants were asked to describe their access to certain services - reproduction and sexual health, psycho-social supports, financial and state programs- as well as their thoughts about and engagement with and the role a healthy lifestyle plays in living cancer free. All of the interviews were recorded with the participant's permission. Recording the interviews allowed me to be fully engaged in the conversation rather than 
being also focused on ensuring that I had accurately taken down field notes (Maykut and Morehouse 1994). Also, recording the interviews allowed me to transcribe verbatim, re-listen to certain parts of the conversation and to quote women with confidence.

\section{Data Analysis}

Much scholarly attention has been given to issues of power and privilege in the data collection stage, however, data analysis processes are often sites in which ethical dilemmas are most prominent (Code 1988, 1991, 1995; Doucet and Mauthner 1998, 2002; Glucksman 1994). Like many other qualitative researchers, I was concerned with the ethical considerations associated with knowledge production and representation and was acutely aware of the power that I held as the primary interpreter of the data. Much of the data analysis process is done in isolation and while I felt intellectually prepared for this stage of the research process, issues related to trust and accountability weighed heavily on my mind. According to Miriam Glucksman (1994: 163) "each researcher is left on trust to draw the difficult line between interpreting the data in terms of its relevance to her research questions as opposed to twisting it in a way that amounted to a misrepresentation of what was said". This account highlights the delicate balance between trust and hearing the data that each researcher must weigh when undergoing this process. In an effort to lessen the severity of these ethical dilemmas, I decided that the practice of relational methods and self-reflexivity would aid in this process especially given my commitment to listening to women's voices. Even though these practices helped, I was still mindful of: (1) privileging some relationships over 
others and (2) the extent to which reflexivity-during the actual research process - could increase the transparency and accountability of the research process and knowledge claims stemming from this project. These two particular concerns will be examined throughout this section.

From the onset of this process I was very aware of how my own experiences, assumptions and preconceived notions about the subject matter could potentially colour and/or influence the way in which I interpreted the data. In an attempt to "open [my] mind to the range of possible meanings, properties, dimensions and relationships inherent in any bit of data" I choose to re-listen to an interview a couple days after each one was conducted and begin a preliminary analysis (Strauss and Corbin 1998: 88). In doing so, I took note of themes and differences in experiences and organized the data into broader categories. In particular, this process also encouraged me to explore other themes that were emerging out of the interviews rather than relying only on my semistructured interview guide that I had created at the inception of the project. Thus, an understanding of how important each interview was in relation to the one before and after was instrumental in allowing me to be more receptive to the data (Denzin and Lincoln 2005). In many respects, this approach is informed by particular epistemological and ontological assumptions that privilege the idea of a relational ontology (Mauthner and Doucet 2003). A relational ontology is a core set of beliefs that reject the notion of a "separate, self-sufficient, independent, rational 'self' or 'individual'" and favour conceptions of relational beings in which individuals are situated in larger social relations (Mauthner and Doucet 2003: 422). A relational theory accounts for the ways in 
which social context is inherently embedded within participants voiced experiences and also recognizes that some 'voices' may be heightened while others silenced during the research encounter. Parallel to these assumptions, relational theory also acknowledges that the researcher is not an objective bystander; rather, they too are located in the research and that stories and storytelling always occurs between individuals (Doucet and Mauthner 2008; Frank 2002; Mauthner and Doucet 2003). In keeping with my epistemological and ontological assumptions, reflexivity was an integral part of the data analysis process because of my close connection to the project in addition to recognizing that subjects are part of larger, complex social webs. As such, I used The Listening Guide (Doucet and Mauthner 2008) as a practical tool to help locate my own subjectivities in relation to the participants while also paying particular attention to the many voices nested in a "person's expressed experiences" (Gilligan et al. 2006: 254).

The Listening Guide is a method that requires the researcher to engage in a series of sequential 'listenings' that are designed to focus on the data in different ways. ${ }^{11}$ Thus the researcher is able to examine the data through different lenses and tune into a participants multi-layered voice. The Listening Guide involves a series of listenings that are based upon a series of broader questions about situating voices: Who is speaking and to whom, what stories are being told about relationships and what are the social and cultural frameworks in which these stories are told? (Brown and Gilligan 1991). Keeping these larger contextual questions in mind, I was able to highlight the

\footnotetext{
${ }^{11}$ Gilligan et al. 2006 make a distinction between 'listening' and 'reading' whereby the former requires the researcher to be an active participant and tune into multiple levels. The researcher is encouraged to "experience, note, and draw" from their intellectual, social and emotional responses to the narrative (Gilligan et al. 2006: 256).
} 
complex and multilayered nature of experience, account for the ways in which stories are relational -stories emerge between teller and listener- and capture how participants made sense of their illness and the impact it has on their daily lives.

In the first listening of transcripts, I focused on the actual story that was being told. In particular, I considered three contextual questions - what happened/what story is being told, when and where it occur, who was involved, and within what context is the story embedded in - and took note of the plot. In the second listening, I attended to my reaction and overall response to the interview. I aimed to intellectually, socially and emotionally locate my own subjectivities in response to the narrative. This process helped in identifying how my own assumptions and experiences influenced how I understood the narrative. In particular, Doucet and Mauthner (2002) argue for a robust understanding of reflexivity that includes accounting for personal, interpersonal, institutional, pragmatic, emotional, theoretical, epistemological and ontological influences. In order to document some of these influences, I created a table to tabulate how my personal biographical characteristics shaped my initial listenings. I also took note of how the women's stories either conformed to or challenged my own assumptions, research question(s) and theoretical frameworks. By doing so, I attempted to maintain research relationships with all the stories and not disregard or give a different weight to the one's that did not 'fit' nicely within my framework. ${ }^{12}$ The first and second listenings allowed me to become familiar with the data, have a good sense

\footnotetext{
${ }^{12}$ Doucet and Mauthner (2002) state that it is impossible to maintain research relationships with each and every respondent however researchers should note which relationships are given more weight.
} 
of each of the women's narratives and formally reflect upon and separate my own experience, assumptions and values.

During the third listening, I focused on locating the women in their own stories. More specifically, I attempted to listen and record the language she used to describe her emotions and role in the experience. In doing so, I created "I poems" from several passages and examined them in relation to one another that helped in identifying the first-person voice (Gilligan et al. 2006). In addition, the 'I statements' were purposeful in establishing connections between the issues which were emphasized by the women and the telling of their story. In the fourth listening, I placed attention on how the women described their experiences in attempting to access resources, how ideas about health shape their understanding of 'living cancer free' and the ways in which a cancer diagnosis becomes an opportunity for reflection and even change. In this stage, listening focused on hearing the multiple voices that are often embedded within the women's expressed experiences. This particular listening allowed me to code and categorize discursive relationships. In other words, this step highlighted how the voices of the participants were saturated with dominant discourses and the influence of others. Additionally, in this stage I attempted to document women's accounts of resistance. In doing so, my goal was to highlight the ways in which women's stories challenged my theoretical framework and encouraged me to not alienate or reject the data that had emerged. Finally, in the last listening I made connections between and amongst the women's individual experiences and broader social structures. I used Foucault's understanding of power and more specifically 'technologies of governance' to 
draw connections between individual experience and modern forms of governance (Foucault 1978, 1980).

In an attempt to break away from the isolating nature of the data analysis process and to also gain a 'fresh perspective' on certain issues that arose in data analysis, I often met informally with other MA colleagues on a regular basis. During our discussions we would often bring a particular issue or topic that we were struggling with and sought each other's opinions. This practice - in which I often explicitly acknowledged my own subjectivities and personal history in addition to offering details about dilemmas that I was encountering in data analysis - provided a space where others who were in similar positions, could reflect upon and make observations or suggestions. In many instances, this process often encouraged me to locate more clearly my own subjectivities and further challenged my epistemological, ontological and theoretical frameworks by reminding me of how subjective data interpretation can be. Furthermore, meeting with other colleagues proved to be an effective way of acknowledging the diversity of situated knowledges within the interpretive process (Siltanen et al. 2008). In many instances the particular insights that my colleagues provided invited me to think through a different lens and try to interpret the data from a different perspective. Even though these informal meetings began as a support network, they inevitably transformed over the course of our MA projects and became a productive space for self-reflexivity, data analysis and the sharing of resources. 


\section{Conclusion}

Qualitative research is often appealing and rewarding to many researchers who seek to understand and give voice to the lived experiences of participants. Yet it can also be a stressful endeavor particularly due to the lack of prescriptive methods. It is an allencompassing process that requires vigilant self-awareness in addition to the continual evaluation of methods and underlying assumptions. In this chapter, I have reflected upon my own standpoint and location within this research, documented my choices and decisions in regards to sampling and recruitment and have outlined my analytic procedures that were used to explore women's experiences and understanding of how a cancer diagnosis and associated care becomes a form of governance. Using the interview data, the next two chapters examine how the women's experiences of cancer can be understood as experiences with a modern form of governance and the making up of good citizens. 


\section{Chapter 3: Lost in a Sea of Pink}

\section{Introduction}

It's funny you know, it's like the whole world has decided to make finding a cure for breast cancer their mission...I get it, but damn it, women are diagnosed with other cancers too but I don't see the whole world dressing up in other cancer colours running, fundraising and fighting for a cure. We become invisible, lost in a sea of pink.

In Welcome to Cancerland Barbra Ehrenreich (2001) asserts that breast cancer is the most visible and recognizable illness of our time. Like the U.S., the sea of pink that Canadian society has grown accustom to witnessing is a symbolic representation of the progressive and on-going public and corporate support for breast cancer initiatives (King 2006; Segal 2010). While breast cancer is the most commonly diagnosed cancer in Canadian women, only $10 \%$ of women diagnosed with breast cancers are young women under the age of 40 . Yet, there has been a considerable effort in recent years to understand and establish resources that specifically address young breast cancer patients 'unique' health care needs (Ali and Warner 2013; Canadian Cancer Society 2010; Gelmon et al. 2005; Gould et al. 2006; Partridge et al. 2012). New research published by the Canadian Cancer Society in 2009 specifies that the most commonly diagnosed cancers in young Canadian women are thyroid, Hodgkin's lymphoma and 
melanomas. ${ }^{13}$ Yet, despite their high incidence rate in young female populations, there is a lack of public knowledge, support and sympathy for these types of cancers and those whom they affect. In Ontario, breast cancer organizations continue to play a rather central role in shaping the landscape of cancer care. ${ }^{14}$ In particular, their influence on the politics of health is establishing many state-of-the-art support networks and publicly funded cancer programs specifically designed for young, white, heterosexual breast cancer patients (Ali and Warner 2013). What this suggests is that there is a growing population of young female cancer patients and survivors who do not enjoy equal access to state and community-based cancer resources.

This chapter sets out to explore the dominance of breast cancer awareness and to further examine how the privileging of breast cancer needs impacts the landscape of access to health care. I argue that there are increasingly differentiated resources and services made available to young breast cancer patients in Ontario and that these exclusive provisions establish boundaries of cancer-type-based inclusion and exclusion. These boundaries have real implications for young women diagnosed with other cancers. In particular, many of these women find that they are unable to access medically necessary care, and their needs, voices and experiences are further marginalized as they continue to get lost in the sea of pink.

This chapter is divided into two parts. In the first section, I explore the evolution of breast cancer culture in Ontario to better situate its present day dominance. More

\footnotetext{
${ }^{13}$ In the 2009 publication Canadian Cancer Statistics, young adults are described as individuals between the ages of 15-29.

${ }^{14}$ The term breast cancer organizations are used in relation to Carlos Novas' (2006: 289) understanding that these types of organizations are made up of "patients, their families, carers as well as the associations that represent them".
} 
specifically, I examine how breast cancer organizations have influenced both the prioritizing and establishment of state-of-the art support networks for young breast cancer patients. In the second section of this chapter, I explore the negative implications of prioritizing the needs of young breast cancer patients on (a) marginalized breast cancer populations and (b) young women diagnosed with less publicized cancers. My intention is to highlight how the identified 'unique' needs of young breast cancer patients are not so distinct by exploring individual participants' illness narratives and experiences in accessing state and community resources.

\section{Evolution of Breast Cancer Culture in Ontario}

Across Canada, breast cancer organizations have a long history of working to tackle the historical silence and stigma associated with this illness and in doing so have forged strong alliances with feminist organizations (Batt 1994; Sweeny 2012). Despite strong organizing efforts by both parties, it was not until the early 1990s that breast cancer's visibility and its position as a political issue took form. In part, the transformation of breast cancer to a social and political issue resulted from a report published by the National Cancer Institute of Canada that revealed high rates of women's mortality from women's cancers (breast, ovarian, cervical and uterine) (Waller and Batt 1995). In response to these findings, breast cancer organizations began to demand an array of changes that included political action, greater participation in directing scientific research and inclusion within the production of knowledge (Waller and Batt 1995). 
In response to these demands, Status of Women - a federal government agency - initiated a standing committee entitled "Breast Cancer: Unanswered Questions" in 1991. The committee explored various issues relating to breast cancer such as epidemiology, treatment, research and detection, and survivor concerns. The final report was published in 1992 and presented 49 recommendations, most of which were aimed at responding to gaps in research and breast cancer treatment (Breast Cancer: Unanswered Questions 1992). The outcome of this initiative proved to be effective in that the federal government committed $\$ 25$ million over a period of five years to support a Canadian Breast Cancer Initiative (Parboosingh et al. 1997). The financial resources allotted to this initiative directly supported several key areas including: research, co-ordination of provincial breast cancer screening programs, uniform standards of care, and a national consensus workshop.

As a way of bridging and including patients, families, care givers and advocacy association concerns, the federal government's commitment included a National Forum on Breast Cancer (hereafter the Forum). The Forum held in 1993 was the first of its kind in Canada and brought together patients, families, doctors, policy makers, and researchers in hopes of establishing future directions (Waller and Batt 1995). Prior to this initiative, members of the public including advocacy groups had few opportunities for direct participation in research planning. However, the Forum encouraged citizen engagement and for the first time the needs and voices of breast cancer patients and survivors were taking center stage (Parboosingh et al. 1997). 
Even though the Forum proved to be effective in shaping public policy, voices of dissent emerged and argued that these health policy successes occurred in part because women found ways to "translate their concerns into the language of science" (Feldberg and Carlsson 1999: 367). Research endeavours stemming from the Forum focused on cancer genes, heritable forms of breast cancer, surgery and treatment options rather than on issues identified by survivors such as stress, occupational and environmental causations, and survivorship resources (Waller and Batt 1995). In this sense, the voices of some were heard while others were completely silenced. Many felt that the initial aims and objectives of the Forum were compromised and only some of women's concerns were validated and legitimized (Waller and Batt 1995). Despite these objections, the gains made by breast cancer advocacy organizations in the early 1990s were effective in prioritizing and establishing a continuum of cancer care services across the country. More importantly, the Forum played a significant role in (a) positioning breast cancer as a worthy political issue and (b) solidified breast cancer organization's authority and direct involvement in the management, organization and coordination of research efforts (Feldberg and Carlsson 1999; Novas 2006; Waller and Batt 1995).

In an attempt to understand the broader significance and long term implications of the active inclusion and involvement of breast cancer organizations in the Forum, I turn to Novas' (2006) work on the political economy of hope. Reflecting on the changing landscape of health politics, Novas (2006) observes the ways patient organizations are increasingly becoming influential actors in the realm of health politics. In particular, Novas (2006) suggests that patient organizations motivated by the "hopes for cures and 
treatments' are successfully shaping biomedical research, specific illness knowledge and the future health and wellbeing of specific populations. This is certainly the case in the context of cancer care in Ontario where breast cancer organizations advocacy and funding efforts are effectively transforming the landscape of cancer research, resources, supports and illness experiences. For instance, organized breast cancer efforts in Ontario are resulting in innovative and interdisciplinary approaches to care that are currently only available to breast cancer patients. While breast cancer advocacy is translating into positive advancements for breast cancer patients, young women diagnosed with less publicized cancers are negatively impacted in a variety of ways even though they too could benefit from such advancements (this will be further explored in the second section of this chapter), arguably because of relatively weak patient organizing associated with the latter kinds of cancers.

At the same time, despite both the positive and negative implications of organized breast cancer advocacy, several scholars suggest that the present day dominance of breast cancer is a result of a complex nexus of relationships established between various stakeholders (Ehrenreich 2001; King 2006). These scholars point to a vast array of relationships and alliances that have supported the rise and proliferation of breast cancer culture, rather than locating its dominance as result of one relationship. Scholars critical of contemporary breast cancer culture, like Samantha King $(2004,2006)$, argue that modern day dominance of breast cancer is not necessarily a result of feminist efforts. Alternatively, King's $(2004,2006)$ work suggests that breast cancer's modern day dominance is a result of the alliances established between the wealthy, large 
corporations and the breast cancer movement's new focus on femininity. For instance, consider the 1996 The New York Times Magazine cover which declared breast cancer as "This Year's Hot Charity" and featured a shot of a topless supermodel. This particular representation "suggested [that] breast cancer had become 'sexy"' and as King argues, this change in focus drastically influenced the public's perception of the disease and initiated its cultural transformation (King 2006: vii).

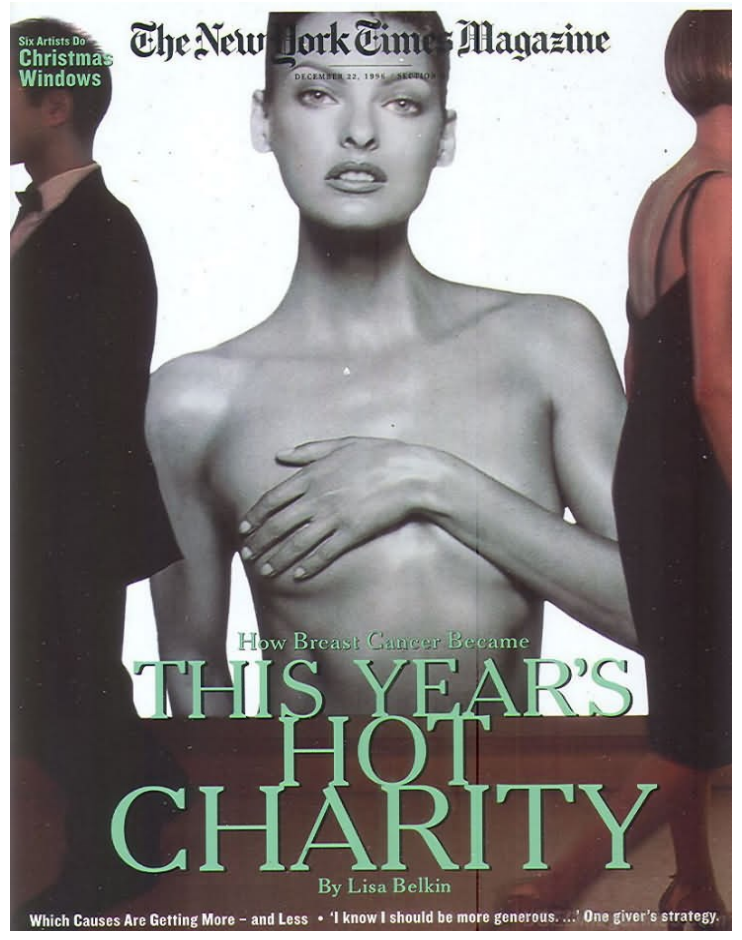

New York Times Magazine, December 22, 1996

King (2006) further suggests that breast cancer's cultural transformation is in part due to three key factors: (1) increased corporate philanthropic practices, (2) reimagining breast cancer and its survivors and (3) an intense focus on femininity. She (2004: 475) states:

"...the disease has been reconfigured from stigmatized disease and individual tragedy best dealt with privately and in isolation, to a neglected epidemic worthy of public debate and political organizing, to an enriching and affirming experience during which women with breast cancer are rarely 'patients' and mostly 'survivors.' In the latter of these three 
configurations, breast cancer survivors emerge as beacons of hope who, through their courage and vitality, have elicited an outpouring of 'American' generosity-a continued supply of which will ensure that the fight against breast cancer remains an unqualified success. While on occasion the discourse of fundraising references women who have died of the disease, less optimistic, more critical perspectives on progress in the fight against breast cancer are few and far between".

Moreover, King is critical of philanthropic partnerships for two reasons. First, she suggests that these partnerships are transforming notions of active citizenship and second, are reinforcing Western ideals of femininity. These will be further explored in greater detail below.

First, partnerships that promote consumption- based activism endorse narrow forms of 'political action' that reduce active and valuable citizenship to one's ability to consume, thus, obscuring other important ways of fighting for breast cancer. For example, consider 'The Look Good, Feel Better' program offered to all female cancer patients across Canada. This is a partnership between the Canadian Cancer Society, The Cosmetic, Toiletry and Fragrance Association and The National Cosmetology Association. The aim of the program is to help women cope with treatment -related side effects in order to regain confidence and self-esteem by looking good. According to the program, these goals are accomplished with the use of cosmetics. The irony of this program lies in the fact that research indicates that cosmetics are a direct source of toxic chemicals and have been associated with a number of health concerns, including cancer. This partnership is illustrative of the very ways in which cancer organizations "feed on [the] generous flow of corporate support" despite its potential implications of causing more harm than good (Ehrenreich 2001). 
Second, many corporate / non-profit breast cancer campaigns are highly gendered and cultivate public support and sympathy by focusing on Western ideals of femininity. The 1996 "Hot Charity" New York Times Magazine cover illustrates this well. Prior to the release of this cover, public images of breast cancer patients and survivors were more feminist and politically driven. For example, in 1993 when the single breasted image of Matuschka braced the cover of New York Times Magazine its purpose was to redefine public perceptions of breast cancer by dispelling fears and challenging popular notions of beauty and illness causation. Matuschka's portrait served to highlight the physical implications of the disease on the female body in addition to promoting more meaningful conversations about environmental, social and economic causations of breast cancer (Feldberg and Carlsson 1999).

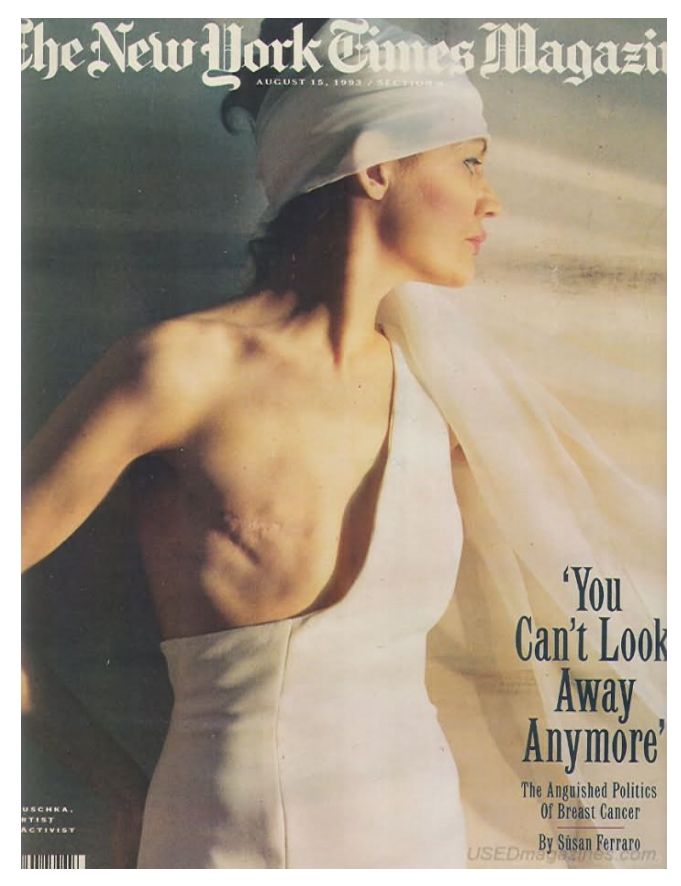

New York Times Magazine, August 12, 1993 
However, a mere three years later, the political framing of messages were superseded by aesthetic concerns. The 1996 "Hot Charity" cover is a provocative image of topless supermodel, Linda Evangelista. This image seductively draws attention to Evangelista's breasts, and specifically attempts to highlight the 'beauty' of a two breasted female figure. In doing so, this image also serves as a stark reminder that breast cancer threatens and disrupts not only the physical female figure but also a woman's sense of femininity, sexuality and motherhood. In this sense, the goal seems to be to steer public conversations away from meaningful discussions about cancer causation and instead capitalizes on the appealing link between breast cancer, femininity, sexuality, and pleasure (King 2006). What is significant about this image and subsequently the reframing of breast cancer messages are the extent to which they play in cultivating public support and mass sympathy by hyper-sexualizing breast cancer. In what follows, I suggest that the reframing of breast cancer messages are pivotal in shaping the dominance of breast cancer, and have created new space for prioritizing the needs of young breast cancer patients.

Saving Boobies? Reframing the Focus of Breast Cancer to Young Women Much of the early (1990s) breast health messages centered on generating common awareness about breast health and the pink ribbon played an integral role in distinguishing this disease from others (King 2006). However, currently many Canadian breast cancer campaigns are reframing the traditional 'think pink' messages, and instead are capitalizing on society's dominant cultural obsession with women's breasts. Female 
breasts in Western culture are not simply just another body part. Cultural studies scholar Meredith Jones (2008: 91) notes that breasts "are layered with cultural and social anxieties" that inevitably stem from being representative of maternity, eroticism and femininity. As such, breasts are imbued with social, cultural and political meanings which shape how women make sense of and experience their embodied selves (Millsted and Frith 2003). Popular discourses outline the ways in which breasts should be understood while also influencing how they should look, feel and be used. In this context, breasts are both symbolic and visual markers of female identity insofar as they are intrinsically associated with a woman's sense of beauty, sexuality, experiences of sexual pleasure and reproduction (Young 2005). Given that breast cancer attacks a highly gendered feature of the female body, I would argue that much of the breast cancers movement's success in generating social support and sympathy - form both women and men - in part stems from Western culture's fetishization with female breasts coupled with the overwhelming presence of breast cancer awareness in social life.

A plethora of provocative, cheeky-toned, overtly sexualized campaigns are springing up in the market in hopes of compelling young women and men to 'save the boobies'. Leading the way in Canada is Rethink Breast Cancer, a Toronto based charity dedicated to "bringing bold, relevant awareness to the under-40 crowd" (Rethinkbreastcancer.com). Some of their most notable campaigns include 'What is Your Bra Colour?', 'Breast Fest Film Festivals', 'The Boobyball', 'Rack-a-Thon', 'Booby Wall' and "Your Man Reminder" all of which use sexual innuendos to attract people's 
attention. In many ways, these campaigns not only objectify women's breasts but also sexualize breast cancer. Although, Rethink Breast Cancer's approach is often considered innovative, and spunky, these messages nevertheless tend to "build on and reproduce traditional stereotypical understandings of gender" and do little to challenge negative connotations associated with the post-mastectomized figure (Johansen et al. 2013: 150).

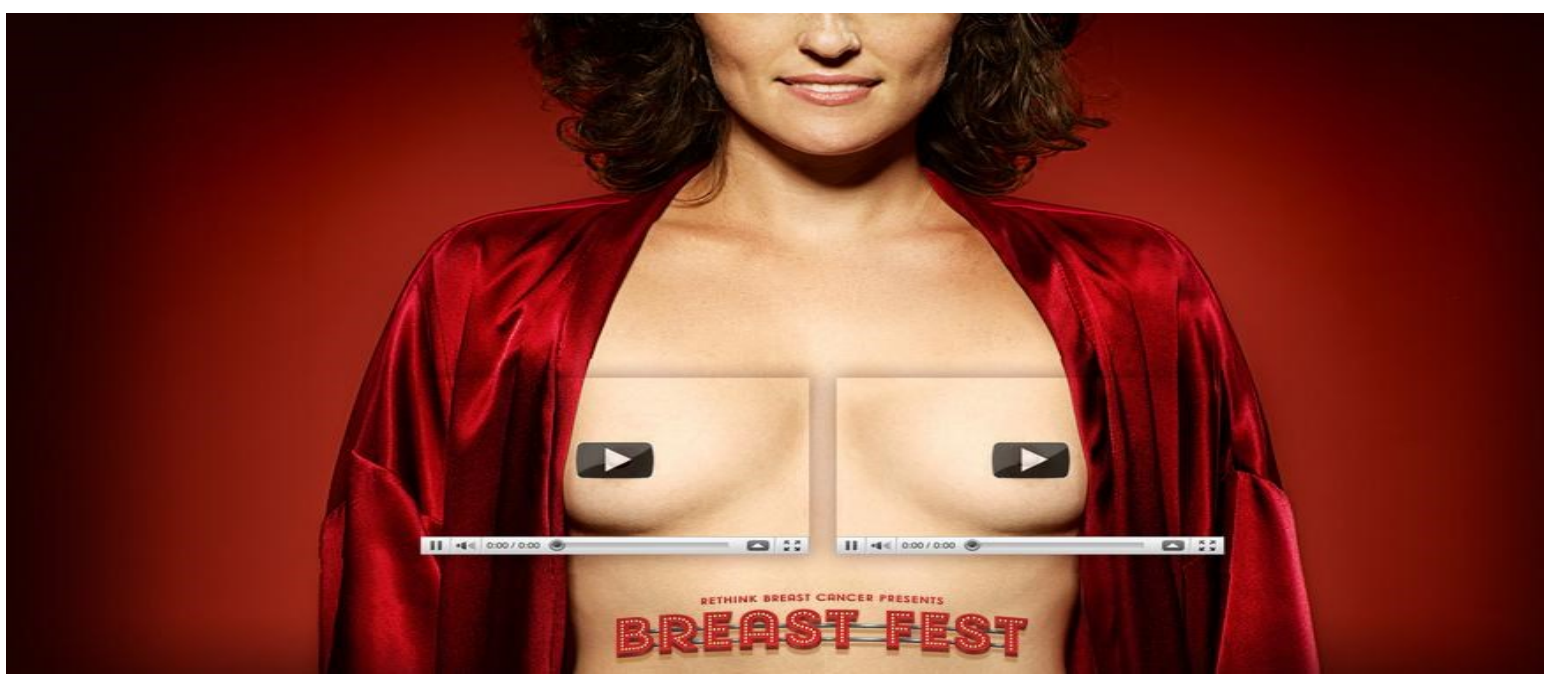

Rethink Breast Cancer www.rethinkbreastcancer.com

While the recent escalation of 'booby' campaigns are intended to capture the attention of young women and men who tend to tune out more traditional messages that feature older women affected by the disease, these campaigns reinforce predominant notions of breasts as a prized part of female identity and beauty. For instance, consider Rethink Breast Cancer's Booby Wall, an online gallery where women are encouraged to upload images of their breasts - in a bra or bare - in an attempt to engage women to touch, look, and check their breasts (Haines et al. 2010). In addition, women also have the choice to upload a first name, leave a message or dedicate their 
breast photo to a loved one. Ultimately, the goal of this campaign is to educate women about early breast cancer detection while also becoming more familiar with their breasts. Despite these positive intentions, the overtly sexualized nature of the campaign has broader implications for the ways we understand and assign value and worth to women's bodies.

Even though this initiative is marketed as an empowering experience that celebrates the beauty of real women's breasts in all of its varieties, the objectification of breasts and the focus on nudity does little to distinguish their presentation from others where the focus is on displaying them as sexual ornaments. In this context, the female body becomes a spectacle whereby breasts are objects to be desired, observed and ultimately consumed by others for pleasure. More than this, the booby wall acts as virtual panopticon where women's breasts are subjected to a high degree of scrutiny, monitoring and surveillance and does nothing to challenge normative heterosexual feminine beauty ideals. ${ }^{15}$ Instead, initiatives such as these continue to communicate and emphasize that “women's external appearances and beauty is valued more than their physical health and wellbeing" (Haines et al 2010: 739). Moreover, trendy messages that focus on saving young women's breasts are proving to be effective in not only capturing the attention of society but these campaigns are resulting in the design and implementation of specific programs for young breast cancer patients.

\footnotetext{
${ }^{15}$ The panopticon is a circular structure designed to allow maximum supervision with minimum effort (Foucault 1980). In this sense, its "potential for surveillance nurtures self-discipline (causing individuals to 'gaze upon themselves')" and becomes a form of social control (Eckermann 1997: 157). I further examine the issue of surveillance in Chapter Four, in relation to health and lifestyles post-treatment.
} 
PYNK[ing] the Boundaries: Prioritizing the Needs of Young Breast Cancer Patients and Survivors

Emergent in Canadian cancer research is a focus on a 'whole person' approach to care that addresses the social, psychological, physical, emotional, spiritual and functional aspects throughout the trajectory of illness (Bal 2005; Gould 2004; Macdonald et al. 2012). In a recent study, Macdonald et al. (2012) concluded that in Ontario access to cancer care services are inconsistent, disjointed and sparse and that there is a growing need to provide coordinated, seamless oncology and non-oncology services to cancer patients, survivors and caregivers. Breast cancer organizations in Ontario were the first to take up this call of action. Breast cancer activism in Ontario has a long history of success that has resulted in positive outcomes specifically for better prevention, detection, treatment and prognosis (Ali and Warner 2013; Cancer Care Ontario 2009). With the growing literature on survivorship, many breast cancer organizations are turning their attention towards establishing a continuum of cancer care that supports patients and survivors throughout their illness trajectory. In doing so, there has been a shift towards acknowledging the needs of young breast cancer patients.

In the early 2000s the needs of young women with breast cancer were at the forefront of several Canadian research initiatives. In Ontario, Breast Cancer Network and the Ontario Breast Cancer Community Research Initiative received funding to inquire into the lived experiences of young women diagnosed with breast cancer (Gould et al. 2006). The taskforce noted that while the incidences of breast cancer in women under the age of 45 in Canada had remained the same in the past 10 years, little was known 
about such experiences in younger women. As such, the task force was particularly interested in understanding the impact of age and life-stage on this experience in an attempt to plan and create "relevant programs/services, information and support for young women" (Gould et al. 2006: 6). After completing 70 interviews with young breast cancer survivors across Canada, the task force identified an overarching theme that encapsulated the main problem, that 'nothing fit' young women's needs while also identifying three main areas in which these needs were increasingly unmet. These three areas are: (1) overall wellbeing, (2) impact on family, and (3) financial welfare.

The women reported that much of the existing information, resources and support did not fit or address any of their specific concerns such as "prematuretreatment induced menopause, infertility, alterations in body image, fear of starting a new relationship, marital strain, financial loss, childcare difficulties, feelings of alienation from healthy peers and the constant threat of reoccurrence and death" (Ali and Warner 2013: 34). The women also further expressed apprehension in regards to health care professionals and their ability to arrange, and provide them with, timely and accurate assistance in dealing with emotional, mental health, fertility and sexual health concerns. These findings were consistent with emerging survivorship research that indicated the needs of young adults - regardless of cancer type - were increasingly unmet by current Canadian health care systems (Aziz 2008; Doll et al. 2008; Gould 2004; Macdonald et al. 2012). The main recommendation stemming from this research initiative was the creation and implementation of a specialized program for young women with breast cancer. In response to this report, and after four years of planning and fundraising, 
Sunnybrook Health Science Center in Toronto launched PYNK: Breast Cancer Program for Young Women (Ali and Warner 2013).

PYNK is the first program of its kind in Canada and has three main goals: (1) direct support for young breast cancer patients; (2) promote research focused on the unique medical and psychological needs of these women; and (3) further educate the public, health care professionals and affected women about breast cancer (Ali and Warner 2013). PYNK's framework is an interdisciplinary approach that brings together multiple disciplines - including medical, radiation and surgical oncology, psychology, social work, gynecology, fertility, physiotherapy and survivors - in an effort to standardize and coordinate interdisciplinary care. In this respect, the program helps "facilitate decision-making; and in providing education, advice, coping strategies, and personalized support throughout treatment and follow-up" (Ali and Warner 2013: 35). Currently, all women under the age of 40 who are newly diagnosed with breast cancer and who are referred to a surgical or medical oncologist at Sunnybrook are eligible to participate (Ali and Warner 2013).

PYNK is a novel program and is the first to seriously address the concerns and needs identified by young breast cancer patients, caregivers, medical professionals and academics. The success of this program resides in three specific key components which are: (1) the use and assignment of a nurse navigator for each individual patient; (2) access to seamless non-oncology medical care; and (3) five years of continuous followup care and access to PYNK programing. These will be discussed below in greater detail. As a result, PYNK is able to provide supportive, timely, responsive and effective 
treatment, thereby decreasing patient stress and improving overall outcomes (Ali and Warner 2013). In what follows, I examine the PYNK program and discuss its strengths.

PYNK: State-of-the-Art Support Networks

Nurse Navigators

In an effort to relieve access barriers and improve patient and survivor outcomes, PYNK provides each individual patient with a nurse navigator. Nurse navigation refers to a process whereby a trained individual facilitates initial contact with newly diagnosed patients to provide timely access to appropriate support, education and information while also being their point of contact throughout the course of treatment and remission (Ali and Warner 2013; Doll et al. 2003; Psooy et al. 2004). Nurse navigation models generally correspond to more integrated and social approaches to health that humanize the illness trajectory while valuing patient empowerment and supportive care (Fillion et al. 2006). In this sense, young female patients are not just passive recipients of care. Rather they are able and encouraged to become more active in the management of their health and nurse navigators play an important role in this process (Ali and Warner 2013).

Nurse navigators are the lynchpin of PYNK. Their role in this program is vital not only for the patients and survivors as they facilitate access to coordinated supportive care but nurse navigators also are the liaison between the team of medical professionals from various disciplines while also assuming the role of intermediary between state services and community resources. Nurse navigators have extensive knowledge about 
what is available to young women and how they can gain access to these programs and services. Thus, nurse navigators are central actors in decreasing the amount of stress, frustration and hopelessness that many young women experience when trying to navigate the health care system (Ali and Warner 2012; Doll et al. 2003). Furthermore, Ali and Warner (2013) note that nurse navigators tend to establish close relationships with patients and survivors as they provide on-going, consistent care. Studies have demonstrated that nurse navigators positively impact care and patients report "improved satisfaction, improved quality of life, reduced uncertainty, lower anxiety, improved access to support services ... and improved the quality of their survival" (Howell et al. 2008:1344; Psooy et al. 2004). These positive outcomes are significant given that cancer patients and specifically young women experience a number of barriers in obtaining access to necessary care (Macdonald et al. 2012).

\section{Coordinated-Care}

In addition to nurse navigators, PYNK also provides all young female patients with seamless and timely access to oncology and non-oncology specialists as the program is designed around facilitating interdisciplinary care. Young women diagnosed with cancer are presented with a host of challenges and often require additional health care services beyond oncology -specific care including obtaining relevant information, referrals to specialists and access to services and programs (Aziz 2008; Gould et al. 2006; Macdonald et al. 2009 Zebrack 2009). These types of programs are useful in facilitating and ensuring that patients are well informed of what services are available to them and guided through the process of accessing them when needed. PYNK's unique framework 
addresses these concerns by incorporating a multi-disciplinary team that acknowledges young women's vast health care needs, and provides continuous and efficient access to a wide array of specialists, services and resources. This framework which incorporates a multitude of service providers - such as fertility and reproductive specialists, psychologists, reconstructive surgeons, physio and occupational therapists and social workers - addresses numerous identified unmet needs and validates the very idea that healing requires more than just physical wellness. Studies continue to reveal that unmet needs often increase patient feelings of anxiety, uncertainty and isolation which can negatively affect treatment outcomes (Beaver et al. 2006; Hack et al. 2005).

\section{Follow-Up Clinics}

Finally, numerous studies indicate that transitions from active treatment back to everyday life are difficult for many young cancer patients (Ashbury et al. 1998; Howell et al. 2011; Macdonald et al. 2009; Zebrack 2009). Anxiety, stress and feelings of unpreparedness often mount as frequent contact with health care professionals decreases when patients transition from acute to follow up care. In an effort to reduce distress and increase continuity of care, PYNK provides follow-up clinics for all active patients up to five years post- treatment (Ali and Warner 2013). Clinics are run by nurse navigators alongside medical oncologists. These clinics are designed to not only monitor disease re-occurrence but provide young breast cancer patients with frequent and consistent opportunities to ask questions, manage side-effects associated with treatment and address anxiety and fear related to cancer relapse (Ali and Warner 2013). Moreover, Ali and Warner (2013) also suggest that follow-up clinics provide prospects of 
meeting other young women in similar circumstances which can result in normalizing the breast cancer experience, informal peer support, and friendships.

This program is indeed visionary and has the potential to improve both overall treatment outcomes and individual experiences with the health care system. However, at this time, only young breast cancer patients in the greater Toronto area have access to this program and their needs continue to be identified as 'unique' and prioritized over the general population of breast cancer patients and the general population of young female cancer patients. ${ }^{16}$ Furthermore, in what follows, I examine two negative implications that are a result of focusing on the 'unique' needs of young, white, heterosexual breast cancer patients specifically in relation to breast cancer patients more generally. First, I examine the health discrepancies that are encountered and experienced by marginalized breast cancer patients and argue that the exclusive provisions provided to young breast cancer patients reinforce boundaries of inclusion and exclusion. Second, I will examine how dominant breast cancer narratives that focus on regaining a sense of 'wholeness' limit the availability and acceptance of counter body narratives in relation to breast cancer. The point of this analysis is to highlight the ways in which the dominance of breast cancer shapes and impacts individual experiences of cancer.

\footnotetext{
${ }^{16}$ Currently PYNK only supports about half (4000) of all young women diagnosed with breast cancer in Ontario each year because it is available only to women in the Greater Toronto area (Cancer Care Ontario 2012).
} 


\section{At the Margins: Cancer Care Disparities among Breast Cancer Patients}

Health care in Canada - Medicare - is a state funded, universal insurance

program that was built on the premise of ensuring equal access to medically necessary care for all citizens. The primary goal of Medicare is to ensure equity in citizens' access to health care services regardless of their ability, or inability, to pay for those services (Armstrong and Armstrong 2010). In efforts to safeguard Canadians entitlements to health care, in 1984 the Federal Government introduced the Canada Health Act which requires health services to be publicly administered, comprehensive, universal, accessible and portable. However, like many other redistributive social policies, health care continues to be subject to increased cost containment strategies, privatization, commodification and off-loading of responsibility from the state to both the individual and community (Armstrong and Armstrong 2012). As a result, the core values of accessibility and universality are threatened by cuts in funding and health care is increasingly incapable of providing care that meets the needs of many Canadians, especially marginalized women.

Despite Medicare's success in contributing to a significant decline in incomerelated inequalities, significant health care related inequalities persist, casting doubt on claims of equity (Bryant et al. 2009; Gould 2004; James et al. 2007; Redden 2002). For instance, in a recent study Gould (2004) noted that currently in Ontario cancer patients receive free hospital services like chemotherapy, diagnostic services, radiation, and surgery, however, there are many additional out-of-pocket expenses that are not publicly insured through Medicare. Out-of-pocket expenses that are often incurred by cancer patients can include: pharmaceuticals, dispensing fees, homecare, 
transportation, food, physiotherapy, alternative medicine, wigs, prosthetics, lost income and child care (Gould 2004; Gould et al. 2006). This list is not exhaustive but it does illustrate many of the additional costs that are often associated with cancer care. Moreover, these out-of-pocket expenses may negatively influence an individual's overall health outcomes and impact their risk of morbidity and mortaility regardless of Canada's universal health care policies (Gould et al. 2009).

Despite many of the successes in breast cancer care, presently in Ontario there are increasing health inequalities between and among breast cancer patients. This is especially evident for women of Aboriginal descent, immigrant women and women of low socio-economic status (Bickell 2002; Bickell and Cohen 2008; Bottorff et al. 2001; Choudhry et al. 1998; Donnelly 2008; Giuliano et al. 1998; Gould et al. 2009; Marrett and Chaudry 2003; McDonald and Kennedy 2007). Health disparities are defined as "a marked difference or inequality between two or more population groups defined on the basis of race or ethnicity, gender, education level or other criteria" (Pearcy and Keppel 2002: 274). In other words, health disparities are the outcome of social processes that distribute resources unequally in society. For the purpose of this chapter I will focus solely on the disparities experienced by Aboriginal women. My intention is to illustrate how social determinants of health - such as economic and social factors i.e. education, employment, social environment, discrimination etc. - influence the health of individuals and the ways in which these inequalities are often replicated by institutional health care systems. As such, in addition to the unequal distribution and access to 
formal health care services, the material conditions of one's life significantly impacts health and wellbeing (Raphael 2009).

Aboriginal populations in Canada endure profound health disparities and their overall health continues to lag in comparison to that of the national population (Waldram et al. 2006). In 2002 the Romanow Report extensively documented the suffering and resultant health inequalities endured by Aboriginal populations. The commission's findings attributed many of these health inequalities to a long history of colonialism, systemic violence, institutional racism and reflect "underlying economic, demographic and cultural realities" (Parsons 2005: 2; Romanow Report 2002). As a result, many Aboriginal populations are subject to higher rates of poverty and debilitating living conditions and lower rates of education, which in turn are associated with poorer health statuses (Li 1999).

In the context of breast cancer, there is significant evidence that suggests incidence rates are rising in Aboriginal populations in Ontario, that those who are diagnosed are diagnosed at a later stage, and that survival rates are significantly worse than the national population (Cancer Care Ontario 2012; Gould et al. 2009). In addition to these historical barriers, Bal (2005) and Townson (2000) note that for women living on the margins the availability and benefits of primary, secondary and tertiary cancer care is far more scarce. In a recent study, Gould et al. (2009) examined underserved breast cancer populations in Ontario and concluded that marginalized women, especially women of Aboriginal decent, are increasingly vulnerable to poorer preventative care, treatment options, psycho-social support and survivorship care due 
to the structural disadvantages associated with their multiple social identities and social locations. In particular, the health care system is unable to accommodate and/or account for their personal circumstances and the ways in which forms of inequality structure their lives. Gould et al. (2009) also note that these women encounter high rates of discrimination which are perpetuated by medical professionals and medical institutions. Many of the participants in Gould's study discussed their need for more 'supportive care' as many of these women are perceived to be outside the purview of traditional breast cancer patients. In addition to being at the margins, many of the women identified that cancer information and treatment resources did not attend to their lived realities, reinforcing dominant stereotypes that situate Aboriginals as being a medically undeserving population.

However, similar to the general population of young women with cancer, many Aboriginal women would benefit from a program like PYNK because marginalized women often encounter the most difficulty in accessing cancer care (Gould et al. 2009; Parsons 2005; Townson 2000). In particular, access to a similar program could potentially aid in cancer care navigation, provide more supportive and individualized care, decrease stress and anxiety, alleviate some social class differences that influence access to certain programs and resources and thus, improve overall wellbeing and survivorship rates. This discussion highlights how disease can be revealing of who is included and who is marginalized. Presently, young, white, heterosexual breast cancer patients are privileged and prioritized over other breast cancer patients thus reinforcing systemic and cultural forms of discrimination. In the following section, I further critique 
the implications of mainstream breast cancer's focus on femininity and the privileging of the two-breasted female figure.

At the Margins: Alternative Breast Cancer Body Narratives

In attempts to hide the visible signs of illness, breast cancer patients are often encouraged to wear breast prosthetics and to have breast reconstruction upon the completion of treatment (Crompvoets 2006). In many ways, the breast-less female body challenges cultural expectations of female beauty and sexuality because these bodies are characterized as ambiguous with respect to sex and gender. Female bodies devoid of breasts are often assumed to be unfeminine and many young women are fearful of breast loss (Cobb and Starr 2012). Audrey a young breast cancer survivor described her breasts as an intrinsic part of identifying as a woman. She recalls:

After surgery I couldn't look down. I can safely say that for two weeks I didn't look down. I felt like I lost my womanhood, I will never feel as much as a woman as I did at one point. To me it's part of being a woman, to me part of being a woman means being able to bear children and nurture children and I am not able to. I will have a reconstruction on one side and a breast reduction on the other.

Breast cancer and mastectomy are associated with (or signified as) loss, which further normalizes the female body as a form with two breasts. Audrey's excerpt demonstrates how normative breast ideals are and how they can influence one's sense of identity. In Western culture, the breast-less female figure is one that is discursively constructed as incomplete, abnormal, freakish and unfeminine. As a result, much emphasis is placed on restoring breasts to a 'normal' state (Cobb and Starr 2012; Crompvoets 2006). Maura a young breast cancer survivor experienced a lot of inner 
turbulence in trying to determine which breast surgery to choose. Aesthetics were important for her:

I was really worried about having a mastectomy. I was looking at pictures of what it would look like after the surgery and it just looked terrible. So I was worried about that and my age and everything else about it. So I thought about that for a long time, but I'm glad that I just got the lumpectomy, I look normal.

This discussion highlights the tension that many young women experience when selecting a surgical option. For young women, their age and life stage often play an important role in deciding which option is best for them.

Julia had a similar experience as Maura where her age was a significant factor in determining which surgical option to choose.

A lot of people asked why I didn't get a mastectomy and to be honest at the time I was 29 and single. I am kind of attached [to my breast]. Maybe if I had been in a long term relationship whatever but guys are nobs. Some guys aren't that shallow but I was still quite attached to my boob and I still am. I said you can take part of it but the rest of it I am going to keep thank you.

In this narrative, Julia clearly states how her age and single status influenced her decision to have a lumpectomy. In addition, she notes that her breast is a significant part of identifying and feeling like a woman and it was important for her to preserve her breasts.

These experiences are powerful and speak to the ways in which "self-identity becomes complicated by societal prescriptions of femininity" and highlight the fears surrounding the breast-less female figure (Hall 1997a: 108). In some ways, the breastless female body serves as a site for the projection of fears about illness, disgust and bodily decay and becomes a means for maintaining boundaries between valued bodies. In attempts to regain a sense of 'wholeness', breast prosthetics and reconstruction are 
positioned as necessary medical procedures in which they are thought to aid in the healing process (Crompvoets 2006). For instance, when Hannah first spoke with her surgeon she inquired about having a double mastectomy and she was told "that studies show that women do better psychologically if we leave the other breast".

Nevertheless, many scholars critical of aesthetic procedures associated with breast cancer treatment argue that these medical operations are not simply about aiding psychological recovery. Rather, these discourses are illustrative of how experiences of cancer become entangled with idealized notions of femininity which compel breast cancer patients to engage in acts (i.e. wearing prosthetics and undergoing breast reconstruction) that allow them to mitigate - or at least temporarily conceal some of the effects of the disease and its various treatments (Cobb and Starr 2012; Crompvoets 2006; Ehlers 2012; Kendrick 2008). In doing so, the breast-less figure is positioned as inferior and undesirable. There is a point to be made, however, about the normalizing discourses of the two-breasted female figure and the ways in which it limits and discourages counter body narratives that embrace the beauty and strength associated with the post-mastectomized body.

Although we should be careful not to downplay the significance of breast loss and the seriousness of actual suffering women encounter, I believe that it is worthwhile exploring body narratives that highlight the exquisite raw beauty and journey some people associate with post-cancerous bodies. These narratives and their public displays of bodily differences speak to the ways in which women reclaim their sense of femininity, sexuality, identity and pride while also aiming to challenge popular 
conceptions of this disease and the people it affects. Moreover, Rosemarie GarlandThomson (2009) suggests that the visual display of extraordinary bodies often invokes acts of staring and that these instances can entice people to think more critically about the status quo. The claim here is that, individuals tend not to stare at people they know but rather when something unfamiliar catches our eye. A stare provokes countless responses stemming from inquisitiveness to discomfort, attraction, misunderstanding and even disgust. Nonetheless, Garland-Thomson (2009) argues that staring is a dynamic cultural process that unavoidably establishes a social relationship between the starer and the staree as it is a conveyor of knowledge. As such, she argues that staring offers occasions to recognize others in new ways as it entices efforts to know the unknown.

Arguably then, when bodies look different from the norm, they demand attention. And, while staring in Western societies tends to be strictly monitored, Garland-Thomson (2009) suggests that individuals should try and engage more with the stare because unpredictable things can happen. In other words, when individuals no longer hide or allow themselves to be hidden, opportunities emerge to re-imagine which bodies we expect to see in public spaces. It is through such encounters, GarlandThomson argues, that expectations around bodies, ability, and beauty can be broadened and made more inclusive. Without visible representations and presences of alternative equally beautiful -bodies, it is difficult to dispute who can and should be seen.

In an attempt to challenge the two-breasted female figure, the 'SCAR Project' publicly celebrates the post-cancerous female body. The SCAR Project seeks to provide 
non-judgmental spaces and increased opportunities for women living with breast cancer (as well as their families) to publicly display their scars, faces, figures and experiences as a form of acceptance and healing. In addition, the post-mastectomized figure can also be "interpreted as a protest against the pressure for technological redesign and reconfiguration of the (female) body" and can actually have positive implications in that it can be a way to disrupt normative bodily aesthetics and a way of challenging bodily taboos (Johansen et al. 2013: 149).
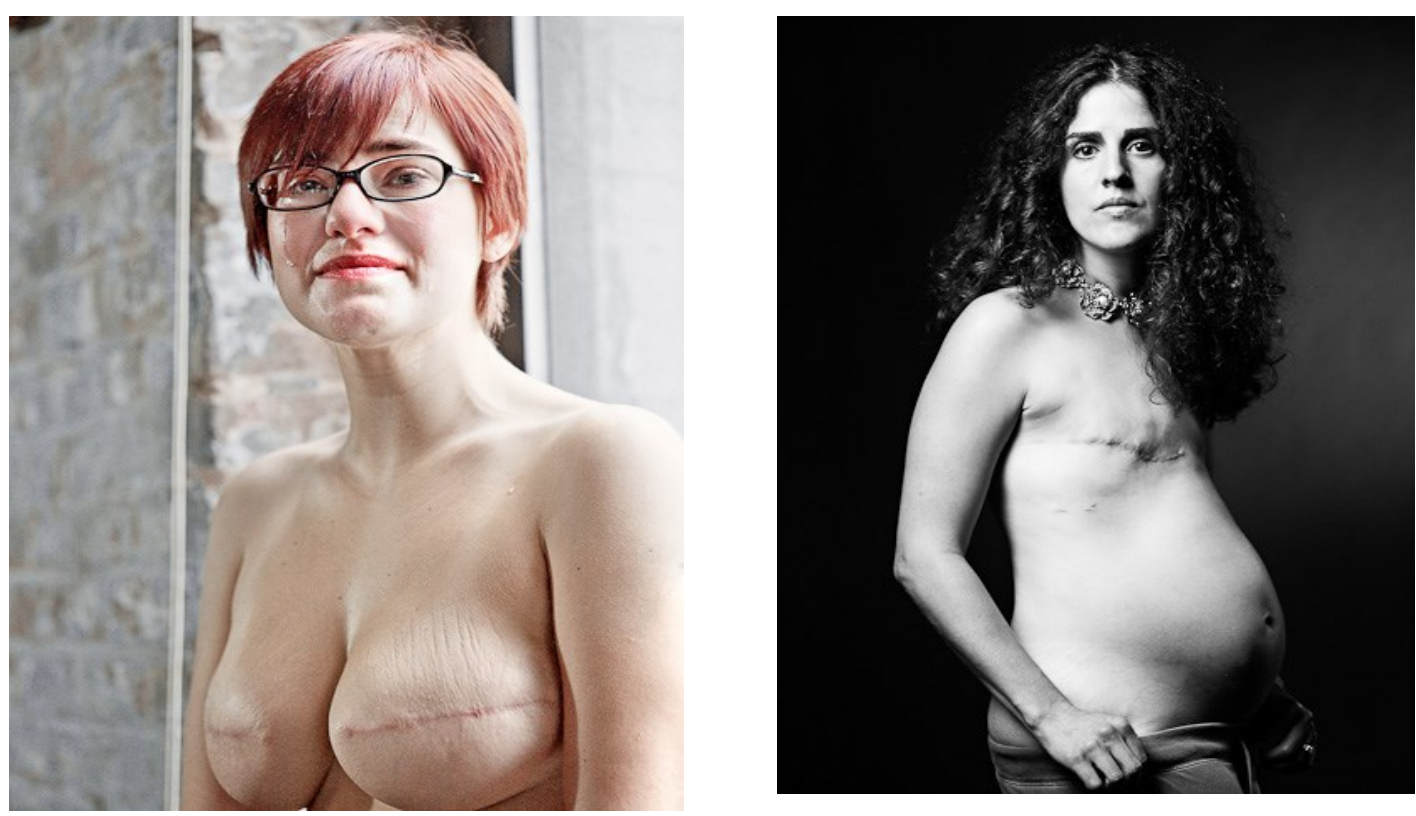

Source www.thescarproject.org

Many of these images are illustrative also of different perceptions of illness and wellness whereby women are resisting normative forms of suffering. These photographs capture raw beauty, character, strength, life transformations and alternative ways of coping. For example, consider the image below of an Ottawa women who chose to tattoo her chest rather than undergo reconstructive surgery. Tattooing her chest was a 
way of coping and celebrating her "transformation, metamorphosis, like a butterfly [she] changed on the outside but remained the same on the inside" (CBC 2013).

Instead of mobilizing 'feel good stories' and normalizing images of these women as survivors, these representations are not only demonstrative of women "coming to terms with the changing planes of her body" (Lorde 1980: 34), but more importantly, they function as a vehicle for thought and action. These images are powerful and can act in ways that open up and provide people with a new space to understand, speak about and explore the material realties that shape illness experience.

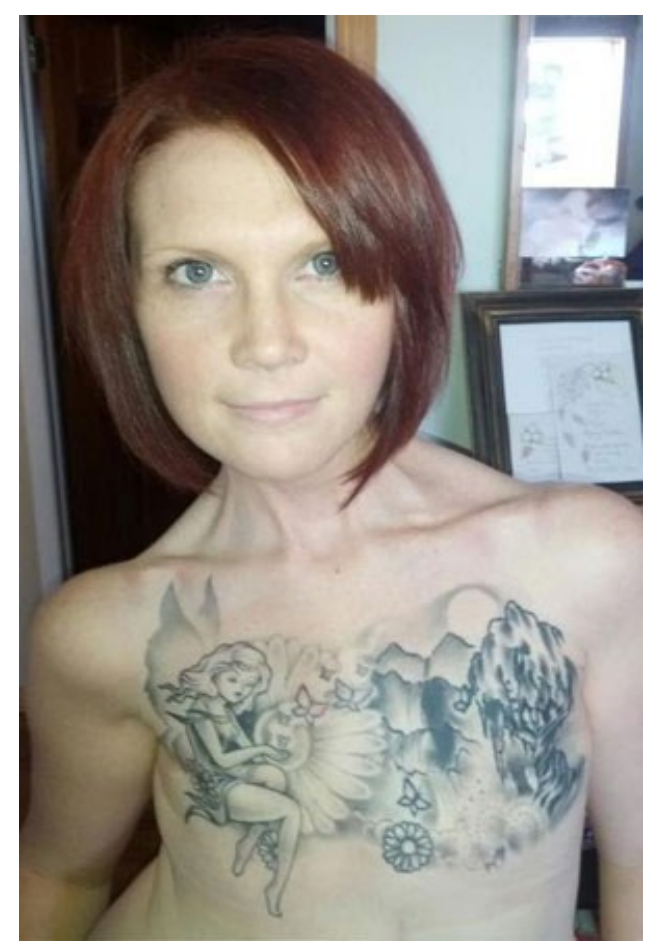

Kelly Davidson, source: CBC Online April 2013

Such images represent one way by which we can challenge and change both the face of cancer and the experiences of those people living with it. However, dominant mainstream breast cancer initiatives and the mobilization of survivor images discourage 
experiences of difference, limit spaces for counter narratives and reinforce prescriptive ways of experiencing breast cancer (Cobb and Starr 2012; Hall 1997; King 2006). In this context, breast cancer's dominance relies on homogenizing women's illness experiences, but downplays and even excludes, the voices and representations of women who are more critical of and resist mainstream breast cancer messages.

\section{At the Margins: Cancer Care Disparities Between and Amongst Young Female Cancer Patients}

Although PYNK is currently only available to young breast cancer patients in the Greater Toronto area, breast cancer programs in Ottawa tend to be more robust than in comparison to programs for other young female cancer patients. In addition to state funded resources, breast cancer organizations like Rethink Breast Cancer and Breast Cancer Action also provide a wide array of services specifically for breast cancer patients and survivors. As such, there are significantly more supports and resources available to breast cancer patients in Ottawa than for other young women diagnosed with less publicized cancers and have implications on their material realities.

In the last section of this chapter, I will explore the dominance of breast cancer in relation to access vis-à-vis the general population of young female cancer patients. I examine three common barriers - that are considered strengths of the PYNK program which many young female cancer patients and survivors encounter and explore issues of access, (un)coordinated care and (lack of) follow-up care as experienced by individual participants. I argue that we need to move beyond the type of analysis that considers and prioritizes the needs of breast cancer patients over other young women and 
consider that many of the health concerns raised are also relevant to all young female cancer patients. More specifically, the PYNK program and its epistemological framework have the potential to benefit the general population of young female cancer patients and improve treatment outcomes as well as individual experiences of illness. Yet as it stands today, PYNK encourages exclusive health and wellbeing provisions which further marginalizes and silences the needs and experiences of young females with nonwomen's cancers.

Access

In Ontario, cancer care systems are diverse, complex and encompass a range of delivery entities. Cancer patients and survivors report difficulty navigating the health care system to obtain information, services and support due to the complexity and multitude of different cancer service agencies (Ashbury et al. 1998; Canadian Cancer Society 2003; Doll et al. (b) 2003; Fitch 2003; Howell et al. 2008). Ontario - like many other Canadian provinces - is witnessing a gradual move towards increased privatization of health care services. As a result, there is a lack of standardized cancer care and many resources that are available tend to be fragmented and discontinuous among providers and care systems (Howell et al. 2008). In addition, many resources and support programs are offered by community-based non-profit organizations and require patients to seek out services. Rutledge and Robinson (2009) note however, that primary care facilities like hospitals lack the appropriate information about community-based offerings, and there is little to no coordination between service providers. 
Consequently, these inconsistencies result in unmet needs and difficulty accessing required care for cancer patients and survivors.

This was the case for several study participants including Nadia, a Hodgkin's lymphoma survivor who described her experience with a lack of coordinated care at the hospital as 'overwhelmingly frustrating'. Nadia had trouble accessing emotional and mental health services and often relied on other young female cancer friends for information. She stated:

I found the hospital not to be very informative to be honest. Which was why I was so happy to know people like Sherri and Tanya because I didn't know the questions to ask or what was available and the hospital was only somewhat helpful if I was asking a specific question or for a specific resource. Like the counselling, Tanya was the one who told me I could get counselling through the cancer center. I was like I can? I want some, I need some. And that's what I specifically said when I was balling in Dr. Jones' office and he was like its fine, everything's fine. I was like no everything's not fucking fine I'm having an emotional breakdown. And then I was like can I not go and see someone and he was like ok if you want to. I was like look at me, I can't go a minute without feeling like totally anxious and depressed. He was like if you really want to. I think it would have been super amazing if the hospital would have informed me of or provided me with some form of counselling during that time or somebody to like let me know that everything that I was experiencing was normal and that I shouldn't be so hard on myself. That would have been really helpful.

Nadia's account demonstrates the difficulty she had in terms of determining which state supports were available to her. In this instance, she was informed of what she was entitled too only informally through another survivor and subsequently went several months without necessary emotional and psychological support.

Similar to Nadia, Aria also had difficulty trying to determine what resources she could access and found her medical team not useful in helping her figure out what was 
available. In documenting her experience, Aria often mentioned that she began to rely on herself and her 'abilities' to find resources that she required:

My doctor never talked about what was available to cancer patients. I looked for resources, they offered me nothing. The researcher in me, went like 'I need everything on cancer I can possibly find' but it was hard cause at first I would get stories of people who were dying and people who were ill, and people that had a lot of problems and I couldn't handle it. I didn't know what I needed either, because I had never been through cancer before, so in the beginning I just felt lost.

This excerpt highlights the lack of communication between medical professionals and patients and the ways that such a disconnect can cause undue hardship. On top of dealing with a cancer diagnosis, Aria was also responsible for determining what supports she thought she would require and was forced to locate them on her own.

In the current study, many of the participants were well educated and were able to draw on non-economic dimensions of power, such as social and cultural capital. In doing so, they were able to negotiate their way through the health care system and gain access to some services more easily than others. However, the experiences of Nadia and Aria illustrate that many women are unequipped to do so and encounter unnecessary stress due to struggling to navigate a complex health care system on their own. All women regardless of cancer diagnosis would benefit from the expertise of nurse navigators as women would be able focus their attention to getting well rather than expending energy on navigating a health care system which is currently a barrier for many female cancer patients.

\section{(Un)Coordinated Care}

In a recent study, Miedema et al. (2012) determined that there is a growing need for age-specific cancer care and that there is currently a lack of coordinated care 
between oncology and non-oncology services. Young women diagnosed with cancer are faced with many additional health challenges that are often associated with their life stage and age range and require consultations with specialists. In addition, young women often face delays in diagnosis - which are common in this age group - and are quickly launched into treatment which affects the transfer of vital information (Miedema et al. 2012). For instance, fertility, reproduction and sexuality are often concerns for young women. While the American Society of Clinical Oncology recommends that oncologists be prepared to discuss these issues and refer patients to other specialists as early as possible during treatment planning, studies indicate that this is not occurring (Goldfarb et al. 2010; Quinn et al. 2009). This was certainly the case for Sophia a Hodgkin's lymphoma survivor:

I don't remember having a discussion about my fertility options when I was initially diagnosed. The doctors were primarily concerned with starting chemo as quickly as possible. It was only after my second treatment when I didn't get my period that I inquired about fertility options and at this point I was informed that it was too late. Nothing could be done now and I would have to wait until treatment was complete to see how much damage was done. Once I finished treatment l asked my hematologist about what could be done to determine what effects the chemo and radiation had on my reproductive system. She told me that I needed to wait at least six months to see if my period would come back on its own, it never did. When I finally asked her what was next, she finally referred me to the Women's Clinic where I waited almost a year and a half before being seen. I called so many times to see if they could see me sooner but they said no that I had to wait. In the meantime I was experiencing intense menopausal symptoms and when I brought them to the attention of my hematologist and family doctor they said they couldn't do anything and it was best that I wait until I could be seen by a specialist. I remember leaving the doctor's office in tears, I had hot flashes, night sweats, no sexual desire and no one was willing to help me, I felt defeated.

Mia a Leukemia survivor recalls her inner turbulence and describes the whole experiences as 'upsetting': 
It wasn't brought up at all until my transplant, and I saw the radiologist, it was not like he was even super nice about it, like it was all very matter of fact. It was like, this is very strong radiation and it's going all over your body, so you won't be able to have kids. So it was never really brought up at all. So, like it was never discussed with me. Like I know that, some people can freeze their sperm or eggs and that was never an option for me. They were moving really fast, like, they never brought it up so. It definitely wasn't easy to hear at all and it's still not easy to deal with, kind of thing. Like yeah, I don't know. My mom was upset, and my dad was really upset, they never said anything, but I could tell that they were. It was upsetting for sure, like who doesn't want kids eventually.

Adriana a Hodgkin's lymphoma survivor also had a similar experience:

When I was diagnosed everything happened very fast. As soon as I found out that I definitely had cancer I was referred immediately to a specialist. I saw this doctor; he did a bone marrow biopsy and told me to come back the following week. I talked to him and he said at that appointment this is what you have, this is how we are going to treat it and were starting in an hour. I had no time. Literally I went from his room to the chemo suite. At that point there was no discussion about banking [eggs] or what this would do to my body. Maybe in passing it came, I mean I got tons of paperwork so it was probably mentioned in the paper work. The only time it ever got discussed was shortly before my transplant and by shortly before probably like a couple of days before I was being transplanted where I said hold on a sec, you know I'm a year and half older now what is this gonna actually do to my reproductive system. And they basically just said it's not going to make your ovaries happy and if you have a problem down the road call us. It was like it wasn't a big deal.

These experiences illustrate that despite the type of cancer a woman is diagnosed with fertility, sexuality and reproduction are concerns that need to be addressed prior to the commencement of treatment as well as upon completion of treatment. Young women need to be informed of their choices, have timely access to specialists while also being educated about the possible effects and outcomes that treatment can have on their reproductive system. These narratives suggest that medical professionals are prioritizing the commencement of treatment over young women's right to make informed choices about their bodies and specifically reproductive options. 
In addition to the absence of understanding young women's concerns, many

studies indicate that young women increasingly encounter a lack of coordinated care in all phases of their illness trajectory (Macdonald et al. 2012). Many of the participants in this study experienced procedural delays in terms of accessing non-oncology related services and openly discussed the burden of uncoordinated care. Ava, a Hodgkin's lymphoma survivor, described her processual complexities as follows:

Nothing is ever offered, I have to ask and keep my thumb in there. I would have to monitor them constantly because it was not a priority to them and so it sort of comes back to always being sort of at the mercy of what work they get done in terms of referrals and I would really have to monitor and work to make sure that these tasks were taken care of. So if I went in for an appointment one week and I asked for referrals the very next week I would be calling the secretary to ask and make sure that the doctor did that referral and every time I have not done that I have been sitting months down the road wondering what's going on with this particular referral and I'll call up and it hasn't been done and months will have passed and I will have to start the process all over again. It's not fair because I am the one who suffers longer and the symptoms often get worse.

What is significant about Ava's response is how she highlights her increased responsibility for managing her health and specifically the referral process. She fears that by not taking an active role within this process that meshe will fall through the cracks of the medical system.

Isabella, a Dermato fibrosarcoma survivor, experienced several delays with her transition from changing care providers when she moved from Western Canada to

Ottawa. She describes how difficult it was accessing services that she required: I just felt as though if I didn't sound the horn or be the squeaky wheel my case was going to be forgotten about. There were a couple of different things in switching from Vancouver to Ottawa and I almost fell through the cracks for monitoring and accessing certain programs and if I didn't take care of myself and advocate for myself then I don't think I would have gotten them. I am educated and I have resources you know, I am someone 
who is not afraid of being a squeaky wheel so what about people who don't have that or the people who don't know how to find those services?

Similar to Ava, Isabella assumed an active role in the management of her care and health and was aware that it was the only way to ensure that she was able to gain access to necessary services. In addition, she established direct and open lines of communication with her medical team which was a difficult task but one that proved to be effective.

These particular experiences highlight the variety of (un) coordinated care experienced by young female cancer survivors and how the disorganization inevitably affected their emotional wellbeing. In addition, their stories suggest that many young women encounter difficulties securing information, referrals and services and that these issues do not seem to be priorities for medical professionals (Gould et al. 2006;

Macdonald et al. 2009).

\section{Follow-Up Care}

The transition from acute to follow-up care is often rife with uncertainty, stress, and anxiety for many patients (Ali and Warner 2013; Bell 2012). There is often this expectation that once treatment is compete patients will be able to return to the life they had prior to illness, however, for many cancer patients this is simply not the case. Often, there are physical, emotional, cognitive, financial, and relationship issues that will need to be navigated through to completely heal Gould et al. 2006; Macdonald et al. 2012). Yet, these issues are rarely discussed. Many of the young women in this study often referred to the completion of treatment as being one of the most challenging stages of their entire journey and that they often felt alone, unprepared and scared. 
For instance, Olivia spoke about the fear she experienced upon the completion

of treatment. She stresses how the health care system is primarily concerned with treating the physical disease but does not place much emphasis on mental and emotional wellbeing:

After treatment that was a very difficult time for me. I think we put a lot of emphasis on the actual treatment, the radiation, the chemo, the surgery, the medications and that's good but there's a major lack of support for the post-treatment. I felt kind of like so what now? So I was done treatment but was very very worried, very scared and anxious of the reoccurrence and kind of stuck. I found it very difficult to live with it, to live with the fear. Even though I am technically disease free, you don't know, it's the feeling of not being able to control what happens to me and there's not much support.

This narrative highlights the tensions between transitioning from stages of treatment to entering stages of remission where young women are required to navigate and come to terms with a 'new normal'. However, as illustrated by Olivia, there continues to be a lack of medical recognition and support for those undergoing such transitions.

For Audrey, her transition into remission was marked with mixed-emotions.

When asked what her transition into remission was like, Audrey stated:

Well I kind of thought that the doctors were going to have a little parade for me, like you're in remission and they make a big deal of it but that was not the case. If anything I kind of felt like I was saying before, I was lost, a little confusion, now what? I refer to it as cancer limbo. You're in this weird place, you're not really a patient anymore you're done treatment but I don't feel like a survivor because my hair's still kind of weird looking, you know. I didn't really associate with either group. So you're in this weird spot and you can never go back to life the way it used to be and it's your new normal and I think I had this misconception while I was in treatment that it was going to be over soon and then you get to the point when treatment's over and then everybody in my family sighed "oh good she's done" and I kind of felt like well now what? It can't just be over, it's not over in here (points to her head) so it just felt incomplete. Like I still had a lot to deal with and everyone else was like I am so happy this is over. 
In this excerpt, Audrey clearly expresses her feelings of apprehension, confusion and frustration with competing treatment. In this recollection, it is clear that her family and friends are relieved and overjoyed that treatment was successful but are also ready to move on from this experience. However, as Audrey notes, cancer is not over just because treatment is complete. Rather, recovery is a complex process that is poorly understood and not well supported (Rutledge and Robinson 2009).

The end of treatment was a challenging experience for most of the young women in this study. Many of the women discussed their reliance on informal social networks, community programs and the internet in supporting their transitions back to everyday life. Yet, many women also identified gaps in supportive programs, the availability and accessibility of information and also the lack of validation from medical professionals which would have eased this period in their illness trajectory. In addition, some of the women experienced more difficulty coming to terms with their illness posttreatment and felt that there was a disconnect between what they needed and what their medical team were able to provide them with. Some participants reported that medical professionals were more apt to prescribe medications than to offer alternative resources such as counselling, mediation, acupuncture and/or yoga. All of the young women in this study reported that psycho-social services should be pro-actively offered as a standard component of care as they felt it was integral to their overall wellbeing.

It is evident from this discussion that many young female cancer patients and survivors have difficulty accessing a wide array of cancer care information, resources and services. Studies continue to document the negative implications that these barriers 
can have on their overall wellbeing and treatment outcomes, yet their needs continue to be dismissed and overlooked in comparison to the 'unique' needs of young breast cancer patients (Beaver et al. 2006; Hack et al. 2005; Gould et al. 2006; Macdonald et al. 2009). Breast cancer's dominance in all areas of social life obscures other forms of cancer and silences the needs of those whom it affects. Programs like PYNK are revolutionary and are changing the ways in which the medical community and society approaches, addresses and manages cancer care. However, the identified 'unique' needs of young breast cancer patients are not just 'unique' to this particular cancer group. These needs are distinct to the specific age demographic and life-stage, and not a particular type of cancer diagnosis. Yet, this program is only available to young breast cancer patients in the greater Toronto area. PYNK's exclusivity reinforces the notion that young breast cancer patients are deserving of better care as their needs and concerns are continually prioritized over the larger population of young women with cancer. This results in much more extensive support and programming for young breast cancer patients which has direct implications for survival outcomes and overall wellbeing for young female cancer patients and survivors. Programs such as PYNK establish and maintain cancer-based hierarchies where some categories of cancer patients are privileged over others. In these instances, the exclusive provisions extended to young breast cancer patients establish boundaries between 'good' cancer patients/survivors who are worthy of specialized medical services and empathy from those who are 'bad' and not as deserving of care. 


\section{Conclusion}

Breast cancer initiatives in Canada are complex and saturate all areas of social life. It is the most recognizable and talked about contemporary disease that continues to garner the support of both women and men alike (King 2006). In this chapter, I have outlined the evolution of politics surrounding breast cancer in Canada and specifically in Ontario, and demonstrated that the cultural transformation from 'breast cancer as a political and feminist issue' to 'breast cancer as a fundraising issue' was influential in securing its modern day dominance. In addition, much of its modern day success can be attributed to the highly gendered and sexualized nature of many campaigns that gather support and sympathy through the fear of breast loss. As such, the breast cancer movement plays on and reinforces gendered stereotypes that suggest breasts are intrinsically linked to female identity. For this reason and others, young breast cancer patients' needs and concerns are continually prioritized over young female cancer care more generally. It has resulted in much more extensive support and programming for young breast cancer patients which has direct implications for the material realties of both marginalized breast cancer populations as well as the general population of female cancer patient/survivors. In the following chapter, I will explore dominant survivor discourses and how they shape individual experiences post-cancer. 


\section{Chapter 4: Governing Survivorship: Ideal Survivors and Model Citizens}

\section{Introduction}

A Survivor is a triumphant person who lives with, after, or in spite of a diagnosis or traumatic event. Survivors refuse to assume the identity of their adversity. They are not imprisoned by the constructs of a label. Instead, survivors use their brush with mortality as a catalyst for creating a better self. We transform our experience in order to further evolve spiritually, emotionally, physically and mentally.

- (Carr 2008:xxi)

The prevalence and public celebration of cancer survivorship in public spaces are relatively new phenomena and speak to the emergence of a new discourse of survival (Bell 2012; Zebrack 2000). In the current political climate, survivorship discourse is not just about defeating cancer. Dominant understandings of what survivorship is, how it is determined, who can be a survivor and what it means to be a survivor propose and reinforce complex values and beliefs specific to certain political, social, and economic landscapes. In thinking through these developments, in conjunction with analyzing the participants' narratives, it becomes clear that survivorship discourses significantly influence how cancer survivors understand themselves and their activities, post-cancer.

This chapter critically examines survivorship discourse and how it shapes young female survivor subjectivities. Using a governmentality lens, I examine how people's cancer-related experiences might best be understood as 'teachable moments' insofar as they compel survivors to take action towards transforming their behaviors, their psychological and emotional selves and, ultimately, their entire lifestyle. My intention is 
to demonstrate that rather than considering a cancer diagnosis as an 'unfortunate circumstance', dominant survivorship discourse tends to represent cancer as a life event that serves as an opportunity to define what and who we are which enables the establishment of what we make ourselves.

The chapter is divided into two parts. In the first section, I situate survivorship discourses as extensions of contemporary public health initiatives which rely on and reproduce understandings of cancer diagnoses as 'teachable moments'. More specifically, I examine how individualized notions of health management take center stage in survivorship discourse and reinforce neoliberal constructs of the "healthy citizen'. In the second section of this chapter, I illustrate the coming together of these discourses by exploring the ways in which the young women I interviewed engage, and in some cases resist, normative expectations and guidelines for living post-cancer. I investigate how commonly circulating discourses related to health and personal development inform participants' subjectivities and senses of self - that is, the ways individual participants come to understand who they are, who they want to be and who they should become, post-cancer. The main argument that I advance is that survivorship discourse - centered as it is upon notions of self-transformation - might usefully be read as instances of neoliberal governance which are premised on efforts to produce morally responsible citizens. Drawing on participants' narratives, I argue that female cancer survivors are 'made up' not only as representations of how illness should be embodied but also as evidence that illness can act as a catalyst for the production of model citizens (Rimke 2000). 


\section{Living with Cancer as Teachable Moments: Taking Charge of Your Own Survivorship}

Improvements in all aspects of cancer care are resulting in an increase in the numbers of people entering stages of cancer remission and survivorship. Since the early 1990s, survivorship and life after cancer have become growing areas of inquiry that are being profoundly influenced by public health literature (Bell 2010, 2012). Given that in Canada, health care services are subject to fiscal restraint and increased privatization, the field of survivorship has been effectively taken up by private, non-profit and community institutions. The result has been heightened awareness about survivorship issues and proliferation of cancer and survivorship centers. Across Canada, for example, cancer and survivorship centers exist in most metropolitan cities. In Ontario, there are several community-based, non-profit cancer/survivorship centers - such as Wellspring, Ellicsr, and Maplesoft. The stated aim of these centres is to educate, engage and empower survivors, patients and caregivers by offering a wide array of programs and resources to help people take action and become active in the management of survivorship.

This depiction of survivorship centres connects well with claims made by critical public health scholars. These scholars suggest that public health is best conceptualized as a collection of practices which seek to govern individuals through a network of expert knowledge that establish norms for conduct and privilege particular types of subjects, those who are self-reliant and responsible for their own health (Gastaldo 1997; Lupton 1995; Oster and Cheek 2008; Nettleton 1991, 1994; Petersen 1997; Petersen and Lupton 1996, 1999; Polzer et al. 2002; Seear 2009). This particular subject is constructed as the 
'healthy citizen' and is best conceptualized as an entrepreneurial individual who not only engages in their own self-governance via processes of self-care ${ }^{17}$, but who also accepts responsibility for protecting themselves and their loved ones from known 'risks' (Petersen and Lupton 1996). ${ }^{18}$ Within this literature, it is argued that public health initiatives are concerned with "how we conduct ourselves, how we attempt to conduct others and how we attempt to control our conduct" (Petersen 2003: 188). Public health initiatives thus seek to direct people's everyday activities and practices by drawing on expert claims that rationalize professional interventions premised on the importance of people being active, vigilant and self-reliant in the pursuit for personal health and wellbeing.

As a collection of practices, public health does not only operate through state sanctioned agencies and programs. It is argued that public health initiatives are most effective when they invoke individuals' "desires to regulate their own conduct in the name of health" (Polzer et al. 2002: 155). In the context of survivorship, there is an abundance of available information that focuses on specific lifestyle factors - namely exercise, body weight, diet, environmental and occupational exposures - and their supposed effects on cancer development, progression and relapse (Bell 2010). Despite a general lack of evidence and agreement within the scientific community about the role

\footnotetext{
${ }^{17}$ Foucault (1988) defines 'technologies of the self' as those "which permit individuals to effect by their own means or with the help of others a certain number of operations on their own bodies and souls, thoughts, conduct, and way of being, so as to transform themselves in order to attain a certain state of happiness, purity, wisdom, perfection, or immortality." As such, self-care involves practices of self-examination and self-reflection often performed in the pursuit of a better and freer life. ${ }^{18}$ Following Lupton (1999:2) I have adopted a constructionist approach to risk insofar as "what are identified as risks, by experts are understood as inevitably the outcome of sociocultural processes and tend to serve certain social, cultural and political functions".
} 
lifestyle factors play in relation to cancer relapse, such risk-related discourses are nonetheless prevalent - even within spaces dedicated to survivorship. In other words, expertise and knowledges about post-cancer health are mobilized in ways that encourage survivors to assume a calculating, self-directed gaze (Fullagar 2002; Lupton and Petersen 1996; Polzer et al. 2002). In this sense, one might thus conceptualize the free programs, resources and services offered within survivorship centres as extensions of public health initiatives which are designed to engage, educate and empower cancer survivors.

More importantly, one also might note overlaps between these initiatives and the ways scholars discuss neoliberal forms of governance. For example, as with Foucault's (1979) discussion of prisons, survivorship centres rely on programs directed by interdisciplinary specialists who both define and establish norms and act as advisors in an effort to produce and foster active decision making. Until recently, medical professionals - doctors, nurses - were predominantly the only profession to be viewed as experts in cancer care and survivorship; however this is no longer the case (Ali and Warner 2013). Issues surrounding life post-cancer extend well beyond the physiological aspects of illness and survivorship discourse includes a more holistic approach to healing (Ali and Warner 2013; Bell 2012; Macdonald et al. 2009). As such, experts now include a multitude of practitioners - cancer coaches, psychologists, dietary and nutritional specialists, yoga therapists, expert patients and a variety of complementary and alternative health practitioners - which results in the pluralisation of expertise. Consequently, responsible survivors are now expected to consult numerous experts in 
attempts to improve their lifestyles and manage related cancer risks. From this perspective, experts and the deployment of their knowledge plays a central role in modern forms of governing, including but not limited to survivorship centres. I argue that, such knowledge does more than render social life into a calculable form; it also helps produce particular subjectivities by influencing the thoughts and actions of individuals who engage in such programs.

In recent years, the concept of the teachable moment has become central to both survivorship discourse and popular perceptions that situate cancer diagnoses as opportunities for self-improvement (Bell 2012). Within the behavioral sciences, the teachable moment is a concept used to describe how naturally occurring life transitions (or health events) such as cancer, chronic illness, pregnancy and parenthood have the potential to motivate individuals to adopt health protective behaviors (Bell 2012; Ganz 2005). In order for a particular event to become a teachable moment, McBride et al. (2003) conclude that three criteria must be met: the event must (1) increase perceptions of personal risk, (2) elicit a strong emotional response and (3) challenge understandings of the self. In other words, teachable moments are most effective when experiences of illness significantly challenge individuals' prior sense of self and invoke a sense of fear thus motivating individuals to adopt lifestyle changes (Bell 2012).

Until recently, medical professionals and descriptive research optimistically indicated that people diagnosed with or at risk of cancer would modify and improve their lifestyles because of the exemplary teachable moments such events present (Bell 2012; McBride et al. 2003). However, there is a growing amount of research that 
suggests that a diagnosis of cancer alone cannot arouse necessary behavioral and lifestyle changes (Blanchard et al. 2008; Demark-Wahnefried 2005). In response to evidence of slow patient response, there has thus been growing interest amongst medical professionals to explore ways to 'take advantage' of and "capitalize on the teachable moment that cancer provides [to] guide... patients to[ward] better health" (Demark-Wahnefried 2005: 5827).

Given that medical professionals are actively seeking out ways to intervene and promote positive lifestyle changes post-cancer, I would argue that survivorship centers are dedicated spaces that are now positioned as exemplary arenas in which to promote and foster such teachable moments. In keeping with this reading, Bell (2012), Ehrenreich (2001) and others (King 2006; Segal 2010) argue that survivor discourses are increasingly conceptualized as opportunities for personal growth and self-improvement. Given the dominance of survivorship discourses - premised on notions of selftransformation - which infuse these centres and their programs, I read survivorship centers as seeking to capitalize on and to transform people's cancer-related experiences into positive life events (Garland et al. 2007). From this perspective, trauma is a productive force that invites individuals to re-evaluate their lives and senses of self and which, as Bell (2012: 586) suggests, "allows the self to be remade from the ground up". Based on this logic, Bell notes, trauma and illness provide the grounds for both intervention and for transformation.

As the above discussion indicates, survivorship centers are community- based, expert driven centers dedicated to encouraging and supporting survivors' quest for self- 
betterment. I have suggested that as survivorship discourse gains public credibility and is increasingly valued within cancer communities and beyond, demand for survivorship centers and related programs grow. Indeed, there is already considerable demand for survivorship centers amongst survivors who want to be pro-active in their efforts to reduce their risk of disease re-occurrence (Ashbury et al. 1998; Bell 2012; Blanchard et al. 2008; Canadian Cancer Society 2003). In particular, survivorship programs are widely praised within cancer communities for their whole person approach to care and their unique interdisciplinary health frameworks (Ali and Warner 2013; Bell 2012). What this means is that survivorship programs incorporate both biomedical and alternative approaches to health, wellness and growth (Bell 2010). Stated more critically, when read through the governmentality framework, one might argue that survivorship centers rely on and mobilize numerous forms of expertise which are central to the surveillance of subject-citizens (Petersen and Lupton 1996).

That said, it is important to note that surveillance is not just watching and monitoring. Rather, Henman (2004: 175) describes it as a "calculated practice for managing and manipulating human behavior". Surveillance, from this perspective, is a form of governance that works at a distance to responsibilize individuals and motivate self-regulation through the manipulation of desire (Rose 1999). Understood in this way, surveillance plays a significant role within survivorship programs as it nurtures practices of self-discipline, inculcating survivors with a desire to transform their behavior and lifestyles in accordance with broader political goals. In this sense, survivorship programs are designed to encourage survivors to become responsible managers of cancer risk. In 
particular, survivorship programs act as 'informal classrooms' that are meant to provide survivors with up-to-date information and resources about cancer-related preventative practices and techniques for modifying and improving one's self.

Read in this way, practices of self-surveillance are intimately linked to the operation of neoliberal government of risk. In the context of survivorship, survivors are called upon and compelled to engage in their own self-governance through "processes of endless self-examination, self-care and self-improvement" (Petersen 1997: 194). Based on this logic, these centers and programs are concerned with survivors' absorption of expert knowledge and how they can be conditioned to voluntarily "conform to their objectives [and] to discipline themselves" (Petersen and Lupton 1996: 11). Similar to public health and health promotion initiatives, then, the goal of survivorship programs is to shape and normalize the behavior of subjects. In doing so, a particular kind of survivor is constructed: one who is autonomous, self-regulated, devoted to self-improvement and who seeks happiness and healthiness.

Before embarking on part two of this chapter, I want to make it clear that I do appreciate the potential of survivorship centers and the importance of finding the socalled silver lining in even traumatic life events. However, I am critical of the very limited models offered to people for how they can - or should- embody and experience illness. More specifically, I view the current dominant survivorship model as promoting a very specific type of healing, one that locates the cause of illness as being in the control of individuals, thus encouraging individuals to see cancer as an opportunity for selfbetterment. What is significant about this contemporary focus on situating cancer as a 
makeover is that it distracts cancer survivors from questioning and exploring broader cancer causations and in a sense deters them from taking any form of action as a means of contestation. Instead, the current survivorship model places particular emphasis on notions of individual responsibility, consumer choice and freedom and does little to support more meaningful conversations about environmental, social and economic causations of cancer. In the remainder of this chapter, I further support this analysis by exploring the ways health-related discourses infused participants' perception of their cancer-related experiences. In particular, I investigate how young female survivors in this study take up the imperatives and expectations at the heart of survivor discourses.

\section{'Remaking the Self' Post- Cancer: Ideal Survivors and Model Citizens}

In what follows, I explore the diverse network of power relations running through participants' individual illness narratives. My particular interest is in the ways these young women might be identified as implicated in their own self-governance via reproduction of normative risk discourses. More specifically, I examine how health risks and self-development discourses infuse participants' narratives of identifying, managing and challenging survivorship discourse. I elaborate overlaps between understandings of survivorship as a form of governance and representations of illness as a catalyst for personal growth. Together, these discussions provide a useful framework for exploring how individualized notions of health management take center stage in participants' narratives. The main argument I advance is that survivor discourse serves both to produce ideal survivors and to construct model citizens. 


\section{Taking Up Health Discourses: Being Aware of Risk}

Within modern Western cultures there is increasing emphasis on individual selfregulation and self-governance in many aspects of life, including the management of health behavior and health risks. The concept of risk is central in producing 'healthy citizens' and does so by anticipating and preventing unfavorable events. Robert Castel (1991: 287) notes that "risk does not arise from the presence of danger [rather] it is the effect of a combination of abstract factors which renders more or less probable the occurrence of undesirable modes of behavior". As such, risk discourses work by encouraging autonomous individuals to ensure their own security and engage in practices of self -care (Castel 1991; Nettleton 1997; Oster and Cheek 2008; Seear 2009). In order for individuals to take responsibility and become active in the management of their health they must be aware of risks and in many instances risks become understood as "diseases to be cured" (Nettleton 1997: 215). Notions of risk become situated as within the control of individuals and, as Nettleton (1997: 215) points out, this contributes to "the confirmation of the active [and healthy] citizen". Individuals are now expected and required to be active in their own health promotion, make responsible choices and act on expert information in attempts to manage health risks.

Numerous cancer risk factors are commonly discussed in medical and public health literature, however, cancer risk discourses are increasingly diffused by public outlets such as the print and digital media (Lupton 1995). Social science research continues to document the conflicting priorities and interests of both the scientific community and media communities (Nelkin 1996; Peters 1995; Henderson and Kitzinger 
1999). This research indicates that media communities may not necessarily prioritize and value the risks judged to be most important by the scientific community. As such, media outlets tend to "misrepresent risk statistics, and distort the facts" in addition to numerous amounts of conflicting and confusing information which can pose particular problems for many individuals but especially for those suffering from illness (Kitzinger 1999: 55).

In recent years, there has been an influx of risk discourses specifically emphasizing the importance of lifestyle factors - diet, weight, exercise, environmental and occupational hazards - in mitigating cancer relapse (Bell 2010; Demark and Wahnefried et al. 2006; Irwin 2008). The Canadian Cancer Society is one of Canada's most trusted resources for cancer information and many patients and survivors rely on them for up-to-date and relevant cancer care material. On their website, there is a space dedicated specifically to prevention and lifestyle risk factors. Much of the literature present tends to address and promote 'good' preventative practices and behavior modification techniques. For example, the Canadian Cancer Society identifies 'healthy eating', 'physical activity', and 'healthy body weight' as determinants that can help prevent the development of cancer. They further advise Canadians "that the science is clear: it's the overall pattern of living that's important. You can lower your risk [of cancer] if you move more, stay lean and eat plenty of vegetables and fruit" (Cancer.ca 2013). 


\section{Eat green.}

Good nutrition reduces the risk of cancer.

Similarly, the Ottawa Regional Cancer Foundation over recent years has hosted public lectures focusing on healthy eating and lifestyle management. In 2009, Dr.

Richard Beliveau, author of 'Foods that Fight Cancer' lectured about the science of nutrition and how certain foods can protect the human body against different cancers.

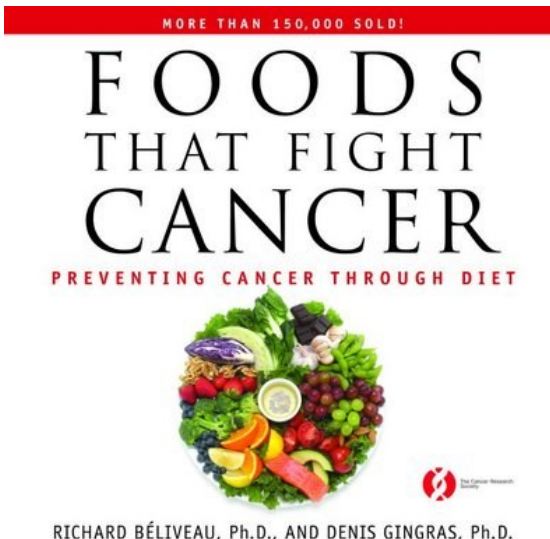

RICHARD BÉLIVEAU, Ph.D., AND DENIS GINGRAS, Ph.D.

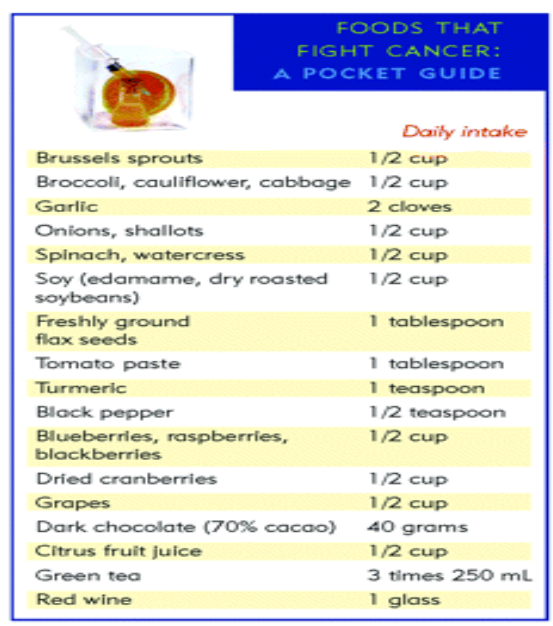

Source, www.richardbeliveau.org

While the Canadian Cancer Society and the Ottawa Regional Cancer Foundation pride themselves on providing accessible and relevant information to people, the focus on lifestyle advice for healthy eating and physical activity establishes moral judgements about food, eating and lifestyle practices (Ristovski-Slijepcevic et al. 2010). In this way, particular foods, activities and lifestyles "become associated with moral acceptability 
based on their 'good' or 'bad' elements", with those who are unwilling or unable to take up such practices judged as less morally worthy than those who do (Ristovski-Slijepcevic et al. 2010: 468). The goal it seems is to motivate and empower survivors to take action and control the disease by taking charge of their bodies and lifestyles by making the 'right choices'. However, there is a general lack of evidence and consensus among the scientific community as to whether lifestyle modifications are effective and/or beneficial in overall disease-free survival (Bell 2010). Despite this absence of agreement, major resource providers such as the Canadian Cancer Society and public media outlets continue to reinforce the importance of healthy lifestyle choices, especially for cancer survivors (Bell 2010).

Cancer survivors encounter abundant amounts of information focused on the management of lifestyle risk factors. For example, the foregoing discussion highlighted the ways survivorship centers and programs rely on, circulate, and reproduce numerous forms of expert knowledge and strategies for the management of risk. Moreover, expert knowledge and lifestyle risk discourses are constantly evolving and as Petersen (1996: 54) points out, there is often disagreement between experts about "what constitutes a risk; levels of risk; how to respond; and so on". Indeed, several young female cancer survivors in this study expressed difficulty in both the navigation and reliability of the information that was often available to them.

For instance, Olivia experienced a lot of stress and anxiety trying to determine what information was accurate and valid. She stated: 
There's so much information out there, I didn't know where to start or what to believe. It's not like heart disease where they can say if you don't eat fat and you don't eat salt and exercise you will be ok. It's not like that. One day coffee is good for you the next it's not, maybe you should drink red wine maybe you shouldn't. There is so much conflicting information that I didn't know what to do anymore, I was so afraid it's going to come back and if I put this in my mouth am I giving myself cancer? Can I drink coffee? Should I be drinking coffee? I was paranoid over everything and it was causing so much anxiety and I didn't want to eat anything.

This discussion highlights the very ways in which risks become internalized, induce anxiety and stimulate action. Olivia engaged in action that was based upon the expertise and knowledge that was available to her. However, as she notes, the conflicting nature of risk discourses proved to be a source of additional stress and anxiety.

Similar to Olivia, Maura also discussed the difficulty she experienced when attempting to determine what information was relevant and what practices she should have been engaging in to try and mitigate controllable lifestyle risks. In documenting her experience, Maura often mentioned that she felt confused and unsure of what to believe:

There's so much information that I didn't know where to start, at times I felt consumed by all of it. I was really discouraged because I thought I was healthy, I wasn't obese, I exercised regularly, I never smoked, I always wore sunscreen. These things are important right? I just don't know. I was just so lost in all of it and confused because I thought I was doing things right. I hear so much about how diet and certain foods can control a lot of ailments but I'm not sure. I have to try harder though to exercise more, to eat healthier, to stress less because I don't want it to come back. I'll do whatever I need to do to make sure that it doesn't happen again.

Maura highlights how she finds it difficult to negotiate cancer and lifestyle risk discourses because prior to her diagnosis she considered herself to be 'healthy' and engaged in numerous risk management practices. Despite these efforts, she still was 
diagnosed with cancer and in some ways feels letdown by this type of expert knowledge.

Unlike Olivia and Maura, Leaha, a colon cancer survivor, and Tessa, a thyroid cancer survivor, were acutely aware of what information, practices and behaviors they should have been partaking in to manage their lifestyle risks. Yet the complexities associated with their illnesses often prevented them from taking control of their bodies. Tessa was fearful that she would be viewed as 'lazy' and 'disinterested' in her health because she often did not have the energy to be as active as she would have liked. Leaha also recalls the struggles she encountered trying to negotiate healthy ideals with the reality and limitations of her physical body:

I know what I should be doing to stay healthy...its very similar to being overweight and I lost 106 Ibs. before I was diagnosed. I ate healthy, exercised a lot sometimes twice a day, and avoided anything that was unhealthy. I was trying to get into the military....but now it's different cause they removed my colon. Now I have a restricted diet that's not the healthiest but I do try to incorporate healthy foods by juicing. I try to exercise regularly, but it depends if I am having a rough day [physically]. It's been a learning process and it can be discouraging because I want to be healthy.

Leaha's response demonstrates the tension she experiences in terms of trying to balance her physical needs with her desire to take a more proactive role in modifying her behaviors and lifestyles. She fears that by respecting her body's limitations as to which foods she can safely consume, people may view her as 'irresponsible' for not adopting healthier behaviors.

For several of the women in this study, the need to obtain up-to-date, accurate and reliable information about the management of risk factors was seen as crucial for several reasons. First, the young women in this study believed that having access to this 
type of information would help facilitate decision making and the adoption of self-care practices aimed at improving their overall behaviors and lifestyles. Secondly, the young women in this study also felt that it was necessary to at least be aware of the current scientific debates surrounding cancer risks. Risk discourses played a central role in the lives of those living post-cancer. Such discourses operate in ways that compel individual survivors to become responsible for their own health even in circumstances where they may have little power to affect the overall outcome.

\section{Taking Up Health Discourses: Participating in Risk Management}

As the above discussion suggests, individuals are positioned as having both a social and personal obligation towards maintaining good health. Indeed, this "duty to be well" supports broader neoliberal objectives which situate health and wellbeing as an individual responsibility (Howson 1999: 402). In the context of survivorship, there is a growing expectation that cancer survivors will engage in self-surveillance as it serves their own best interests. These individuals, according to Rose (1990), exemplify good citizenry in that the individual pursuit of good health is a central component of social membership. However, those who do not assume a calculated, self-directing gaze are increasingly scrutinized and are often viewed as culpable for their poor health and illness in light of known risks (Galvin 2002). This is resulting in a culture of victim blaming that, as Galvin (2002) notes is becoming difficult to contest. 
One participant, Hannah, experienced victim blaming when she sought out the expertise of a local plastic surgeon. Hannah recalled this experience as 'absolutely unbelievable':

This doctor told me, when I asked her what I could do to be proactive and make the chances of radiation less damaging to my skin so that I could be able to have reconstruction, to you know 'eat lots of fruits and vegetables and exercise'. I said I am a vegetarian; I eat mostly organic and exercise regularly. Her response was 'that's interesting because people who eat like that don't usually get cancer'. I was like wow, seriously? Like people who eat well don't get cancer? Like is this what you're telling me right now. Well if you eat well, what else did you do wrong to get cancer? People don't get cancer who eat well, it's weird that you got it and you eat well. What a jerk. I never saw her again.

Hannah's experience demonstrates how dominant discourses of lifestyle risk reinforce erroneous notions that cancer causation is a result of poor and irresponsible choices. From this perspective, those diagnosed with cancer are increasingly viewed to be responsible for their illness and downplays other causations of cancer.

Many of the young women in this study were acutely aware that they had a responsibility for their health and sought to become active and take preventative measures in the minimization of lifestyle risks. Several of the young women acknowledged that while there were things out of their control, the "little things mattered and added up in the end'. Audrey, for example, spoke about the 'little things' in greater detail. She stated:

You know there is a lot of stuff I can't control like the stuff that we breathe in, it's not so easy to control that. But there are things that I can control and like I have really tried to change. I use organic mascara and use organic moisturizer, I am really trying to pump up the fruits and vegetables and make that a priority and drink lots of water. I have done things like cut pop from my diet and tried to exercise more. I feel pressure by those around me to be healthier and do more and I feel that a lot of people assume how they would react if they had cancer and project that onto me. 
What is particularly interesting about Audrey's response is the ways she negotiates personal responsibility for her particular choices and actions in light of risk factors that are out of her control. She is aware that others may judge her by the choices she makes and is making an effort to engage in supposedly healthy behaviors and act responsibly in ways that are publicly and medically sanctioned.

Interestingly, several of the women noted the amount of internal and external pressure they felt to adopt healthy behaviors. For these women, this additional pressure often resulted in feelings of guilt and stress. This was certainly the case for Nadia who felt that taking up healthy practices was actually a burden and became a source of stress:

I am trying to focus on two things, trying to avoid stress and eating better. Anytime I try to deal with stress I get myself more stressed because I am afraid I will get myself sick again and give myself cancer. I just don't want to be stressed...I don't eat a lot of meat anymore. I tried to become a vegetarian but it didn't work for me. I'm not an only eat organic, granola, vegan kind of person, it's not realistic. I have a young family and it's just not possible. I hate going to support groups that have to do with nutrition I feel guilty when I eat poorly and hate to think I'm giving myself cancer again. I don't want to be blamed if I eat a cookie and that's the way it feels a lot of the time at these things.

What is significant about Nadia's response is how she highlights the role of cancer support groups and the ways they attempt to monitor and control the conduct of other survivors. While the aim of support groups is to offer a listening ear and to provide support from those with similar experiences, in Nadia's case support groups act in ways that surveil individual behaviour.

Many of the participants with young families also felt compelled to take responsibility for themselves as well as their families' health. These women wanted to 
set positive examples for their children and this often added additional pressure. This was the case for Sophia:

I think that our way of life has changed drastically since my treatments, because health seems so much more important this day in age where everything purchased is food product as opposed to food. It's important to me to be aware of what we consume and how much we consume of it. I use vinegar for almost everything, I use mostly organic, petroleum free products, I purchase a lot of organic foods and try to make as much as I can from scratch. I am afraid of the formaldehydes chemicals, sugars and sodium in a lot of prepackaged foods. All are so bad for your body and health. Physical activity is very important for me and my children. They participate in formal activities and we do family walks in the evenings. It can be stressful but I try and prioritize my time to be able to do all of it. When I don't have time to do it I feel more guilt and stress for not preparing way ahead of time.

Sophia's concern for maintaining both her and her families health are illustrative of the competing influences on her knowledge of what it means to be 'healthy mother/citizen'. Whether she is aware of it or not, Sophia is trying to negotiate between intersecting and competing - motivations; she wants to be healthy and take care of herself but she also wants to be a good mother, set positive examples and be vigilant about her family's health. This experience highlights the very ways in which neoliberal rationalities are entangled with risk discourses and reinforce notions that women are primarily responsible for protecting the health of their families (Seear 2009).

Adriana and Katia both thought that maintaining a well-balanced lifestyle was important to their overall wellbeing. However, both of these young women were very critical of information linking diet and exercise to cancer relapse. Katia felt that like other fad health regimes "these things come and go" and opted to stay away from reading about foods and lifestyle factors that cause cancer. Katia felt that "there [was] no guarantee that taking on these practices was going to ensure that it never [cancer] 
comes back" and did not want the additional stress associated with these types of expert claims. Similarly, Adriana stated:

I definitely steer away from buying into that kind of stuff; I think its purpose is to make people feel guilty. I'm definitely more of a everything in moderation kind of person. Yes, I have had cancer but I don't eliminate foods, like even fast food. Some people would eliminate it totally. I mean I don't eat it regularly, once it a while I'm ok with it. I definitely don't buy into those things because I don't think there's much evidence backing their claims. They say don't drink red wine and then the next day there's a study saying it's good to drink red wine. So it's very contradictory and confusing, so moderation is a much better approach for me.

Despite the pressure to adopt these particular practices and lifestyles post-cancer, Adriana and Katia both resist dominant health discourses. Instead, these young women are determining what is healthy and reasonable for them and are trying to live their life accordingly.

Taking Up Health Discourses: Complementary and Alternative Medicine (CAM) Therapies

Several of the participants in this study turned to alternative sources of knowledge in their attempts to regain a sense of control over their lifestyles and behaviors. Some of the women in this study sought out complementary and alternative medical (CAM) therapies which are transforming ideas of how health is best achieved (Sointu 2006). As such, CAM therapies tend to challenge biomedical frameworks and include a diverse set of approaches that are not readily integrated into Western health care models (Bell 2010). More specifically, CAM therapies provide end users with a more holistic approach and "claim to care for the needs of the whole person" (Sointu 2006: 345). Although survivorship centers introduce and promote several CAM therapies these 
centers do not actually provide such services to those using their center. Individuals wishing to engage with CAM therapies are required to seek out professionals and pay for their services. Thus, CAM therapies are limited to those who are financially able to afford such services. Two of the women in this study actively sought out and integrated CAM therapies as another source of care.

For example, Hannah recalled that she was drawn to CAM therapies for their healing and empowering potential and spent thousands of dollars seeing a traditional Chinese Acupuncture specialist who helped her manage pain and nausea. Hannah recalled her experience:

It's a different approach which is why I am glad I am doing it in addition to traditional medicine. There's only one oncologist in Ottawa willing to discuss or entertain the idea of naturopathic medicine and I fought to see him. You know though, it's expensive and I have to pay for it. It's not covered. I am really glad that my partner makes a great salary because I have spent my entire income on complementary therapies; I literally spend thousands a month on complementary therapies because I want the best possible care and I like knowing that I am active in the process.

In this excerpt, Hannah clearly expresses her feelings of uncertainty with the level of care she receives from her medical team and feels a sense of responsibility for ensuring that she is doing everything in her power to guarantee that she receives the best care she can. Hannah's narrative also highlights the exclusivity and class privilege associated with CAM therapies.

Social scientists in the field of health and illness acknowledge that CAM therapies often resonate strongly with lived experiences of illness, while at the same time recognizing that CAM therapies align well with neoliberal forms of governance. These scholars suggest that CAM therapies and their underlying assumptions support ideal 
neoliberal conceptualizations of the 'healthy citizen': one who is autonomous, free and responsible for their own health and wellbeing (Bell 2010; Sointu 2006, 2011). In addition, by analyzing young women's use of CAM therapies, it is clear that the ideal survivor requires considerable access to time and money. As mentioned above, CAM therapies are not covered by provincial health insurance or by community-based survivorship centers and while some private insurance companies do subsidize care, users are required to pay for services out- of- pocket (Armstrong and Armstrong 2010). Those who are able to financially afford additional forms of care also require the time and freedom to seek out alternative health practices. As such, those who are able to access and afford CAM therapies are often individuals who are economically privileged. Numerous scholars have also demonstrated how engaging in CAM therapies is not just solely about challenging biomedical knowledge and/or improving one's physiological health (Broom 2009; McClean 2005; Sointu 2006, 2011). Indeed, a great deal of literature suggests that CAM therapies are linked to broader understandings of health and wellbeing situated within processes of continual reflexivity. CAM therapies promote and seek to develop, an ongoing sense of bodily and self -awareness. In other words, CAM therapies are concerned with how we conduct ourselves and seek to remedy the post-modern dilemma of 'how shall I live' (Giddens 1991:14).

Isabella turned to CAM therapies in the hope of gaining accountability and a sense of control over her health. Dissatisfied with biomedical approaches, she decided to engage with complementary and alternative therapies and incorporated them into 
her everyday life. Isabella recalls that her experiences with these therapies completely changed her life. She stated:

Prior to being diagnosed, I had been so healthy and I was so young and did all the things you are supposed to be doing and I was doing all those things so I felt betrayed by all that information and a real betrayal of my body. I was angry and discouraged but it changed my life and my perspective. I decided to go back to school and I've retrained to be a massage and yoga therapist. I realized that I wanted to live something where I felt like everything in my life was working together so that the next fifty years I have resources and tools at hand and I am just living more completely as a person. I am really active and health conscious and don't really listen or give much credence to popular health claims. Instead I practice reiki, Qi Gong, cranial sacral and believe in more integrated approaches to life and health.

Isabella's narrative informs us about how some young female survivors turn to CAM therapies not just solely for the quest of better health but also as a way of continually being self-reflexive and working on the self. In this sense, her narrative is embedded within notions that view cancer as an opportunity for self-transformation.

Practices of self-care that stem from CAM therapies can be understood as both enabling and constraining in that they allow the participants to exercise regulated forms of freedom while also constructing themselves as neoliberal subjects (Heyes 2007). Health discourses provide a legitimate motivation for the regulation of bodies and behaviours. Those who seek out, take up and incorporate CAM therapies into their everyday practices are often portrayed as responsible managers of their own health, while those who fail or refuse to do so are constructed as 'bad' citizens who are irresponsible, and lazy. 
Taking Up Self-Development Discourses: Positivity and Self-Improvement

In Welcome to Cancerland, Barbra Ehrenreich (2001) makes the compelling point that in the contemporary era, experiences of cancer are discursively depicted in 'overwhelmingly positive terms'. Public representations of survivor narratives tend to be upbeat, cheery and focus on the positive aspects and outcomes that experiences of cancer may produce. These types of public conversations as Segal $(2010,2012)$ argues and I most certainly agree with her assertion - tend to direct conversations away from unconventional stories and limit the ways individuals are able to experience and talk about their illness. A growing body of qualitative research suggests that public presentations of dominant cancer stories are not innocent (Bell 2012; Kaiser 2008; King 2006; Little et al. 2002). Scholars such as Bell $(2012)$ and Segal $(2010,2012)$ point to the coercive elements within cancer narratives that operate to compel survivors to act, feel, think and live a certain way.

In recent years, positive psychology is increasingly permeating all areas of social life and is particularly influential in survivor discourse. Within survivor discourse, young women are increasingly urged to adopt and take up positive attitudes and optimistic outlooks (Bell 2012; Ehrenreich 2001, 2009; King 2006; Segal 2010, 2012). In Bright Sided: How the Relentless Promotion of Positive Thinking Has Undermined America, Ehrenreich (2009) explores the powerful relationship between positive psychology and cancer culture. She argues that positive psychology discourses are saturating cancer culture and are promoting widely circulating myths that advance the idea that good health is a matter of positive thinking and that it is within individual's reach. In the 
context of survivorship, positive discourses operate in ways that aim to cultivate individual self-control and self-mastery (Binkley 2011; Rimke 2000). As such, these discourses generate new forms of normalizing practices that focus on regulating and managing thoughts and emotions (McGrath et al. 2006).

The idea that survivors should subscribe to positive ways of thinking was evident in the data. Julia felt that having a positive attitude was the one thing that she could control:

I knew I could control my attitude and I wanted to deal with it or look at it a positively as I could. Attitude is huge and I am very sarcastic, I do have a sense of humor kind of and I've said the whole time it's either you laugh or you cry and I choose to laugh the whole time. And nobody really wants to hear about the shitty stuff. The support system that you have helps and that will help in your attitude as well because if you are not surrounded by positive good people then if you're feeling shitty then you're going to keep on feeling shitty because your surrounded by shitty people. But if you're feeling shitty and you're surrounded by good people, you're ok, you can get through it. The way I thought about it the whole time was just because I might have been feeling horrible right now does not mean I am going to be feeling the same way an hour from now or in two hours and tomorrow's another day, so there is something good to look forward to.

What is particularly striking about Julia's response is that way she touches upon an element of dominant survivor discourse that presents the way one approaches illness as an individual choice which is deemed to be reflective of one's character and outlook on life. More specifically, she repeats one of the main messages circulated in survivor discourse: "humor is good; despair is bad; surviving is a personal accomplishment; dying by implication, is the opposite" (Segal 2010: 298).

Similar to Julia's experience, Audrey emphasized how being positive helped her get through the worst of times. Audrey stated: 
Without a positive attitude, I'd still be hiding under the covers. I had bad days but my attitude was positive. To be honest, I laughed more than I cried which I made a rule almost. It was too exhausting to cry, you know, there was too much to cry about. At the same time, if I was having a bad day I let myself have the bad day. I think there's this misconception that being positive means having a smile on your face whereas I think being positive can mean lying in bed crying all day because you are being positive and getting through that point. I think I didn't want to look weak primarily. So many people had told me how strong I was, "oh you're so strong", I didn't want to let them down. I know that seems foolish but being positive helped and it some ways made everyone feel better.

Both Julia and Audrey touch upon the very ways in which having a positive attitude comforted those around them and helped others come to terms with their illness. In some ways, the embodiment of a positive attitude served as a coping mechanism for these young women in addition to those around them. If they could be positive and look on the bright side, then so could everyone else.

For Mia, being positive allowed her to see the good in a really tough situation. She often talked about needing to be strong - not only for herself but for her two younger siblings and friends - and thought that self-pity was a waste of the little energy she had:

I was definitely in the fight-mode. I didn't want to feel sorry for myself or anyone to feel sorry for me. I was glad that it was me [who was sick] as opposed to somebody else, like my sister or my brother. I couldn't have been the person watching. I think I wasn't sorry it happened, when I was going through treatment. And I don't know if it was because I didn't want to feel sorry for myself and so I was just like well if it had to happen, at least it's going well, and there is no point in feeling sorry for myself, because it had to happen, and everything happens for a reason. And then, I think it was after, it was after everything, that I kind of just realized well maybe this was a good thing, and it definitely shaped who I am now. And I'm not sorry for that.

In short, Julia, Audrey and Mia describe how powerful positive discourses are and the ways in which they become embodied and informed how they dealt with their illness. 
Through their experiences it is evident that such discourses discursively produce distinct subjectivities - those of thriving survivors.

The preoccupation in Western society with human happiness and self-projects is increasingly echoed in dominating discourses on survival. From these perspectives, cancer is no longer viewed as a death sentence and patients are no longer constructed as passive victims (Kaiser 2008). Rather, as Ehrenreich (2001) argues, cancer is increasingly conceptualized as a gift that empowers survivors to transform their physical, psychological, and spiritual selves. Rose, a participant in this study, described cancer as a 'badge of honour', a status that she does not hide from. For Rose, cancer is an experience to be proud of, one that changed her and her life for the better. According to this logic, cancer diagnoses are now perceived to be opportunities for personal growth and creative self-transformation (Bell 2012; Cobb and Starr 2012). These normative narratives serve as mechanisms which describe acceptable responses for how cancer should be dealt with and embodied. Within this framework, cancer survivors are expected to desire growth and, as Bell (2012) notes, are often aware of the growing expectation that cancer should spark forms of self-development. Many of the participants' stories are reflective of Frank's (1995) quest narrative, in that experiences of cancer are often thought to be a positive motivator for personal change.

For Ava, her experience brought about a new found sense of reflexivity and a sense of peace for who she had become:

This experience has changed me in so many ways. I have more self-awareness, I ask myself a lot of questions about my actions and the ways that I think. Sometimes my behaviour is not always that different, sometimes it really is but it's the constant asking myself these 
questions which I don't think a lot of people do. I can't really sum it up more than selfawareness. My pursuit of living my truth is much stronger and my ability to defend what I want is stronger but in sort of telling people what I want to do with my life or what I am doing right now before I may not have told anybody because I didn't want them to judge it or I did something that would be more appealing in other people's eyes, like friends or family. If I did I needed people to understand and support it. I don't feel like that anymore. It's like cancer has given me this permission to do what I want so I really like that and I keep trying to channel that as much as I can. I am a much more empathetic person that's a big shift I would say. My degree of empathy has grown and I feel much more empathetic and willing to listen to many different sides of the scenario before making my judgements. But there are some ways that I have changed that I don't always like. Sometimes I feel a lot more uncertain about myself. I used to be a lot more outwardly self-confident and outgoing, I miss those characteristics. But the experience has changed me for good and bad.

Ava is extremely self-reflective and very much aware of both the positive and negative implications of this experience on her sense of self. Her narrative highlights the difficulty and tensions many young women experience when trying to reconcile who she was prior to cancer with who she is post-cancer. Although Ava's narrative is embedded in the dominant survivor discourse, she recognizes that not all the changes and improvements are for the better.

Like Ava, Mia believes that although cancer was the most difficult experience she has encountered and that it has possibly taken away her ability to conceive a child, she does not regret being diagnosed with this illness:

You know I'm going to be honest, cancer sucks, it really does, especially when you are so young and you have so much life still to live. I just think though everything happens for a reason and although I have lost a lot, a lot of opportunities have opened up for me after all of this happened. Cancer has given me drive, new interests, new goals. I'm doing my Masters in a field I wasn't interested in before so it definitely gave me a path to explore and I really love it. So really cancer has offered a lot of things to me even though it was really awful.

Here, Mia's excerpt highlights how she is able to find empathy for her situation and instead of dwelling on all the losses, she chooses to see the good in a bad circumstance. 
All of the participants touched upon how their experiences of cancer compelled them to re-evaluate their priorities and life goals. Many discussed a need for constant reflection. As Nadia said 'I often ask myself if I was diagnosed with cancer again tomorrow, would I be happy with what I am doing?' These types of questions reinforce notions of cancer being a gift and further promote the idea that one should learn something from this experience and become a better person. In addition, many also felt an urge to give back to the cancer community. Several of the participants felt that they had become more empathic and that they had a desire to help others that was much stronger than prior to their diagnosis.

When Audrey was diagnosed, she was overwhelmed by the amount of support that she received from family and friends. She described it as if she "had won the lottery and all these people had come out of the woodwork' just for her. Now that she is done treatment, she wants to help other young women who may not have the same time of support she received:

I feel responsible to give back because so many people helped me get through cancer and treatment that I want to pay that forward and because my support system is so strong and I know that not everyone has that so I want to be there for someone who doesn't have someone there for them.

What is interesting about Audrey's response is how she conceptualizes giving back as an individualized act that she feels compelled to do because she had so many people help her.

Similarly, Hannah too felt a need to help others and this stemmed from her not so great experience with the cancer system. Hannah had a very difficult time navigating cancer care and establishing an open and responsive form of communication with her 
doctors. In particular, she felt that the lack of communication affected her ability to take charge and make informed decisions that were best for her. Today, Hannah strongly believes in the need for patient advocacy and uses her time and efforts to help other patients:

I feel like I have something to give, I feel that I have a lot to offer and a lot of insight and we need to stick together because nobody else is going to tell you except another woman who has been through it. There is such a huge need for support and advocacy in the cancer community, at every level. I feel like it's something that you don't know until you know and in that sense, being in the know, I need to give what I can of my time and energy towards making someone else's cancer journey as supported as I can possibly offer. I know it makes a difference. It was people in the cancer community that really made a difference for me and still do every day, so I hope I can do the same for someone else.

Audrey's and Hannah's excerpts both demonstrate the very little faith cancer survivors have in the formal supports that are available to cancer patients and survivors. As such, both young women feel that they are best suited to help others and that they have a duty to give back.

From this discussion it is clear those normative perceptions which situate cancer as opportunities for personal growth are being taken up by many young female cancer survivors. While I do agree that it is often difficult not to be unaffected by a serious illness, what is particularly problematic about survivor discourse centered upon ideas of growth and transformation is that they prescribe normative guidelines for how illness should be taken on and embodied (Segal 2010, 2012). The dominant survivor discourse defines certain ways of being ill as better than others and silences those who do not internalize or take up these public values. Understood in this way, it seems that survivor discourse advances erroneous notions that survivors "possess the ability to choose happiness over unhappiness, success over failure and even health over illness" (Rimke 
2000: 73). This was reflective in many of the participants' experiences and informed the very ways they understood themselves post-cancer.

Judy Segal (2010, 2012), a breast cancer survivor, also suggests that survivor narratives in public spaces work to reinforce certain illness values. These values are reflective of broader social and political rationalities and in Western society emphasize virtues that are strongly aligned with the ideal neoliberal citizen (Rimke 2000). Survivor discourse, premised upon ideas of personal growth and self-transformation, discursively produces distinctly neoliberal subjectivities (Binkley 2011; Rimke 2000). Survivor narratives work on people in particular ways but ultimately encourage young female survivors to "be strong in the face of illness and fight, be positive and optimistic [and] in the end learn things about oneself" (Segal 2012: 311). Many of the participants in this study were influenced by these discourses and embodied many of these virtues. They were hesitant to talk about feelings of insecurity almost in fear that acknowledging such emotions would reflect negatively on their ability to care for their own welfare. Particularly by discouraging the expression of anything other than a positive outlook, survivor discourse limits the ways in which illness can be talked about and experienced. Young female survivors are not encouraged to talk about their fears or feelings of anger and despair. Rather, these women are expected to transcend negative feelings and emerge from their cancer experience as new and improved people (Bell 2012). 


\section{Conclusion}

In this chapter I have analyzed the pervasiveness of survivor discourse and the norm of survivorship as a neoliberal mode of governance. Survivor discourse presumes and seeks to produce autonomous self-regulation and self-governance in hopes of: maintaining one's health, and improving one's psychological and emotional self. In doing so, survivor discourses call upon survivors to engage in particular kinds of practices - practices of the self- through which young women mitigate potential lifestyle risks while constructing themselves as responsible citizens. I also explored how survivorship discourses discursively produce neoliberal subjectivities. I have argued that discourses of positivity and self-transformation are laced with neoliberal logics which aim to limit the ways cancer should be discussed and experienced, and produce morally responsible survivor/citizens. 


\section{Chapter 5: Concluding Thoughts}

\section{Introduction}

For the master's tools will never dismantle the master's house. They may allow us temporarily to beat him at his own game, but they will never enable us to bring about genuine change.

- (Audre Lorde, 1981)

The previous chapters have explored the effects of dominant cancer/survivor discourses on shaping young women's illness experiences. In doing so, I have attempted to show how issues of health are increasingly entangled with notions of exclusion and responsible citizenship and the ways such discourses work to construct particular kinds of survivor/citizens. This chapter will summarize some of these findings and the contributions of this study to the field of sociology. Further, I review the study's strengths and limitations and address potential directions for future research.

\section{Sociological Significance}

The results of this study indicate two key contributions to the field of sociology and specifically, health and citizenship studies. First, although this study is not statistically generalizable, the narratives of young women living beyond cancer are telling of particular relationships to social citizenship rights and access to material resources. In this study, illness narratives exposed boundaries of inclusion and exclusion between and amongst those diagnosed with different types of cancers, revealing structures of inequality and social exclusion. Second, this research adds to the growing 
body of literature that is concerned with the ways expressions of citizenship are being pushed into the body (Galvin 2002; Lupton 1995, 1999; Novas 2006; Oster and Cheek 2008; Petersen 1997, 2003; Petersen and Lupton 1996; Robertson 2000). The language of risk and responsibility are weaved throughout participant narratives, suggesting that experiences of illness - like cancer - are now opportunities to actively shape and produce model citizens (Rimke 2000). These contributions will be discussed in greater detail below.

First, this research supports Gray's (2010) compelling argument that a cancer hierarchy exists and that in advanced liberal democracies, the regulation of healthcare its distribution, allocation and access - is a matter of recasting citizenship (Isin 2008). As I argued in Chapter Three, this cancer hierarchy perpetuates the separation and social exclusion of particular groups - namely young women with less publicized cancers - and privileges the needs of those diagnosed with breast cancer, despite the fact that 'equal' social rights exist in legal doctrines, such as the Canada Health Act. In recent years a considerable effort by both public and private institutions, has focused on addressing the 'specific' and 'unique' needs of young, white, heterosexual breast cancer patients. The exclusive provisions provided to those with breast cancer are resulting in differentiated access to health care services and resources that are establishing and reinforcing boundaries of cancer-type-based inclusions and exclusions. Consequently, the existence of these boundaries and those who lie outside them reflects the reality that social citizenship entitlements are limited and in some cases unequally accessible (Isin 2008). 
In the contemporary era, the politics of disease and illness are increasingly entrenching boundaries between bodies deserving of care from those that are not. The stories of young women living beyond cancer are now revealing of who is socially and politically valued and included, from those who are marginalized and excluded (Redden 2002). These particular boundaries have real implications for young women diagnosed with less publicized cancers as many encounter a wide array of health care disparities compared to those diagnosed with breast cancer. While there are several areas in which disparities in access are particularly glaring, several of the women in this study noted that the lack of coordinated care between oncology and non-oncology services had the most severe impacts on their bodies, sense of self and relationships with their significant - or potentially significant - others. Several of the women diagnosed with less publicized cancers had extensive amounts of difficulty accessing reproductive and sexual health professionals, resources and services. The absence of communication and the lack of timely access in many instances impacted the women's ability to make favourable and informed choices about fertility preservation options, reproductive and sexual health.

In these instances and upon the completion of treatment, many of these young women also had to come to terms with their potential infertility in addition to the latent effects of treatment on their reproductive and sexual health. Scholars in the field suggest that complications associated with treatment can often be avoided and/or the degree of difficulties lessened, if these areas are discussed prior to the commencement of treatment (Ali and Warner 2012; Howell et al. 2011; MacDonald et al. 2012). While young women with less publicized cancers faced increased difficulties in regards to 
reproductive and sexual health, participants diagnosed with breast cancer did not encounter the same degree of tribulation. Those with breast cancer reported that fertility, reproduction, and sexual health were often discussed at the initial appointment with oncology professionals. From these discussions, it became clear that fertility and reproductive health were standardly addressed and that women were informed of their options and referred accordingly. In addition, women who are treated for breast cancer at the Ottawa Hospital are provided with a very detailed patient kit that provides those newly diagnosed with information in regards to the following: the disease, treatment and surgery options, guidance on what questions to ask and to whom, important state and community resources and most importantly has an entire section dedicated to fertility and reproduction (Personal Breast Cancer Information Guide 2011). ${ }^{19}$ Thus, it seems breast cancer patients are better informed and prepared for making decisions in regards to matters of fertility and reproductive health while also having better access to these services.

In Canada, universal access to comprehensive health care is considered a social right of citizenship (Marshall 1964; Redden 1999). However, in recent years Canadian governments have engaged in increased privatization and fiscal restraint which has resulted in the rationing of health care services (Redden 1999). This rationing of care requires governments to make value-laden decisions as to which services and resources will be de-listed, limited and/or funded by public health insurance (Charles et al. 1997;

\footnotetext{
${ }^{19}$ To view the complete package please see: http://www.ottawahospital.on.ca/wps/wcm/connect/51a4f3004b25b20b8f03df1faf30e8c1/Personal+Bre ast+Cancer+Information+Guide1.pdf?MOD=AJPERES accessed June 15, 2013.
} 
Redden 1999). These decisions can have drastic implications on many Canadians that require certain types of care. In the context of this study, participants have shed light on the subtle but very important differences in the types of resources and services that are available to patients diagnosed with certain types of cancers. Participants' narratives revealed what health care resources were offered, and what health care resources were available to them, and thus carried messages about notions of belonging and citizenship (Sinding 2010). In particular, it is clear that in this study young, white, heterosexual breast cancer patients have greater access to a continuum of health services in comparison to other young women diagnosed with less publicized cancers. The findings of this study do suggest that entitlements based on cancer type do exist.

Second, this study supports the growing literature documenting the ways health and illness are increasingly bound to notions of neoliberal citizenship. In this study, I demonstrate how dominant survivorship discourse acts as a neoliberal technique of governance in that it works to compel survivors to engage in active self-reflection and assume personal responsibility for the management of their health. In doing so, survivorship discourse establishes normative expectations and prescriptive guidelines for living post-cancer, thus defining the ethical and ideal survivor/citizen. Those who take up active self-care practices are increasingly viewed as responsible survivor/citizens who are using their power ethically to care for oneself and those whom they are responsible for. In this study, participants' narratives highlighted the ways they engaged with, negotiated and, in some instances, resisted normative survivorship discourse. Their narratives reveal the ways survivorship discourse permeates and informs many of 
their daily practices, routines, and knowledge about health and in doing so shapes their individual subjectivities.

For the majority of the participants in this study, survivorship discourse and more specifically discourses focused on health risks and personal development, were both enabling and constraining (Heyes 2007). In many instances, these processes were acted out through the body. Several of the young women noted that their experiences of cancer challenged them to take a much more pro-active role in the management of their health. For these particular participants, controlling and being more aware of lifestyle risk factors was a source of empowerment and enablement. However, at the same time, many of these women subjected themselves to forms of surveillance and made regulated choices that resulted in their own self-governance. The majority of the participants took up 'healthy lifestyles' in attempts to mitigate chances of relapse but also to negate negative perceptions that situate passivity and non-action as 'not trying hard enough' to stay alive. In this sense, survivorship narratives and the expectations of how one shall behave act as constraints that urge compliance to specific ways of being that may limit the ways survivors experience their own illness (Heyes 2007).

Most importantly, the findings of this study demonstrate the ways neoliberal notions of citizenship are saturating survivorship discourse, are informing individual subjectivities and are being taken up in individual bodies. These findings suggest that experiences of illness in our neoliberal times can no longer be understood as 'unfortunate circumstances'. Rather, instances of illness now serve as teachable moments to responsibilize and encourage individuals to become active in their own 
wellbeing. In many ways, this study highlights how neoliberal rationality permeates survivorship discourse and informs subject formation, thus drawing boundaries between 'good' cancer survivors/citizens who are worthy of empathy from those who are 'bad' and undeserving of further care. As such, the imperative of health is intimately linked to expressions of good citizenship which are increasingly found in individual illness narratives.

\section{Strengths and Limitations}

This study offers insight about the public function of cancer narratives and how they serve to describe normative expectations for how one shall be ill (Segal 2012). As such, this study is concerned with understanding how young women negotiate these dominant discourses and explores the ways they influence and shape individual experiences of cancer and life post-cancer. Although young women - between the ages of 20-44 - account for almost two-thirds of all young cancer diagnoses, they are often an understudied population (Canadian Cancer Society 2010). This study is unique in that it focuses solely on young female cancer survivors and enabled me to understand the ways in which widely circulating cancer and survivorship discourses impacted their behaviors and subjectivities post-cancer. The intent of this study was to only highlight the voices and experiences of a limited number of young female cancer survivors and as a result the findings of this study are not statistically generalizable. Nevertheless, the findings of this study do provide insight into cancer-type-based inequalities that currently exist in Ontario and illustrate the material implications they can have on the day-to-day lived experiences of young female cancer patients and survivors. 
One of the most significant strengths of this study was the support and positive connection that was established between myself and the participants. This study was reliant on young women sharing their stories and experiences of cancer. Many of these experiences were personal, difficult at times to share and for some a reminder of the trauma and loss that are often associated with this life event. Despite the tears, the 'what ifs' and the laughs, a majority of the women expressed a sense of comfort and positive feelings towards the entire interview process. From the outset my intention was to create a safe and relaxed environment in which participants would feel at ease and be open to sharing their intimate experiences, feelings and ultimately stories. In addition, many of the women also expressed gratitude towards the focus of studying young women's cancer experiences and many of the women thanked me for using my own experience as inspiration and a catalyst for further investigation. While my own experience has guided this project in many ways it ultimately would not have been possible without the support of the Ottawa cancer community and specifically the young women who so graciously participated in this research.

I choose to recruit participants by approaching local cancer support groups, personal acquaintances and Young Adult Cancer Canada. While this approach did prove to be successful in recruiting young female participants with a variety of cancers, I have to acknowledge that it was not effective in recruiting a diverse sample and this may influence my findings. Although I did not actively collective information on the participants' socio-cultural background, my sample of 17 participants was racially, ethnically and socially homogenous. The study population was limited to white, 
predominantly middle-class, well educated - all participants completed some form of post-secondary education, heterosexual and able-bodied young women.

As noted previously, young female cancer patients and survivors are an understudied population and while this study attempts to understand their experiences with the disease and widely circulating cancer discourses, it cannot speak to the ways in which race, ethnicity, ability, and sexuality affect young women's cancer experiences. Although the study diversified its population in relation to cancer-type diagnosis and included the experiences of several different types of cancers that commonly affect young women, it was unable to achieve diversity as it related to race, ethnicity, ability and sexuality. It is possible that a study with a more diversified sample could obtain different results. I recognize that intersections of identity and women of different backgrounds may have different values that can influence their experiences.

In addition, all of the participants - with the exception of one - lived and/or received treatment in Ottawa. A limitation of not expanding the recruitment area is the ability to capture the experiences of young women living with cancer in other geographical locations and spaces in Ontario. In recent years, Ottawa has transitioned into a hub for cancer research and treatment and not only serves those living in the Ottawa region but also those living in the Ottawa Valley and surrounding areas. Young women living in metropolitan cities tend to have greater resources at their disposal in part due to being located in a larger city. However, those who live in rural or smaller towns across Ontario do not necessarily have access to the same or similar resources which may impact their day-to-day experiences of cancer. This study was unable to 
explore how geographic location affects young women's material realties. While discussions of geographical location and space are important in unpacking the relationship between health disparities and material conditions, a focus on these discussions fell beyond the scope of this current project. Future studies need to expand their sample to ensure the inclusion of vulnerable populations in order to understand how intersections of identity and one's social and geographical location impact young women's experiences of cancer.

\section{Future Research Possibilities}

This study contributes to a better understanding of how dominant cancer/survivor discourses shape young female survivors' material realities and the ways they come to understand themselves post-cancer. I am confident that the results of this study can shed light on the current landscape of cancer care in Ontario, and hope that it may initiate new conversations directed towards improving cancer care and health equity. While this study is a step in the right direction, I am aware of the need for more empirical research and in-depth explorations of the discursive effects of widely circulating, cancer/survivor narratives. In particular, there is a need to further explore how these discourses impact the types of citizenship claims young women make in times of illness and how they understand and negotiate state boundaries of inclusion and exclusion. A project that includes a larger and more diverse group of young female cancer patients and survivors could allow researchers to investigate the impacts of the intersection of race, ethnicity, religion, socio-economic status, ability, sexuality and other structural factors on the types of social citizenship claims young women make. It 
would also be interesting to include young female cancer survivors from other provinces in an attempt to provide a greater understanding of the impacts dominant cancer/survivor discourses on supporting health as a personal responsibility and access to health as a right of citizenship for young women diagnosed with cancer. The possibilities for study are exciting, timely and important.

\section{Concluding Thoughts}

Reflecting upon the last year, I could not have imagined how much this research project could have benefited me. Yet, this project has been instrumental in my own healing process. I am truly grateful to all the young women who invited me to be part of their journeys, to listen to their stories and to also be trusted with their experiences. The conversations I had with these young women were moving, fascinating, full of variety and richness as each and every one of them positively influenced this project. This entire process at times has been difficult, challenging, positive, enlightening and therapeutic. Engaging with narrative analysis has taught me to listen more deeply, be more mindful of the language we use, recognize that nothing is absolute and that reality is subjective. Moreover, this project has taught me that at times it is "perfectly alright for our cultural identities and subjectivities to be contradictory, inconsistent and not perfectly in sync all the time" and that these imperfections shape our experiences and who we are (Abou-Rizk 2012: 208). Most importantly, this project has shed light on how I can use my personal experience to encourage social change. To think that this study has the potential to initiate change, improve the scope and access of cancer care or 
even improve the well-being of even one young woman, makes this entire endeavour worthwhile. 


\section{Bibliography}

Abel, Jackie., Locke, Abigale., Condor, Susan., Gibson, Stephen., \& Stevenson, Clifford. 2006. "Trying similarity, doing difference: The role of the interviewer, self-disclosure in interview talk with young people." Qualitative Research, 6(2):221-44.

Abou-Rizk, Ziena. 2012. Young Lebanese-Canadian Women's Discursive Constructions of Health, Obesity and the body. PH DDissertation, University of Ottawa Press: Ottawa.

Ali, Asma., and Warner, Ellen. 2012. "PYNK: Breast Cancer Program for Young Women". Current Oncology, 20(1):34-39.

Armstrong, Pat., and Armstrong, Hugh. 2010. Wasting away: The undermining of Canadian health care. Toronto: Oxford University Press.

Ashbury, Fredrikc., Findlay, Helen., Reynolds, Barbra., McKerralehen, Krista. 1998. "A Canadian survey of cancer patients' experiences: are their needs being met? ". Journal of Pain Symptom Manage, 6:298-306.

Aziz, Noreen. 2008. "Cancer Survivorship Research". Late Effects of Cancer Treatment on Normal Tissues, 109-130.

Bacchi, Carol. Lee., and Beasley, Chris. 2002. "Citizen Bodies: Is embodied citizenship a contradiction in terms?". Critical Social Policy, 22(2), 324-352.

Bal, Dileep. 2005. "Cancer and Social Justice". Cancer 104(s12):2891-94.

Bassett-Smith, J. 2001. Women with breast cancer and their living in and through discourses: a feminist post-modern study. Dissertation, University of Victoria, Canada.

Batt, Sharon. 1994. Patient no more: the politics of breast cancer. Spinifex Press.

Beaver, Kinta., Twomey, Mary., Witham, Gary., Foy, Sharon., Luker, Karen. 2006. "Meeting the information needs of women with breast cancer: piloting a nurse-led intervention". European Journal of Oncology Nursing, 10(5), 378-390.

Bell, Kirsten. 2010. "Cancer survivorship, mor(t)ality, and lifestyle discourses on cancer prevention". Sociology of Health and IIIness, 32(3):349-364.

Bell, Kirsten. 2012. "Remaking the Self: Trauma, Teachable Moments, and the Biopolitics of Cancer Survivorship". Culture, Medicine, and Psychiatry, 36(4), 584-600.

Bell, Kirsten., and Ristovski-Slijepcevic, Svetlana. 2013. "Cancer survivorship: Why labels matter". Journal of Clinical Oncology, 31(4), 409-411. 
Bezruchka, Stephen. 2010. "Epidemiological approaches to population health". In D. Raphael, T. Bryant and M. Rioux, editors. Staying Alive: Critical Perspectives on Health, Illness and Health Care. Toronto: Canadian Scholar's Press Inc.

Bickell, Nina. 2002."Race, ethnicity, and disparities in breast cancer: victories and challenges". Women's health issues: official publication of the Jacobs Institute of Women's Health, 12(5), 238.

Bickell, Nina., and Cohen, Alicia. 2008. "Understanding reasons for underuse: An approach to improve quality and reduce disparities in breast cancer treatment". Mount Sinai Journal of Medicine: A Journal of Translational and Personalized Medicine, 75(1), 23-30.

Binkley, Sam. 2011. "Happiness, positive psychology and the program of neoliberal governmentality". Subjectivity, 4(4), 371-394.

Blanchard, Christopher., Courneya, Kerry., Stein, Kevin. 2008. "Cancer survivors' adherence to lifestyle behavior recommendations and associations with health-related quality of life: Results from the American Cancer Society's SCS-II". Journal of Clinical Oncology, 26(13):2198-220.

Bloom, Leslie. 1996. "Stories of One's Own: Nonunitary Subjectivity in Narrative Representation". Qualitative Inquiry, 2(2):170-197.

Bottorff, Joan., Balneaves, Lynda., Sent, Lorna., Greal, Suki., and Browne, Annette. 2001. "Cervical Cancer Screening in Ethnocultural Groups: Case Studies in Women-Centered Care". Women \& Health 33:29-46.

Breast Cancer: unanswered questions. 1992. Report of the Standing Committee on Health and Welfare, Ottawa.

Brodie, Jane. 1997. "Meso-discourses, state forms and the gendering of liberal-democratic citizenship". Citizenship Studies, 1(2):223-41.

Broom, Alex. 2009. "Intuition, subjectivity, and le bricoleur: Cancer patients' accounts of negotiating a plurality of therapeutic options". Qualitative Health Research, 19(8): 1050-1059.

Brown, Lyn. and Gilligan, Carol. 1991. "Listening for voice in narratives of relationship". In Narrative and Storytelling: Implications for understanding moral development. New directions for child development, edited by M. Tappen \& M. Packer. San Francisco: Jossey-Bass.

Bryant, Toba., Raphael, Dennis., Schrecker, Ted., Labonte, Robert. 2011. "Canada: A land of missed opportunity for addressing the social determinants of health". Health Policy, 101(1):4458.

Bury, Mike. 2001. "Illness narratives: fact or fiction?". Sociology of Health \& IIIness, 23(3):263285.

Butler, Judith. 1993. Bodies that Matter: On the Discursive Limits of 'Sex'. New York: Rutledge. 
Canadian Cancer Society .2003. The needs of Ontario cancer patients: an assessment. Canadian Cancer Society, Toronto: Ontario.

Canadian Cancer Society. 2009. Canadian Cancer Statistics. Toronto: Ontario. Retrieved February 1,2013

(www.cancer.ca/ /media/cancer.ca/CW/cancer\%20information/cancer\%20101/Canadian\%20ca ncer\%20statistics/Canadian-Cancer-Statistics-2009-EN.pdf).

Canadian Cancer Society. 2010. Canadian Cancer Statistics. Toronto: Ontario. Retrieved February 1,2013

(http://www.cancer.ca/ /media/cancer.ca/CW/cancer\%20information/cancer\%20101/Canadia n\%20cancer\%20statistics/Canadian-Cancer-Statistics-2010-EN.pdf).

Cancer Care Ontario. Cancer Statistic. Toronto, Ontario. Retrieved February 1, 2013

(https://www.cancercare.on.ca/cms/One.aspx?portalld=1377\&pageld=8630).

Carr, Kris. Crazy, Sexy Cancer Survivor: More Rebellion and Fire for Your Healing Journey.

Castel, Robert. 1991. "From dangerousness to risk". In The Foucault Effect: Studies in

Governmentality edited by, G. Burchell, C. Gordon and P. Miller. London: Harvester Wheatsheaf.

CBC News. 2013. "Chest tattoo covers woman's scars from 3 bouts of cancer". CBC News, April 13. Retrieved June 20, 2013

(http://www.cbc.ca/news/canada/ottawa/story/2013/04/10/ottawa-woman-chesttattoo.html).

Charles, Cathy., Lomas, Jonathan., Bhatia, Mita., \& Vincent, Victoria. 1997. "Medical Necessity in Canadian health Policy: Four meanings and . . a funeral?" Milbank Quarterly 75(3):365-94.

Charmaz, Kathy. 1999. "Stories of suffering: Subjective tales and research narratives". Qualitative Health Research, 9(3):362-382.

Cheek, Julianne. 2000. Postmodern and poststructural approaches to nursing research. Thousand Oaks, CA: Sage.

Choudhry, Naithani., Srivastava, Mehra and Fitch, Margret. 1998. "Breast Cancer Detection Practices of South Asian Women: Knowledge, Attitudes, and Beliefs". Oncology Nursing Forum 25(10):1693-1701.

Cobb, Shelley and Starr, Susan. 2012. "Breast cancer, breast surgery and the makeover metaphor". Social Semiotics, 22(1):83-101.

Code, Lorraine . 1988. "Experience, Knowledge and Responsibility". In Feminist Perspectives in Philosophy, M. Griffiths and M.Whitford, editors. Indianapolis: Indiana University Press.

Code, Lorraine. 1991. What Can she Know? Feminist Theory and the Construction of Knowledge. Ithaca, N.Y.: Cornell University Press. 
Code, Lorraine. 1995. "How do We Know? Questions of Method in Feminist Practice". In Changing Methods: Feminist Transforming Practice, S.Burt and L. Code, editors. Peterborough, Ontario: Broadview Press.

Commission on the Future of Health Care in Canada, \& Romanow, R. J. (2002). Shape the future of health care: Interim report. Commission on the Future of Health Care in Canada.

Coulter, Kendra. 2009. "Deep neoliberal integration: The production of third way politics in Ontario". Studies in Political Economy, 83.

Crawford, Robert. 1980. "Healthism and the medicalization of everyday life". International journal of health services, 10(3):365-388.

Crompvoets, Samantha . 2006. Breast Cancer and the Post-Surgical Body. New York: Palgrave MacMillan.

Daugherty, Amber. 2013. "Why young adults with cancer have distinct needs". The Globe and Mail, July 11. Retrieved July 16, 2013 (http://www.theglobeandmail.com/life/health-andfitness/health/young-adults-with-cancer-have-distinct-needs/article13124538).

Dean, Mitchell. 1997. "Sociology after society". In Sociology after postmodernism, D. Owen, editor. Thousand Oaks, Calif.: Sage.

Demark-Wahnefried, Wendy., Aziz, Noreen., Rowland, Julia., Pinto, Bernardine. 2005. "Riding the crest of the teachable moment: Promoting long-term health after the diagnosis of cancer". Journal of Clinical Oncology, 23(24):5814-5830.

Denzin, Norman. , and Lincoln, Yvonna. 2005. The Sage handbook of qualitative research. Thousand Oaks: Sage Publications.

Doll, R., Kazanjian, A., Smillie, K., Ward, A., \& Chasen, M. 2012. "A call for action in survivorship research and care". Current Oncology, 19(1) 16.

Doll, R., Stephen, J., Barroetavena, MC., Linden, W., Poole, G., Ng, E., Fyles, G., Habra, M. 2003. "Patient navigation in cancer care: program delivery and research in British Columbia". Can Oncol Nurs J 13(3):193.

Donnelly, Tam. 2008. "Challenges in Providing Breast and Cervical Cancer Screening Services to Vietnamese Canadian Women: The Healthcare Providers' Perspective". Nursing Inquiry 15, no. 2:158-168.

Doucet, Andrea., and Mauthner, Natasha. 1998. 'Voice, Reflexivity, and Relationships in Qualitative Data Analysis'. Annual Conference on Interdisciplinary Qualitative Studies: 1998 Conference Proceedings. Atlanta, Georgia: QUIG, University of Georgia

Doucet, Andrea., and Mauthner, Natasha. 2002. "Knowing responsibly: Ethics, Feminist Epistemologies and Methodologies". In_Ethics in Qualitative Research, N. Mauthner, M. Birch, J. Jessop and T. Miller, editors. London: Sage Publications. 
Doucet, Andrea., and Mauthner, Natasha. 2008. "What can be known and how? Narrated subjects and the listening guide". Qualitative Research, 8:399.

Ehlers, Nadine. 2012. "Tekhne of reconstruction: breast cancer, norms and fleshy rearrangements". Social Semiotics, 22(1):121-141.

Ellis, Carolyn. 2004. The Ethnographic I: A Methodological Novel about Autonethnography. New York: Altamira.

Ehrenreich, Barbra. 2001. Welcome to Cancerland. Harper's Magazine, November: 43-53.

Ehrenreich, Barbra. 2009. Bright Sided: How the Relentless Promotion of Positive Thinking Has Undermined America. New York: Metropolitan Books.

Fafard, Patrick., Rocher, Francois., Côté, Catherine. 2009. "Clients, citizens and federalism: A critical appraisal of integrated service delivery in Canada". Canadian Public Administration, 52(4): 549-568.

Feldberg, Georgina., and Carlsson, Marinne. 1999. “Organized for Health: Women's Activism in Canada and Sweden". In Women's Organizing \& Public Policy in Canada \& Sweden, L. Briskin, and M. Eliasson, editors. Montreal: McGill-Queen's University Press.

Fillion L, de Serres M, Lapointe-Goupil R et al. 2006. Implementing the role of patient-navigator nurse at a university hospital centre. Can Oncol Nurs J, 16(1):11-7.

Finlay, Linda. 2002. "Outing the Researcher: Provenance, Process and Practice of reflexivity". Qualitative Health Research, (12):531-45.

Fischer, Bendikt., Turnbull, Ssarah., Poland, Blake., Haydon, Emma. 2004. "Drug use, risk and urban order: examining supervised injection sites (SISs) as "governmentality"." International Journal of Drug Policy, 15(5): 357-365.

Fitch, Margret. 2003. "Supportive care: rebalancing efforts". In Strengthening the quality of cancer services in Ontario, T. Sullivan, W. Evans, H. Angus, A. Hudson, editors. Cancer Care Ontario, Toronto Ontario.

Flyvbjerg, Brent. 2005. "Social science that matters". Foresight Europe, 2(38):42.

Foucault, Michel. 1972. The archaeology of knowledge and the discourse on language. New York: Tavistock Publications and Harper Colophon.

Foucault, Michel. 1978. The birth of biopolitics : lectures at the Collège de France, 1978-79. M. Senellart, editor. New York: Palgrave MacMillan.

Foucault, Michel. 1979. Discipline and punish: The birth of the prison. New York: Vintage Books. 
Foucault, Michel 1980: Power/Knowledge: Selected Interviews and Other Writings 1972-1977. C. Gordon, editor. Brighton: Harvester.

Foucault, Michel. 1988. "Technologies of the self. In Technologies of the self: A seminar with Michel Foucault". L.H. Martin, H. Gutman and P.H. Hutton, editors. Amherst, MI: University of Massachusetts Press.

Foucault, Michel. 1990. History of Sexuality, Vol.I: An Introduction. New York: Vintage.

Foucault, Michel. 1991, "Governmentality". In The Foucault Effect, G. Burchell, C. Gordon and P. Miller, editors. Chicago: University of Chicago Press.

Frank, Arthur. 1991. At the Will of the Body: Reflections on Illness. New York: Houghton Mifflin Company.

Frank, Arthur. 1994. "Reclaiming an orphan genre: the first-person narrative of illness". Literature and Medicine, 13(1): 1-21.

Frank, Arthur. 1995. The Wounded Storyteller: Body, Illness and Ethics. University of Chicago Press.

Frank, Arthur. 2002. "Why Study People's Stories? The Dialogical Ethics of Narrative Analysis" International Journal of Qualitative Methods, 1(1):109-17.

Frank, Arthur. 2005. "What is Dialogical Research, and Why Should We Do It?". Qualitative Health Research, (15):964-73.

Frank, Arthur. 2010. Letting stories breathe: A socio-narratology. University of Chicago Press.

Fullagar, Simon. 2002. "Governing the Healthy Body of Leisure and Lifestyle Within Australian Health Policy". Health 6(1)69-84.

Galvin, Rose. 2002. "Disturbing notions of chronic illness and individual responsibility: Towards a genealogy of morals". Health, 6(2):107-137.

Ganz, Patricia. 2005. "A teachable moment for oncologists: Cancer survivors, 10 million strong and growing!" Journal of Clinical Oncology, 23(4):5458-5460.

Garland, Sheila., Carlson, Linda., Cook, Sarah., Lansdell, Laura., Speca, Michael. 2007. "A nonrandomized comparison of mindfulness-based stress reduction and healing arts programs for facilitating post-traumatic growth and spirituality in cancer outpatients". Supportive Care in Cancer, 15:949-961.

Garland-Thomson, Rosemarie. 2009. Starring: How we look. Oxford University Press.

Gastaldo, Deborah. 1997. "Is health education good for you? Rethinking health education through the concept of bio-power" In Foucault, Health and Medicine, A. Petersen, R. Bunton, editors. London: Rutledge. 
Gazso, Amber . 2009. "Gendering the 'responsible risk taker': citizenship relationships with gender-neutral social assistance policy". Citizenship Studies, 13(1):45-63.

Gazso, Amber., and McDaniel, Susan. 2010. "The risks of being a lone mother on income support in Canada and the USA". International Journal of Sociology and Social Policy, 30(7/8): 368-386.

Gelmon, K., Partridge, AH., Morrow, M., Davidson, NE. 2005. "Breast cancer in young women: epidemiology, treatment, and survivorship issues". American Society of Clinical Oncology, Educational Book. pp. 61-7.

George, Tammy., and Rail, Genevieve. 2005. "Barbie meets the bindi: constructions of health among young South-Asian Canadian women". Women's Health \& Urban Life, 4(2):44-66.

Giddens, Anthony. 1991. Modernity and self-identity: Self and society in the late modern age. Stanford: University Press.

Gilligan, Carol., Spencer, Renne., Weinberg, Katherine., and Bertsch, Tatina. 2006. "On the Listening Guide". In Emergent methods in social research, S.N. Hesse-Biber and P.L. Leavy, editors. Thousand Oaks, CA: Sage Publications.

Glucksmann, Miriam. 1994. "The work of knowledge and the knowledge of women's work". In Researching Women's Lives from a Feminist Perspective, M. Maynard and J. Purvis, editors. London: Taylor and Francis.

Goldfarb, S. B., Dickler, M. N., McCabe, M. S., Thom, B., Jia, X., Hudis, C., Kelvin, J. 2010."Oncology physicians' knowledge, attitudes, and practices regarding fertility preservation". In J Clin Oncol. 28(15).

Gould, Judy. 2004. "Lower-Income Women with Breast Cancer: Interacting with Cancer Treatment \& Income Security Systems”. Women's Health and Well-Being, 24(1):31-6.

Gould, Judy., Grassau, Pamela., Manthorne, Jackie., Gray, Ross., Fitch, Margret. 2006. "Nothing fit me": nationwide consultations with young women with breast cancer". Health Expectations,(9):158-73.

Gould, Judy., Sinding, Chris., Mitchell, Terry., Gustafson, Diana., Peng, Ito., McGillicuddy, Patti., Fitch, Margret ., Aronson, Jane., Burhansstipanov, Linda. 2009. "Below Their Notice": Exploring Women's Subjective Experiences of Cancer System Exclusion”. Journal of Cancer Education, 24:308-14.

Gray, Lyndsay. 2010. The Cancer Hierarchy: Risk, Responsibilization and Morality. MA Thesis, Carleton University: Ottawa.

Greco, Monica. 1993. "Psychosomatic subjects and the 'duty to be well': Personal agency within medical Rationality". Economy and Society, 22(3): 357-371. 
Green, Esther., Gorman, Eunice., Bartlett, Karen., Brooks, Laura., Struthers, Cynthia. 2005. Canada: An External Quality Review Process-The Wellspring Model. Journal for Healthcare Quality, 27(3), 15-21.

Grills, S. 1998. Doing Ethnographic Research: Fieldwork Setting. London: Sage.

Giuliano, A., Papenfuss, M., de Guernsey, D. Z. J., Tilousi, S., \& Nuvayestewa, L. 1998. "Breast cancer screening among southwest American Indian women living on-reservation". Preventive Medicine, 27(1), 135-143.

Hack, Thomas., Degner, Lesley., Parker, Patricia. 2005. "The communication goals and needs of cancer patients: a review". Psycho-Oncology, 14(10): $831-834$.

Haines, Rebecca. , Bottorff, Joan., McKeown, Stephanie., Ptolemy, Erin., Carey, Joanne., and Sullivan, Kelli. 2010. "Breast cancer messaging for younger women: Gender, femininity, and risk". Qualitative health research, 20(6):731-742.

Hall, Lorraine. 1997. "Re-Figuring Marked Bodies on the Borders: Breast Cancer and "Femininity". International Journal of Sexuality and Gender Studies, 2(2): 101-121.

Hall, Stuart. 1997. Representation: Cultural representations and signifying practices. London: Sage.

Hammersley, Martin., and Atkinson, Paul. 1983. Ethnography: Principles in Practice. London: Tavistock.

Henderson, Lesley., and Kitzinger, Jenny. 1999. "The human drama of genetics: 'hard' and 'soft' media representations of inherited breast cancer". Sociology of Health \& IIIness, 21(5):560-578.

Henman, Paul. 2004. "Targeted! Population segmentation, electronic surveillance and governing the unemployed in Australia". International sociology, 19(2):173-191.

Hesse-Biber, Sharlene. 2007. "The practice of feminist in-depth interviewing". In Feminist Research Practice, S.N. Hesse-Biber and P.L. Leavy, editors. Thousand Oaks, CA: Sage Publications.

Heyes, Cressida. 2007. "Cosmetic surgery and the televisual makeover: A Foucauldian feminist reading". Feminist Media Studies, 7(1):17-32.

Hewitt, Maria., Greenfield, Sheldon., Stovall, Ellen. 2006. From cancer patient to cancer survivor: lost in transition. National Academy Press.

Howard, Cosmo. 2007. "Introducing individualization". In Contesting Individualization: Debates about Contemporary Personhooh, C. Howard, editor. New York: Palgrave MacMillan. 
Howell, D., Hack, T. F., Oliver, T. K., Chulak, T., Mayo, S., Aubin, M., Sinclair, S. 2011. "Survivorship services for adult cancer populations: a pan-Canadian guideline". Current Oncology, 18(6), e265.

Howson, Andrea . 1999. "Cervical Screening, compliance and moral obligation". Sociology of Health and IIIness, 21(4):401-25.

Ilcan, Suzan. 2009. "Privatizing responsibility: Public sector reform under neoliberal Government". The Canadian Review of Sociology and Anthropology, 46(3): 207234.

Irwin, Melinda. 2008. "Influence of pre- and post-diagnosis physical activity on survival in breast cancer survivors: the Health, Eating, Activity, and Lifestyle (HEAL) study". Journal of Clinical Oncology, 26: 1-7.

Isin, Engin Fahri. 2008. Recasting the social in citizenship. Toronto: University of Toronto Press.

James, Paul., Wilkins, Russell., Detsky, Allan, Tugwell, Peter., Manuel, Doug. 2007. "Avoidable mortality by neighbourhood income in Canada: 25 years after the establishment of universal health insurance". Journal of Epidemiology and Community Health, 61(4): 287-296.

Johansen, Venke., Andrews, Therese., Haukanes, Haldis., and Lilleaas, Ulla-Britt. 2013. "Symbols and Meanings in Breast Cancer Awareness Campaigns". NORA-Nordic Journal of Feminist and Gender Research, 21(2): 140-155.

Josselson, Ruthellen., and Lieblich, Amina. 1995. Interpreting experience. Sage Publications.

Jones, Merdith. 2008. "Makeover Culture's Dark Side: Breasts, Death and Lolo Ferrari". Body and Society, 14(1):89.

Kaiser, Karen. 2008. "The meaning of the survivor identity for women with breast cancer". Social Science and Medicine, 67:79-87.

Kelly, Christine. 2012. Re/Moving Care: Making care accessible through the Ontario Direct Funding Program. PHD Dissertation. Carleton University: Ottawa.

Kendrick, Karen. 2008. "Normalizing Female Cancer Patients: Look Good, Feel Better and other Image Programs". Disability and Society, 23(3):259-69.

King, Samantha. 2004. "Pink Ribbons Inc: breast cancer activism and the politics of philanthropy". International Journal of Qualitative Studies in Education, 17(4):473-492.

King, Samantha. 2006. Pink Ribbons Inc. Breast Cancer and the politics of philanthropy. Minneapolis: University of Minnesota Press.

Kitzinger, Jenny. 1999. "Researching risk and the media". Health, Risk \& Society, 1(1):55-69. 
Khan. NF., Harrison, S., Rose, PW. 2012. "Interpretation and acceptance of the term 'cancer survivor': A United Kingdom-based qualitative study". European Journal of Cancer Care 21:177186.

Klawiter, Maren. 2005. "Breast cancer in two regimes: the impact of social movements on illness experience". Sociology of health \& illness, 26(6):845-874.

Kleinman, Arthur. 1988. The illness narratives: Suffering, healing and the human condition. PP unknown: Basic Books.

Kvale, Steinar. 2006. "Dominance through interviews and dialogues". Qualitative inquiry, 12(3):480-500.

Langellier, Kristen., and Sullivan, Clair. 1998. "Breast talk in breast cancer narratives". Qualitative Health Research, 8(1):76-94.

Larner, Wendy. 2000. "Neo-liberalism: Policy, ideology, governmentality". Studies in political economy, 63.

Lee, Stephanie., Schorer, Leslie., Partiridge, Ann., Patrizio, Pasquale., Wallace, Hamish., Hagerty, Karen., Beck, Lindsay., Brennan, Lawerence., and Oktay, Kutluk. 2006. "American Society of Clinical Oncology recommendations on fertility preservation in cancer patients". Journal of Clinical Oncology, 24(18):2917-31.

Lemke, Thomas. 2001. "The birth of bio-politics: Michel Foucault's Lecture at the College de France on Neo-liberal Governmentality." Economy and Society 30(2):190-207.

Li, Peter. 1999. Race and ethnic relations in Canada. Toronto: Oxford University Press.

Lightman, Ernie., Vick, Andrea., and Herd, Dean. 2009. "Not Disabled Enough: Episodic Disabilities and the Ontario Disability Support Program". Disability Studies Quarterly, 29(3).

Little, Miles., Paul, Kim., Jordan, Christopher., Sayers, Emma-Jane. 2002. "Survivorship and discourses of identity". Psycho-Oncology, 11:170-178.

Lorde, Audre. 1980. The cancer journals. San Francisco: Aunt Lute Books.

Lupton, Deborah. 1994. Medicine as Culture: Illness, Disease and Body in Western Societies. London: Sage.

Lupton, Deborah . 1995. The imperative of health: Public health and the regulated body. London: Sage.

Lupton, Deborah. 1999. Risk and sociocultural theory. Risk and sociocultural theory-New directions and perspectives, 1-11. 
Macdonald, Doune., and Wright, Jan. 2010. "Anxieties and aspirations: The making of active, informed citizens". In Young people, physical activity and the everyday. London and New York: Rutledge.

Macdonald, G. T., Baldassarre, F., Brown, P., Hatton-Bauer, J., Li, M., Green, E., \& Lebel, S. 2012. "Psychosocial care for cancer: a framework to guide practice, and actionable recommendations for Ontario". Current Oncology, 19(4): 209.

Marrett, Loraine., and Chaudhry, Munaza. 2003."Cancer incidence and mortality in Ontario First Nations, 1968-1991 (Canada)". Cancer Causes \& Control, 14(3):259-268.

Marshall, T. H. 1964. Class, citizenship and social development. New York.

Mauthner, Natasha., and Doucet, Andrea. 2003 "Reflexive accounts and accounts of reflexivity in qualitative data analysis". Sociology, 37(3): 413-431.

Maykut, Pamela., and Morehouse, Richard. 1994. Beginning Qualitative Research. Pennsylvania: The Falmer Press.

McBride, C., Emmons, K., Lipkus, I. 2003. "Understanding the potential of teachable moments: the case of smoking cessation". Health Education Research, 18(2):156-170.

McClean, Stuart. 2005. "The illness is part of the person': discourses of blame, individual responsibility and individuation at a centre for spiritual healing in the North of England". Sociology of health \& illness, 27(5): 628-648.

McDonald, James., and Kennedy, Steven. 2007. "Cervical Cancer Screening by Immigrant and Minority Women in Canada". Journal of Immigrant Minority Health 9:323-334.

McGrath, C.K., Jordens, K., Montgomery , I.H. Kerridge, H. 2006. "Right" Way to "Do" Illness? Thinking Critically About Positive Thinking'. Internal Medicine Journal 36: 665-8.

Meirow, D., and Nugent, D. 2001. "The effects of radiotherapy and chemotherapy on female reproduction". Human Reproduction Update, 7(6):535-43.

Miedema, B., Easley, J., \& Robinson, L. M. 2013. "Do current cancer follow-up care practices meet the needs of young adult cancer survivors in Canada? A qualitative inquiry". Current Oncology, 20(1):14.

Miller, Peter. and Rose, Nikolas. 1994. "On therapeutic authority: psychoanalytical expertise under advanced liberalism." History of the Human Sciences, 7(3):29-64.

Miller, Peter., and Rose, Nikolas. 2008. Governing the present: Administering economic, social and personal life. Cambridge: Polity Press.

Millsted, Rachel., and Frith, Hannah. 2003. "Being large-breasted: Women negotiating embodiment". Women's Studies International Forum 26( 5):455-65.. 
Mullan, Fitzhugh. 1985. Seasons of survival: Reflections of a physician with cancer". New England Journal of Medicine, 313:270-273.

Nelkin, Dorothy. 1996. "An uneasy relationship: the tensions between medicine and the Media". Lancet, 347:1600-3.

Nelson, Jennifer., Gould, Judy., and Keller-Olaman, Sue. 2009. Cancer on the Margins. Toronto: University of Toronto Press.

Nettleton, Sarah. 1991. "Wisdom, diligence and teeth: discursive practices and the creation of mothers". Sociology of Health and IIIness, 13(1): 98-111.

Nettleton, Sarah. 1994. Disciplinary power and dentistry. In Reassessing Foucault: Power, Medicine and the Body, C. Jones, and R. Porter, R., editors. London: Rutledge.

Nettleton, Sarah . 1997. "Governing the risky self". In Foucault, health and medicine, A. Petersen and R. Burton, editors. New York: Rutledge. .

Novas, Carlos. 2006. "The political economy of hope: patients' organizations, science and biovalue". BioSocieties, 1(3):289.

O'Malley, Pat. 2000. "Uncertain subjects: risks, liberalism and contract". Economy and society, 29(4):460-484.

Orgad, Susan. 2009. "The survivor in contemporary culture and public discourse: A genealogy". The Communication Review, 12(2): 132-161.

Oster, Candace., and Cheek, Julianne. 2008. "Governing the contagious body: genital herpes, contagion and technologies of the self". Health, 12(2):215-232.

Parboosingh, Jane., Stachenko, Sylvie., and Inhaber, Suzanne. 1997. "A model of consumer participation: the Canadian Breast Cancer Initiative". Canadian Public Policy, 177-186.

Parsons, Renee. 2005. Institutionalized Racism and Classism: A Meta-analysis of Canadian and American Studies of Breast Cancer Care. MA Thesis, Windsor, ON: University of Windsor.

Partridge, Ann., Ruddy, Kathry., Kennedy, Jamie., Winer, Eric. 2012. "Model program to improve care for a unique cancer population: young women with breast cancer." Journal of Oncology Practice, 8(5):105-110.

Patton, Michael. 1990. Qualitative Evaluation and Research Methods. London: Sage.

Pearcy, Jeffrey., and Keppel, Kenneth. 2 002. "A summary measure of health disparity". Public Health Reports, 17:273-80. 
Personal Breast Cancer Information Guide. 2013. Retrieved July 13, 2013

(www.ottawahospital.on.ca/wps/wcm/connect/51a4f3004b25b20b8f03df1faf30e8c1/Personal+ Breast+Cancer+Information+Guide1.pdf?MOD=AJPERES).

Peters, Peter. 1995. "The interaction of journalists and scientific experts". Media, Culture and Society, 17: 1-48.

Petersen, Alan. 1996. "Risk and the regulated self: the discourse of health promotion as politics of uncertainty". Journal of sociology, 32(1):44-57.

Petersen, Alan. 1997. "Risk, governance and the new public health". In Foucault, health and medicine, A. Petersen and R. Burton, editors. New York: Rutledge.

Petersen, Alan. 2003. "Governmentality, critical scholarship, and the medical humanities". Journal of Medical Humanities, 24(3-4):187-201.

Petersen, Allan., and Lupton, Deborah . 1996. The new public health: Health and self in the age of risk. Sydney: Allen \& Unwin.

Polzer, Jessica., Mercer, Shawna., Goel, Vivek. 2002. "Blood is thicker than water: genetic testing as citizenship through familial obligation and the management of risk". Critical public health, 12(2):153-168.

Psooy, Brian., Schreuer, Dianna., Borgaonkar, Joy., Caines, Judy. 2004. "Patient navigation: improving timeliness in the diagnosis of breast abnormalities". Canadian Association of Radiology Journal, 55(3):145-150.

Quinn, Gwendolyn., Vadaparampil, Susan., Lee, Ji., Jacobsen, Paul., Bepler, Gerold., Lancaster, Jonathan., Albrecht, David. 2009." Physician referral for fertility preservation in oncology patients: a national study of practice behaviors". Journal of Clinical Oncology, 27(35): 5952-5957.

Raphael, Dennis . 2009."Escaping from the Phantom Zone: social determinants of health, public health units and public policy in Canada". Health Promotion International, 24(2): 193-198.

Rapley, Timothy. 2001. "The art (fulness) of open-ended interviewing: some considerations on analysing interviews". Qualitative Research, 1(3): 303-323.

Redden, Candace. 1999. "Rationing care in the community: engaging citizens in health care decision making". Journal of health politics, policy and law, 24(6):1363-1389.

Redden, Candace. 2002. "Health as Citizenship Narrative". Canadian Journal of Political Science, 35(1):103-125.

Riessman, Cathey. 1993. Narrative analysis (Vol. 30). Sage Publications, Incorporated.

Rimke, Heidi. 2000. "Governing citizens through self-help literature". Cultural studies, 14(1):6178. 
Ristovski-Slijepcevic, Svetlana. 2008. Environmental scan of cancer survivorship in Canada: conceptualization, practice and research. Vancouver, BC: Canadian Partnership Against Cancer.

Ristovski-Slijepcevic, Svetlana, Gwen E. Chapman, and Brenda L. Beagan. 2010. "Being a 'good mother': Dietary governmentality in the family food practices of three ethno-cultural groups in Canada." Health, 14(5): 467-483.

Rose, Nikolas. 1990. Governing the soul: The shaping of the private self. Taylor \& Frances:

Rutledge.

Rose, Nikolas. 1993. Inventing Ourselves: Psychology, Power and Personhood. New York: Cambridge University Press.

Rose, Nikolas. 1996. "Governing "advanced" liberal democracies". In Foucault and Political Reason: Liberalism, Neo-liberalism and Rationalities of Government, A. Barry, T. Osborne, and N. Rose, editors. Chicago: University of Chicago.

Rose, Nikolas. 1999. Powers of Freedom. Cambridge: Cambridge University Press.

Rowland, Julia., Hewitt, Maria., and Ganz, Patrica. 2006. "Cancer survivorship: A new challenge in delivering quality cancer care". Journal of Clinical Oncology, 24:5101-5104.

Rutledge, Robert., and Robinson, Lloyd. 2009. "Community-based organizations are critical partners in providing complete cancer care". Current Oncology, 16(2): 29.

Sakalys, Jurate. 2003. "Restoring the Patient's Voice the Therapeutics of Illness Narratives". Journal of holistic nursing, 21(3):228-241.

Sandelowski, Margarete. 1995. "Sample Size in Qualitative Research". Research in Nursing and Health, 18:179-83.

Scar Project: breast cancer is not a pink ribbon. 2013. Retrieved April 16, 2013 (www.thescarproject.org).

Schulzke, Marcus. 2011. "Hidden Bodies \& the Representation of Breast Cancer". Women's Health \& Urban Life, 10(2):37-55.

Seale, Clive. 2002. "Cancer heroics: a study of news reports with particular reference to gender". Sociology, 36(1):107-126.

Seear, Kate. 2009. "Nobody really knows what it is or how to treat it': Why women with endometriosis do not comply with healthcare advice". Health, risk \& society, 11(4):367-385.

Segal, Judy. Z. 2007. "Breast Cancer Narratives as Public Rhetoric: Genre Itself and the Maintenance of Ignorance". Linguistics and the Human Sciences, 3(1):3-23. 
Segal, Judy. 2010. Cancer isn't the Best Thing that Ever Happened to Me. Vancouver Sun 1 April: A15. Electronic document, http://rethinkbreastcancer.com/newsletter-articles/cancer-isnt-thebest-thing-that-ever-happened-to-me/, accessed June 8, 2013.

Segal, Judy . 2012. "Cancer Experience and its Narration: An Accidental Study". Literature and Medicine, 30(2): 292-318.

Siltanen, Janet., Willis, Alette., and Scobie, Willow. 2008. "Separately together: Working reflexively as a team". International Journal of Social Research Methodology, 11(1): 45-61.

Sinding, Christina., and Gray, Ross. 2005. "Active aging- spunky survivorship? Discourses and experiences of the years beyond breast cancer". Journal of Aging Studies. 19:147-61.

Sinding, Christina. 2010. "Using institutional ethnography to understand the production of health care disparities". Qualitative Health Research, 20(12):1656-1663.

Sinding, Christina., Miller, Patricia., Hudak, Pamela., Keller-Olaman, Sue., Sussman, Jonathan. 2012. "Of time and troubles: Patient involvement and the production of health care disparities". Health, 16(4):400-417.

Sointu, Eeva. 2006. "The search for wellbeing in alternative and complementary health practices". Sociology of health \& illness, 28(3):330-349.

Sointu, Eeva. 2011. "Detraditionalisation, gender and alternative and complementary medicines". Sociology of health \& illness, 33(3): 356-371.

Sontag, Susan. 1979. Illness as Metaphor. 1977. New York: Vintage.

Stacey, Jackie. 1997. Teratologies: A cultural study of cancer. Rutledge.

Strauss, Anselm., and Corbin, Juliet. 1998. Basics of Qualitative Research: Techniques and Procedures for Developing Grounded Theory. $2^{\text {nd }}$ Ed. Thousand Oaks: Sage Publications.

Sweeny, Ellen. 2012. "Tracing the Role of Gender in the History of Breast Cancer Social Movements". Women's Health and Urban Life, 11(1):76-93.

Thomas-MacLean, Rose. 2004. "Understanding breast cancer stories via Frank's narrative types". Social Science \& Medicine, 58(9):1647-1657.

Thompson, Kate., Palmer, Susan., Dyson, Gavin. 2009. "Adolescents and young adults: issues in transition from active therapy into follow-up care". European Journal of Oncology ogy Nurse, 13:207-12.

Tritter, Jonathan., and Calnan, Michael. 2002. "Cancer as a chronic illness? Reconsidering categorization and exploring experience". European Journal of Cancer Care 11: 161-165.

Twine, France Winddance., and Warren, Jonathan. 2000. Racing Research, Researching Race: Methodological Diliemmas in Critical Race Studies. NYU Press. 
Twombly, Renne. 2004. "What's in a name: who is a cancer survivor?". Journal of the National Cancer Institute, 96(19):1414-1415.

Townson, Monica. 2000. A report card on women and poverty. Canadian Centre for Policy Alternatives.

Ucok, Ozum. 2005. "The meaning of appearance in surviving breast cancer". Human Studies, 28(3):291-316.

Ucok, Ozum. 2007. "The fashioned survivor: institutionalized representations of women with breast cancer". Communication and Medicine, 4(1):67-78.

Young, Iris, Marion. 2005. Throwing like a girl and other essays. New York: Oxford University Press.

Waldram, J.ames. 2006. Aboriginal health in Canada: Historical, cultural, and epidemiological perspectives. Toronto: University of Toronto Press.

Waller, Margret., and Batt, Sharon. 1995. "Advocacy groups for breast cancer patients". CMAJ: Canadian Medical Association Journal, 152(6):829.

Waskul, Dennis. and van der Riet, Pamela. 2002. "The Abject Embodiment of Cancer Patients: Dignity, Selfhood and the Grotesque Body. Symbolic Interaction, 25(4):487-513.

Wasserfall, Rahel. 1993. "Reflexivity, feminism and difference". Qualitative Sociology, 16(1):2341.

Weedon, Chris. 1997. Feminist practice and poststructuralist theory. Oxford: Blackwell

Wendell, Susan. 2001. "Unhealthy Disabled: Treating Chronic Illnesses as Disabilities". Hypatia 16(4):17-33.

Zebrack, Brad., Mills, Jennifer., Weitzman, Tammy. 2000. "Health and supportive care needs of young adult cancer patients and survivors". J Cancer Survivor, 1:137-45.

Zebrack, Brad. 2009. "Information and service needs for young adult cancer survivors". Supportive care in cancer, 17(4):349-357. 


\section{Appendix A: Participant Demographic}

\begin{tabular}{|c|c|c|c|c|c|c|c|}
\hline Pseudonym & $\begin{array}{c}\text { Age } \\
\text { Range of } \\
\text { Initial } \\
\text { Diagnosi } \\
\text { S }\end{array}$ & Children & $\begin{array}{c}\text { Education } \\
\text { Level }\end{array}$ & $\begin{array}{l}\text { Employed/ } \\
\text { Unemployed } \\
\text { at Time of } \\
\text { Interview }\end{array}$ & $\begin{array}{l}\text { Accessed } \\
\text { Community } \\
\text { Supports }\end{array}$ & $\begin{array}{c}\text { Accessed } \\
\text { Formal } \\
\text { State } \\
\text { Supports } \\
\text { (El/ODSP/ } \\
\text { Welfare/ } \\
\text { CPP) }\end{array}$ & $\begin{array}{l}\text { Accessed } \\
\text { Private } \\
\text { Insurance }\end{array}$ \\
\hline Olivia & $30-34$ & Yes & $\begin{array}{c}\text { Post- } \\
\text { secondary }\end{array}$ & Employed & Yes & Yes & Yes \\
\hline Nadia & $30-34$ & Yes & $\begin{array}{c}\text { Post- } \\
\text { secondary }\end{array}$ & Employed & Yes & No & Yes \\
\hline Aria & $30-34$ & Yes & $\begin{array}{c}\text { Post- } \\
\text { secondary }\end{array}$ & Employed & Yes & Yes & No \\
\hline Julia & $25-30$ & No & $\begin{array}{c}\text { Post- } \\
\text { secondary }\end{array}$ & Employed & No & No & Yes \\
\hline Audrey & $25-29$ & No & $\begin{array}{c}\text { Post- } \\
\text { secondary }\end{array}$ & Employed & Yes & Yes & Yes \\
\hline Adriana & $20-24$ & No & $\begin{array}{c}\text { Post- } \\
\text { secondary }\end{array}$ & Employed & No & No & Yes \\
\hline Isabella & $30-34$ & Yes & $\begin{array}{c}\text { Post- } \\
\text { secondary }\end{array}$ & Employed & Yes & No & Yes \\
\hline Mia & $20-24$ & No & $\begin{array}{c}\text { Post- } \\
\text { secondary }\end{array}$ & Employed & No & No & Yes \\
\hline Ava & $25-29$ & No & College & Unemployed & Yes & Yes & No \\
\hline Maura & $25-29$ & No & $\begin{array}{c}\text { Post- } \\
\text { secondary }\end{array}$ & Unemployed & Yes & Yes & No \\
\hline Leaha & $25-29$ & No & $\begin{array}{c}\text { Some } \\
\text { post- } \\
\text { secondary }\end{array}$ & Employed & Yes & Yes & No \\
\hline Ellia & $35-40$ & Yes & $\mathrm{N} / \mathrm{A}$ & Employed & Yes & No & Yes \\
\hline Hannah & $35-40$ & Yes & $\begin{array}{c}\text { Post- } \\
\text { secondary }\end{array}$ & Employed & Yes & No & Yes \\
\hline Tessa & $20-24$ & No & $\begin{array}{c}\text { Post- } \\
\text { secondary }\end{array}$ & Employed & No & No & Yes \\
\hline Sophia & $20-24$ & Yes & $\begin{array}{c}\text { Post- } \\
\text { secondary }\end{array}$ & Unemployed & Yes & Yes & No \\
\hline Rose & $30-34$ & Yes & $\begin{array}{c}\text { Post- } \\
\text { secondary }\end{array}$ & Employed & Yes & No & Yes \\
\hline Katia & $20-24$ & Yes & $\begin{array}{c}\text { Post- } \\
\text { secondary }\end{array}$ & Employed & Yes & No & Yes \\
\hline
\end{tabular}




\section{Appendix B: Interview Guide}

\section{Carleton}

\section{Sample Questions}

Questions will be organized to reflect a trajectory of young women's cancer experiences. Section $\mathrm{A}$ is concerned with life prior to diagnosis, Section B is interested in initial diagnosis/treatment and Section $\mathrm{C}$ is concerned with life after treatment/remission.

\section{Section A: Life Prior to Diagnosis}

1. Perhaps we could begin with talking about yourself and your life prior to cancer diagnosis? (daily routines, activities, school life, work life, were you living at home? With whom?)

2. Can you please tell me what you did for a living?

3. Can you describe your overall health?

4. How health conscious were you, if at all?

\section{Section B: Initial Diagnosis and Treatment}

\section{Diagnosis/Treatment}

1. What type and stage of cancer were you diagnosed with?

2. How old were you when you were diagnosed?

3. Can you please briefly describe your cancer treatment?

\section{Fertility and Mental Health}

1. Was the issue of fertility addressed prior to the commencement of treatment? If so, did you inquire about this issue or did the doctors bring it to your attention?

2. How would you describe your emotional wellbeing during this time?

3. When you were in treatment, did your medical team ever address mental/emotional health? Was this a concern for you at the time?

\section{Relationships and Community Supports}

1. How did your family and friends react to the diagnosis?

2. Did you ever participate or seek out outlets? If so, which ones and did you find them effective?

3. Did you ever connect with other young adults? If so, how did it help you?

\section{State and Private Supports}

1. Did you continue to work during treatment?

2. Can you recall if you were offered any supports after you initial diagnosis? If yes, what were they and who informed you of these services?

3. Have you made any attempts to apply for state funded supports (ODSP, CPP) If so, can you briefly describe your experiences of applying for them? 
4. Did you have any private insurance coverage through work benefits and/or spousal/family benefits? If yes whose benefits were they and can you tell me about the coverage?

\section{Section C: Life After Treatment}

\section{Body, Sexuality and Mental Health}

1. Tell me about the changes in your body. What were these like for you?

2. Many individuals often find the transition into remission the most difficult stage in one's cancer journey was this similar for you?

3. Now, when you go for routine appointments are your doctor's concerned with your emotional/mental wellbeing?

\section{Health and Lifestyle}

1. Have you become more health conscious since your illness? If yes, how so?

2. What do you do to be or stay healthy? Why do you engage in these activities?

\section{State and Private Supports}

1. Can you recall if you if you were offered any supports and/or resources upon completion of treatment? If yes, what were they and who informed you of these services?

2. Do you feel that the reoccurrence of cancer causes some uncertainty in your life?

3. Can you briefly describe your life now?

4. Have you experienced any pressure to return to a 'normal' life? If so, by whom? 